NBSIR 81-2358

\title{
Analysis of Data From the Energy Monitoring and Control System At the Norris Cotton Federal Office Building
}

U.S. DEPARTMENT OF COMMERCE

National Bureau of Standards

National Engineering Laboratory

Center for Building Technology

Building Equipment Division

Washington, DC 20234

\section{September 1981}

Issued November 1981

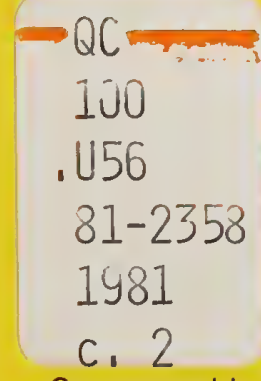

Sponsored by:

The Department of Energy

Washington, DC 20585 

ANALYSIS OF DATA FROM THE ENERGY

MONITORING AND CONTROL SYSTEM

AT THE NORRIS COTTON FEDERAL OFFICE BUILDING

William B. May, Jr.

U.S. DEPARTMENT OF COMMERCE

National Bureau of Standards

National Engineering Laboratory

Center for Building Technology

Building Equipment Division

Washington, DC 20234

September 1981

Issued November 1981

Sponsored by:

The Department of Energy

Washington, DC 20585

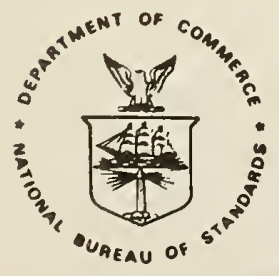

U.S. DEPARTMENT OF COMMERCE, Malcolm Baldrige, Secretary NATIONAL BUREAU OF STANDARDS, Ernest Ambler, Director 


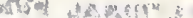

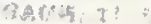

$7+253$ 


\section{ABSTRACT}

The Norris Cotton Federal Office Building (NCFOB) in Manchester, New Hampshire, is a medium-size office building, occupied in September 1976, designed to serve as a demonstration and a feasibility test for energy-conserving building features. A building energy monitoring and control system was operated as a data acquisition system over a 13-month period ending in September 1980. Experience encountered during the checkout and operation of the system is discussed. Results from data reduction procedures used to calculate approximately 160 parameters describing the energy performance of the building are presented on a monthly basis. Hourly data are also presented for daily building operation profiles, building envelope performance, and performance of the mechanical systems.

Key Words: building performance data; computer data acquisition; energy conservation in commercial buildings; building envelope; mechanical systems; energy monitoring and control systems. 


\section{PREFACE}

This report is one of a series of reports documenting National Bureau of Standards (NBS) research and analysis efforts in developing energy and cost data in support of the Department of Energy (DoE)/NBS Building Energy Conservation Criteria Program. The work described in this report was supported by DoE/NBS Task Order No. A008-BCS under Interagency Agreement No. EA 77A 016010. 
1. InTRODUCTION $\ldots \ldots \ldots \ldots \ldots \ldots \ldots \ldots \ldots \ldots \ldots \ldots \ldots \ldots \ldots \ldots \ldots \ldots \ldots \ldots$

2. DESCRIPTION OF NORRIS COTTON BUILDING ................... 2

3. DESCRIPTION OF DATA ACQUISITION SYSTEM $\ldots \ldots \ldots \ldots \ldots \ldots \ldots \ldots \ldots \ldots$

4. DATA REDUCTION PROCESS $\ldots \ldots \ldots \ldots \ldots \ldots \ldots \ldots \ldots \ldots \ldots \ldots \ldots \ldots \ldots \ldots \ldots . \ldots \ldots$

5. RESULTS--MONTHLY PERFORMANCE PARAMETERS ................... 19

6. RESULTS--DAILY PROFILES OF NON-HVAC ENERGY ............... 22

7. RESUlts--BUILding ENVELOPE PERFORMANCE .................. 23

8. RESULTS--MECHANICAL SYSTEMS $\ldots \ldots \ldots \ldots \ldots \ldots \ldots \ldots \ldots \ldots \ldots \ldots \ldots \ldots$

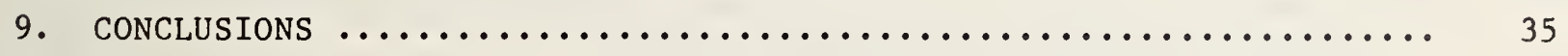

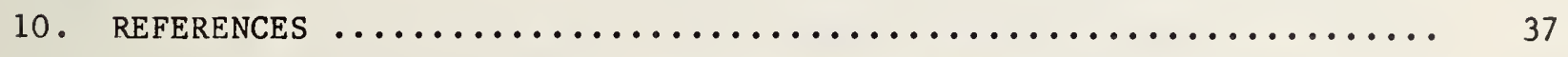

APPENDIX Detailed Description of NCFOB Energy Data Sheets ..... 64 


\section{LIST OF FIGURES}

1 Schematic diagram of Norris Cotton Federal Office

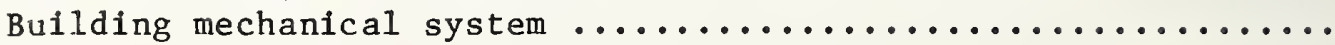

2 Diagram of JC-80/55 minicomputer control system configuration

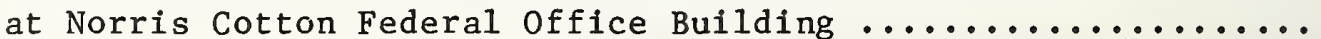

3 Format of data contained on magnetic tapes generated at the Norris Cotton Federal office Building ...................

4 Diagram of electric power distribution system at Norris Cotton Federal office Building. Circled numbers indicate

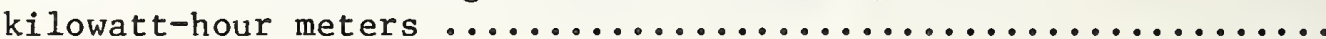

5 Sample instruction file for table-producing data retrieval

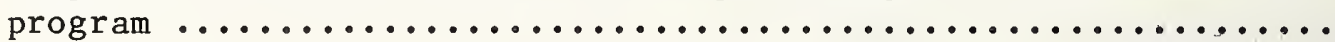

6 Total energy consumption at the NCFOB building boundary as

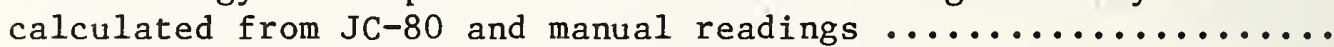

7 Natural gas consumption at NCFOB as calculated from JC-80

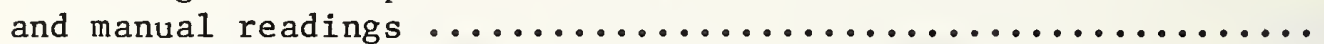

8 Major categories of electrical energy consumption for the NCFOB as calculated from $\mathrm{JC}-80$ and manual readings ..........

9 Electrical energy use for lighting on lower floors of NCFOB as calculated from $\mathrm{JC}-80$ and manual readings $\ldots \ldots \ldots \ldots \ldots \ldots$

10 Electrical energy use for lighting on upper floors of NCFOB as calculated from $\mathrm{JC}-80$ and manual readings $\ldots \ldots \ldots \ldots \ldots \ldots$

11 Electrical energy use for lighting on essential circuits of

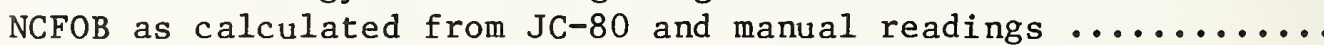

12 Miscellaneous office electrical energy use at NCFOB as

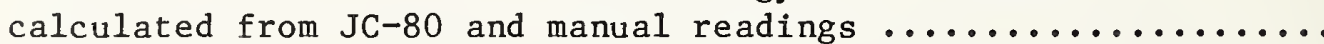

13 Miscellaneous office electrical energy use at NCFOB as

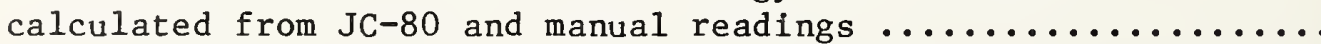

14 Electric energy used by fan coils and solar pumps at NCFOB as calculated from JC-80 and manual data .............. 48

15 Electric energy use by heat pumps at NCFOB as calculated from

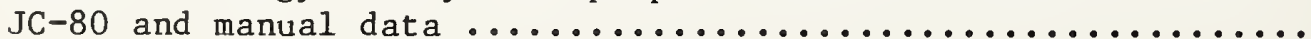




\section{LIST OF FIGURES (Continued)}

Number

$\underline{\text { Page }}$

16 Mechanical equipment electrical loads at NCFOB as calculated from JC-80 and manual data ........................ 49

17 Demand profile of total energy for lighting at NCFOB ....... 50

18 Demand profile of office miscellaneous electric loads at NCFOB

19 Electrical circuit analogy for equivalent thermal parameter mode1

20 Comparison of average inside temperature at Norris Cotton Federal Office Building measured by JC-80 and calculated by

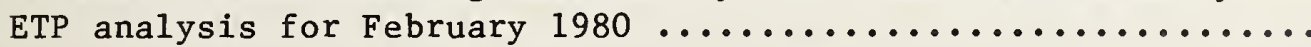

21 Measured outdoor, indoor and structure temperatures calculated by ETP analysis for Norris Cotton Federal Office Building

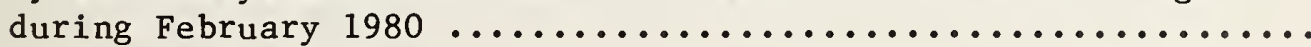

22 Measured addition of internal and heating energy to building space of Norris Cotton Federal office Building during

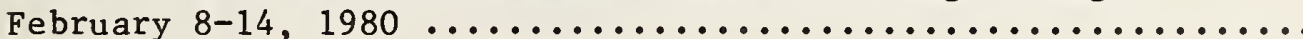

23 Measured outside and inside temperatures and structure temperatures calculated by ETP analysis for Norris Cotton Federal office Building during June 20-29, 1980 ...........

24 Natural gas boiler efficiency as a function of boiler output at the Norris Cotton Federal office Building ..............

25 Heating performance of heat pump system at Norris Cotton Federal office Building during February 1980 ..............

26 Cooling performance of heat pump system at Norris Cotton Federal office Building during July 1980 ................

27 Measured performance of electric chiller at Norris Cotton Federal office Building during July 1980 ................

28 Solar collector array efficiency at Norris Cotton Federal

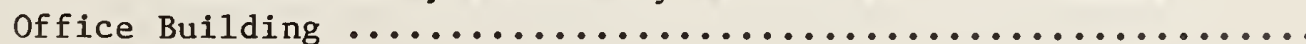

29 Fuel energy for heating versus calculated heating requirements at Norris Cotton Federal office Building during February 1980 


\section{LIST OF FIGURES (Continued)}

Number

$\underline{\text { Page }}$

30 Operating energy versus calculated heating requirements during February 1980 at the Norris Cotton Federal Office Building .....

31 Fuel energy for cooling versus cooling requirements at the Norris Cotton Federal Office Building during July 1980 .......

32 Operating energy versus calculated cooling requirements during July 1980 at Norris Cotton Federal office Building ...........

33 Total mechanical system efficiency for heating versus calculated heating requirements at Norris Cotton Federal office Building

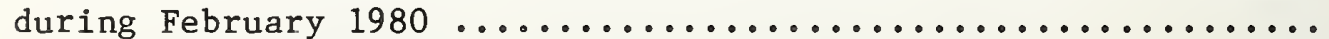

34 Total mechanical system performance factor for cooling versus calculated cooling requirements at Norris Cotton Federal

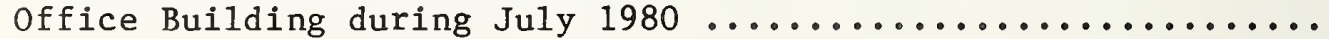

\section{LIST OF TABLES}

1 Analog sensor types used by JC-80 system at the Norris Cotton Federal office Building .......................... 60

2 Description of data loss from NCFOB data acquisition system ....

3 Estimates from least squares fit to equivalent thermal parameter model using data from February 9-15, $1980 \ldots \ldots \ldots \ldots$. .

4 Results from equivalent thermal parameters analysis of four

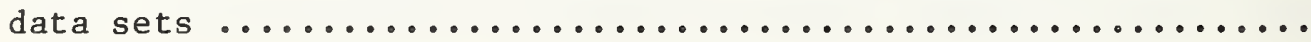




\section{CONVERSION FACTORS}

This report uses only SI units. The following conversion factors to US Customary Units are provided for convenience during the transition to SI units.
$1{ }^{\circ} \mathrm{C}$
$=\left(1.8{ }^{\circ} \mathrm{C}+32\right)^{\circ} \mathrm{F}$
$1 \mathrm{~J} /\left(\mathrm{kg} \cdot{ }^{\circ} \mathrm{C}\right)=2.39 \times 10^{-4} \mathrm{Btu} / 1 \mathrm{~b}^{\circ} \mathrm{F}$
$1 \mathrm{~kg} / \mathrm{m}^{2}=0.2051 \mathrm{bm} / \mathrm{ft}^{2}$
$1 \mathrm{~kg} / \mathrm{m}^{3}=0.0631 \mathrm{~b} / \mathrm{ft}^{3}$
$1 \mathrm{~kJ} / \mathrm{m}^{2} \cdot \mathrm{h}=0.088 \mathrm{Btu} / \mathrm{ft}^{2} \cdot \mathrm{h}$
$1 \mathrm{~kL}=264$ gallon (US)
$1 \mathrm{~kW}=0.284$ tons, refrigeration $3413 \mathrm{Btu} / \mathrm{h}$
$1 \mathrm{~kW} /{ }^{\circ} \mathrm{C}=1895 \mathrm{Btu} / \mathrm{hr} \cdot{ }^{\circ} \mathrm{C}$
$1 \mathrm{kWh} /{ }^{\circ} \mathrm{C}=3.6 \mathrm{MJ} /{ }^{\circ} \mathrm{C}=525.7 \mathrm{Btu} /{ }^{\circ} \mathrm{F}$
$1 \mathrm{kWh} / \mathrm{m}^{3}=0.0961$ therms $/ \mathrm{CCF}$
$1 \mathrm{~L} / \mathrm{s}=2.12 \mathrm{cfm}$
$1 \mathrm{~m}^{2}=10.76 \mathrm{ft}^{2}$
$1 \mathrm{~m} / \mathrm{s}=15,848 \mathrm{gpm}$
$1 \mathrm{MJ} / \mathrm{m}^{2} \cdot \mathrm{yr}=0.088 \mathrm{kBtu} / \mathrm{ft}^{2} \cdot \mathrm{y}$
$1 \mathrm{~W} / \mathrm{m}^{2} \cdot{ }^{\circ} \mathrm{C}=0.176 \mathrm{Btu} / \mathrm{ft}^{2} \cdot \mathrm{hr} \cdot{ }^{\circ} \mathrm{F}$ 



\section{INTRODUCTION}

The Norris Cotton Federal office Building (NCFOB) is a seven-story government office building located in Manchester, New Hampshire. This building, first occupied in September 1976, was intended to serve as a demonstration of and feasibility test for a number of building energy conservation features. Each floor utilizes different types and arrangements of heating, ventilation, and air conditioning (HVAC) equipment and lighting systems. The concepts used in the building include heat pumps, modular boilers, fan coil units, fin-tube radiation, variable-volume air distribution, heat recovery, and solar energy. The building envelope is designed to minimize thermal transmission losses by making use of a cubical shape, minimum fenestration, massive construction, and external insulation.

The original building design was developed by an architect/engineering firm under contract to the General Services Administration (GSA), the agency responsible for federal buildings [1]. The National Bureau of Standards (NBS) has participated in the project since the design stages under contract to the Department of Energy (DoE). Besides evaluating the performance of the lighting systems, the user acceptance of the building, and lessons learned in operating the NCFOB [2, 3], NBS staff members have been collecting and analyzing energy performance data on the building.

Included as part of the NCFOB control system is a minicomputer which functions as a monitoring, control and data acquisition system using over 700 temperature sensors, flow-meters, watt-hour meters, and other measuring devices located throughout the building. Hourly average data have been collected by the data acquisition system and were compiled for approximately one year--from September 1979 to September 1980. These data have been reduced and analyzed at NBS to produce hourly, daily, and monthly values of performance parameters, energy usage data, and other detailed information from the NCFOB. 


\subsection{BUILDING ENVELOPE}

The envelope of the Norris Cotton Federal Office Building was designed to minimize heating and cooling loads by making use of several innovative ideas. The building has an approximately cubical shape to minimize surface area. The wall design, intended to minimize thermal transmission losses in the winter and thermal gains in the summer, uses a massive masonry construction with insulation installed on the exterior of the masonry and covered with a granite facade. The wall has an overall heat transfer coefficient (U-value) of $0.34 \mathrm{~W} /\left(\mathrm{m}^{2}{ }^{\circ} \mathrm{C}\right.$ ) and a mass of approximately $390 \mathrm{~kg} / \mathrm{m}^{2}$ of surface area. The window area averages only six percent of the total wall area, and the north building wall is completely windowless. Overhangs and fins surround the double-glazed windows to contro1 solar gain.

There are seven floors of offices in the NCFOB with a total office floor area of $9072 \mathrm{~m}^{2}$. The upper six floors are approximately the same size with an aspect ratio of $1: 1$. The first floor is larger than the upper floors providing a one-floor base below the cubical shape formed by the upper floors. Two sets of entrance doors are located on the first floor. Two underground basement levels provide parking facilities and storage.

Approximately two and one half years after the building was first occupied, the rate at which outside air was entering the building was measured using a tracer gas technique [4]. The measurements (taken in February 1979) indicated that the air exchange rate with all outside air dampers closed (no ventilation air; 100 percent recirculation) was 0.75 air change per hour on the first three floors and 0.39 on the upper four floors with a building average of 0.54 air change per hour $[2,5]$.

\subsection{MECHANICAL SYSTEMS}

As in any new building, after the NCFOB was occupied in September 1976 , differences between the design predictions for the building and the actual operational performance became apparent. The experimental nature of the NCFOB required that the mechanical systems be more complex than in most buildings. Therefore, the process of overcoming start-up problems and design inadequacies took over two years. The major problems encountered at the building have been described in a previous paper [5]. In many cases, problems with the automatic controls forced building operators to resort to manual operation of systems. The period during which the automated data acquisition system was collecting data followed the "break-in" period, and during this time the NCFOB was not operating as designed but operating in the best way possible given shortcomings of the installed systems and controls. The following descriptions reflect the building operation during the monitoring period.

Distribution and Terminal Equipment: The mechanical system at the NCFOB includes a central plant providing heated and chilled water for two major distribution subsystems which supply heating and cooling for different parts of the building. The first three floors of the building are served by a unitary water-loop heat pump system consisting of 57 water-to-air heat pumps having 
a combined capacity of $350 \mathrm{~kW}$ for heating and $280 \mathrm{~kW}$ for cooling. The first and third floors use large ceiling-mounted heat pumps for the perimeter zones and floor-mounted heat pumps for the core zones. The second floor has small console-type heat pumps on the perimeter and larger ceiling-mounted heat pumps for the core. A closed water loop supplies all of the heat pumps with thermal energy for heating, and acts as a heat sink for cooling. During the cooling season, thermal energy is removed from the heat pump loop through a closedcircuit evaporative cooler in the basement. The loop may be heated by boilers in the central plant and operates at a temperature of $18-27^{\circ} \mathrm{C}$ depending on the season.

The upper four floors of the building are served by several types of central hot-water heating and chilled-water cooling systems, and the terminal equipment on the upper four floors varies from floor to floor. The fourth floor has a standard variable air volume (VAV) system with perimeter hot-water finned-tube radiation to offset transmission losses. The fifth floor has a variable air volume system with a separate single-duct system and a large floor-mounted heating-only two-pipe fan coil unit to offset transmission losses. The sixth and seventh floors each have variable air volume for the core and three ceilingmounted four pipe fan coil units for perimeter heating and cooling. The fourth and fifth floors and the sixth and seventh floor cores do not have local chilled-water-cooling equipment but receive chilled air from the central plant.

A hot water loop supplies the equipment on the upper four floors and also supplies a few unit heaters and fin-tube radiators located in the basements. The hot water loop is maintained at a temperature of from $37-60^{\circ} \mathrm{C}$ depending on the magnitude of the hot water system load. This loop is shut down during the cooling season.

A chilled water loop supplies water to the six four-pipe fan coils on the upper two floors. The chilled water system also supplies a coil in the air handling unit serving the upper four floors. This system is not operational during the heating season.

The NCFOB has two separate systems for handling outside air. One system, the heat pump air system, supplies ventilation air to the lower three floors by bringing outside air down from the penthouse mechanical room where the supply fan, return fan, outside air dampers, and return air dampers are located. Cooling and heating of the air is accomplished by having the air pass in parallel through six floor-mounted heat pumps before reaching interior areas of the lower three floors. This air system is a variable air volume type.

The upper four floors are supplied with ventilation air through a second air handling system located in the penthouse. This system, which is also a VAV system, is configured much like the heat pump air system, except that the only heating and cooling equipment in the air stream is a chilled water coil in the air handing unit. A heat pipe heat recovery system is used to preheat the outside air using energy recaptured from the exhaust air. 
In addition to the main air-handling systems, untreated ventilation air is provided for the two below-grade parking levels and a mechanical equipment penthouse is heated and ventilated.

During the data acquisition system monitoring period, the space temperature thermostat setting was $18^{\circ} \mathrm{C}$ for heating and $25.5^{\circ} \mathrm{C}$ for cooling with a winter setback to $15.5^{\circ} \mathrm{C}$ from $6 \mathrm{pm}$ to 5 am during the week and all day on weekends and holidays.

Plant Equipment: The NCFOB has a number of energy conversion devices in a central plant utilizing natural gas, fuel oil or electric power to provide heated or chilled water for the building water loops. Figure 1 is a schematic of the central plant equipment in the NCFOB. Four-55 kW natural gas modular boilers and two number two fuel oil modular boilers (not shown in figure 1) can supply hot water to the heat pump and hot water loops. The oil boilers are used as backup equipment in the event of an interruption of natural gas, or can be used during winter operation in sequence with the gas boilers to meet higher than expected heating loads. A $211 \mathrm{~kW}$ electric reciprocating chiller and an $88-\mathrm{kW}$ hot water driven absorption chiller provide chilled water. Electric power for the reciprocating chiller can be purchased or supplied by a 150-kVA natural-gas-fueled engine-generator set with heat recovery to hot water from engine and exhaust cooling. During the monitoring period the electric chiller was always driven by purchased power. The absorption chiller was used in sequence with the electric chiller and was seldom operated, since the electric chiller capacity was sufficient to meet the load in most cases.

Solar Energy System: A solar energy system is installed at the NCFOB and includes $353 \mathrm{~m}^{2}$ of liquid-type flat-plate collectors mounted on the roof of the building at an angle of 45 degrees. In the winter, the system is operated with an ethylene-glycol/water solution as the collector fluid, and a heat exchanger is used between the collector loop and the building solar storage loop. For summer operation, water is used as the collector fluid and the heat exchanger is bypassed. Energy collected in the solar array can be stored in one of three $37.850 \mathrm{k}$ storage tanks located in the basement.

The NCFOB solar system is used to supply energy to the service hot water system. If no solar energy is available, the service hot water is heated by a natural gas-fired storage water heater. Energy for the hot water heating system may be provided by the solar system during the spring and fall. During midwinter, the heating water system temperature is raised to $60^{\circ} \mathrm{C}$ and at this temperature the efficiency of the existing solar system is too low for any usable energy to be collected.

Controls: The NCFOB has two distinct automatic control systems for the mechanical equipment. A pneumatic system provides basic local loop control and device actuation. Tied to the pneumatic system is a supervisory minicomputer monitoring and control system. The minicomputer system was designed to provide some overall control functions such as solar system mode selection, programmed start/stop control, optimum start-time, nighttime thermostat setback, and maintenance management. In addition, the computer monitors over 900 binary and analog sensors, allowing the building operators to watch critical 
equipment and set up alarm signals for changes of state. Part of the function of the minicomputer is to act as the automated data acquisition system for the building.

\subsection{LIGHTING SYSTEMS}

The NCFOB has six different illumination systems, all having approximately the same connected electric power per unit floor area. The fourth floor uses high pressure sodium lighting with a power density of $18.3 \mathrm{~W} / \mathrm{m}^{2}$. On the fifth floor, the lighting is built into the furniture, and illuminates only task areas. The fifth floor lighting power density varies with furniture spacing, but was measured as $26.2 \mathrm{~W} / \mathrm{m}^{2}$. The remaining floors all use fluorescent lighting with a variety of luminaire spacings and lense types. All floors with fluorescent lighting have a lighting power density of $19.8 \mathrm{~W} / \mathrm{m}^{2}$.

\subsection{MISCELLANEOUS EQUIPMENT}

Additional energy-consuming equipment at the NCFOB includes electric-resistance snow-melting coils in the driveway to the underground parking garages, two nine-story passenger elevators, one ten-story freight elevator, and a packaged air-conditioning unit for the elevator machine room. A portion of the first floor is occupied 24 hours per day as a security office for the building. 


\section{DESCRIPTION OF DATA ACQUISITION SYSTEM}

The minicomputer-based supervisory control system which performed automated data acquisition functions at the Norris Cotton Federal Office Building is a Johnson Controls JC-80/55 building automation system*. The JC-80/55 is offered by Johnson Controls as a proprietary, off-the-shelf system with capabilities for supervisory control and monitoring of mechanical systems. The proprietary system was chosen by a bidding process to provide system monitoring and control capability for GSA and to satisfy existing government and GSA criteria for building control systems.

The JC-80 system was installed during construction of the building and was nominally operating by November 1976. Johnson Controls was a contractor only to the General Services Administration (GSA) under the construction contract, and did not have any agreements with NBS. NBS was under contract only to DoE and did not have a direct agreement with GSA. This lack of close contact resulted in an installed JC-80 system which was not capable of satisfying NBS requirements to monitor the energy performance of the building. Meetings in September 1977 between Johnson Controls, GSA, and NBS staff members resulted in Johnson Controls agreeing to upgrade the existing JC-80 system and install features which would allow NBS to use the JC-80 to collect hour-by-hour data. The modifications to the original JC-80 (a JC-80/45) were completed by April 1978 and NBS staff began a process of collecting data and evaluating the data collection system. NBS staff members spent the following year and a half performing calibrations of the instrumentation sensors, uncovering problems with the JC-80 and reporting them to Johnson Controls for correction, and developing a data reduction plan. The process was complicated by several factors. First, since the JC-80 was a proprietary system, most of the software was unavailable for examination by NBS. This meant that software problems had to be discovered by examining externally available inputs and outputs to the software during operation of the system and reporting discrepancies to Johnson Controls. Secondly, the building and the JC-80 were owned and operated by GSA, which was naturally reluctant to allow NBS personnel to work on the control system of an operating building. Finally, the JC-80 system was constructed as a commercial system and it was usually not possible to make modifications to the system at the site. Software system changes had to be made at a Johnson Controls facility in Wisconsin and the modified software system had to be stored on magnetic tape and shipped to the building. In several cases, required changes were delayed by weeks. By August 1979, repairs and modifications to the JC-80 had been completed and an evaluation of the system had resulted in a data reduction plan which took into account the limitations of the system. Data collection was then accomplished from September 1, 1979 to October 1, 1980 with only small interruptions.

* Commercial equipment is identified in this publication in order to adequately describe the data aquisition system used. Such identification does not imply recommendation or endorsement by the National Bureau of Standards, nor does it imply that the materials or equipment identified are necessarily the best available for this purpose. 
Figure 2 illustrates the system configuration for the JC-80. The philosophy of this system is to allow local-loop controls to function conventionally with the JC-80 providing set-point adjustment and overriding indirect device control. Each of the sensors and actuators in the system connects to the central system through a signal conditioning cabinet called a loop remote. Communications with the loop remotes in the $\mathrm{JC}-80 / 55$ system are not handled by the central processor, but by a peripheral processor called the loop controller, using a concept of limited distributed processing. The loop remote cabinets do not have "stand-alone" capability and do not operate if the central system is not operationa1.

\subsection{LOOP REMOTES}

The loop remote field cabinets contain the circuitry for analog-to-digital conversion and other signal conditioning. Each loop remote may contain up to 50 "point module" circuit cards, each of which may be connected to from four to eight sensors depending on the sensor type. There are a total of 19 loop remotes in the NCFOB. The loop remotes are interrogated sequentially by the loop controller processor, and updated sensor values are transmitted to the central system.

\subsection{JC-80 CENTRAL SYSTEM}

The JC-80 central processor is a Modcomp minicomputer processor using Johnson Controls software to accomplish monitoring and control functions. The system is designed to scan the system data points approximately every 20 seconds. Sensor point values which have changed by an amount called the filter increment are updated and are stored in the central system half-megaword (16 bit word) magnetic disc storage. The central system software converts digital values received from the loop controller to a number in engineering units using equations appropriate to the sensor type.

A cathode ray tube terminal (CRT), lineprinter, and teleprinter (TTY) provide operator interface to the JC-80. From the CRT, an operator can display sensor values, direct information to be printed on the lineprinter or TTY, start or stop devices, and direct execution of system programs using the JC-80 command mnemonic language.

A number of JC-80 software routines are used to allow the JC-80 to function as a data acquisition system. "Calculated point" software is used to make calculations using the sensor point values as inputs to an algorithm. An averaging algorithm is used to calculate hourly average values for sensors using instantaneous values as input. The averaging routine is executed a number of times during an hour and is set up so that the average value stored in the JC- 80 is the average for the hour up to that point in time. The average is reset to zero at the start of each hour. The number of instantaneous values included in the average is determined by a parameter which may be termed the "calculated point interval." For each hourly average data point there is a calculated point interval in minutes representing the time period between applications of the averaging equation. As the specified value of the calculated point interval is decreased, the value of the calculated average approaches the true average value. 
In order to transmit hourly averaged values of sensor readings to NBS, a magnetic tape drive was included in the central system peripheral equipment. A JC-80 software routine called the "data logger" took values for 720 instrumentation sensors and placed the data in storage locations on the system disc at the beginning of each hour. Each night at midnight, the data logger routine wrote 24 hours of data on magnetic tape.

of the 720 instrumentation sensors whose values were written on the magnetic tape, 107 were binary sensors which indicated on-off or mode status for various pieces of equipment in the NCFOB. The binary values on the tape represented the state of the sensors at the beginning of the hour. Five hundred fifteen of the data logger points were hourly average values from analog sensors. Nine types of analog sensors were used. Table 1 lists the analog sensor types and the number of each type. The 98 remaining data logger points represented readings from kilowatt-hour meters in the building. The kilowat-hour meters produce a contact closure on a data line each time a certain quantity of electrical energy passes through the meter. Software pulse counting routines accumulated total contact closures for one hour and these values were stored on the magnetic tape by the data logger software. 
The process of reducing the information gathered on the automated data acquisition system at the NCFOB consisted of extracting data from the magnetic tapes generated at the NCFOB and using them to calculate a number of parameters describing the building on hourly, daily, and monthly levels.

\subsection{READING, CHECKING, AND COMPRESSION OF DATA}

The magnetic tapes used to store and transport data from the NCFOB JC- 80 were $732 \mathrm{~m}(2400 \mathrm{ft})$, nine-track tapes written at a density of 32 characters/mm ( $800 \mathrm{cpi})$. The information was stored on the tape in ASCII code with a lineprinter image format using 134 characters per tape record and one record per tape block. Each 52 records of the data comprised one line-printer image "page" with the format shown in figure 3. A page contained the hourly values for 18 data points from a 24 hour period and for each day of data, 40 lineprinter image pages were generated. The magnetic tapes were sent to NBS by mail when one week of data had been collected. One week was felt to be the maximum time that should elapse between collecting and examining data so that problems with the data could be detected early.

Data reduction at NBS was performed using a UNIVAC 1108 computer. A number of computer programs were used to process the data before calculations were actually made. After reading the information from the magnetic tape, the ASCII code on the tape was translated to "fieldata," the internal alphanumeric character code of the UNIVAC computer. The data, after translation, had to be "transposed" so that the calculation program could read all data points for each hour in sequence. The tapes were originally written in a form such that 18 point values for all hours of one day were written and followed by values for a different 18 points for all hours of the same day. It was necessary to strip off a large quantity of extraneous header information leaving only an index number, point value, and engineering unit code for each data point. The data transposition routine checked through the data for missing data, offline points, "glitches," and out-of-range numbers. Values for the kilowatthour meters were converted from counts of meter contact closures to kilowat hours by taking the difference between counts for successive hours and applying a conversion factor. The original magnetic tape files were archived on magnetic tape at a higher density (246 characters/mm) (6250 bpi) with two weeks to a tape. The transposed, condensed and checked data files were also stored on archival tapes in a compressed form. Where 26 magnetic tapes were required to store the original data logger output, only one tape was required to store the condensed data.

\subsection{CORRECTION OF DATA LOSS}

In a long term-data collection effort, it is difficult to avoid the loss of some data. The collection of data by the JC-80 was no exception to this rule, but the losses involved did not prevent the evaluation of the data. Three types of data loss were experienced with the JC-80 system. The first type occurred when the sensors and the data acquisition system operated properly but problems with the actual magnetic tape drives at the site caused a garbling 
or loss of data. In most cases this type of error was detected by the computer programs used to read, check, and transpose the data at NBS, and corrections could be made by the use of a text editor. A second type of data loss usually involved malfunctions in the field hardware of the JC-80 system, causing a partial outage of the complete set of data points for a time period ranging from one hour to several days. If the loss was short term or a lost point was not critical in the calculation of performance parameters, this type of outage could be dealt with by interpolation or assumption of data values. In some cases, partial loss of data required that the entire data set for a number of hours be rejected. The most serious loss of data occurred when the total JC-80 system at the site was inoperative due to one of a number of causes. The failure of the JC-80 resulted in a complete data outage of all points for a period lasting from one hour to several days. The most frequent causes of complete failure of the JC-80 system were inability of the system to restart properly after a very short power failure or voltage "dip," and problems with software which caused the system to "hang" and require a manual reset, with resulting loss of stored data logger information.

Since the calculation of daily and monthly parameters was a goal of the data collection, a technique for deriving monthly values from incomplete data had to be used. Two techniques were possible. One method is the averaging of all available data over the period of successful data collection, using the assumption that missing data is similar to the data collected. This technique is not acceptable, however, if it is desired to have data which appears to be continuous, such as needed in verification of building simulation computer programs. Therefore, all complete data outages requiring complete rejection of data were handled by a data replacement technique. By the use of this technique, missing or incomplete blocks of data were removed from the continuous hourly data and replaced by blocks of data taken from another day during which no outage occurred. The replacement blocks were carefully chosen to represent conditions as close to the original as possible, and only the dates on the replacement blocks were changed. The criteria used to evaluate replacement blocks were whether or not the rejected data blocks were from a weekend or holiday and the weather during the blocks. Weather conditions were determined from tabulated weather measurements reported monthly by the National Climatic Center for nearby Concord, New Hampshire. The measurements used included sky cover, temperature, windspeed, percent sunshine, and precipitation readings taken every three hours. Table 2 is a summary of the completeness of the data taken by the JC-80 system during the year of data acquisition. The table shows that there is a general improvement in the completeness of the data during the first part of the collection period but a leveling off in completeness during the latter part. The number of hours requiring replacement remained around 15 to 25 percent of total hours with occasional dips to approximately 5 percent. The longest uninterrupted period of data collection was 17.75 days in one month and after a few months into the collection period, the longest outage in each month ranged from one to five days.

After the replacement of missing or rejected data, the complete 13 months of data were divided into data files each containing one half month of data and the files were archived on a magnetic tape. These files were used as input to the parameter calculation routine. 
A complex computer program (written in FORTRAN V) was used to calculate parameters from the magnetic tape data. Although 720 values of sensor readings were taken for each hour, not all of the values were used for calculations. After studying the installed sensors and evaluating their performance on the basis of sensor location, adherence to installation specifications, type of measurement, sensor type, and results of sensor calibrations, a number of sensors were judged to be unusable. Readings from the rejected sensors were generally not reproducible or consistent with other sensor readings, and the effort to salvage the rejected sensors was considered to be excessive. The sensor types that were most often considered unacceptable were fluid flow measurements in small diameter piping, air flow measurements, duct dewpoint temperature measurements, illumination sensors, and natural gas measurements using a sampling technique rather than a totalizing technique (as used in the main gas meter). Rather than being unable to calculate parameters dependent on data from sensors judged unacceptable, assumptions were made in the calculations to allow many of the originally planned parameters to be determined.

Approximately 160 parameters were calculated by the reduction program from the data collected in each hour. After the calculations for one hour were completed, the output values were stored and added to data for previous hours to produce totals and averages of the output values on a daily and monthly basis.

Data Conversions and Calibrations: The data taken from the JC-80 magnetic tapes were initially in English units. SI units were selected as the internal units and output units for the reduction program. Kilowatt-hours were chosen as the basic unit of energy (since the data were in one-hour blocks).

All of the critical sensors used in the calculations were given a calibration check before the sensor values were used. Special instrumentation was transported to the site and used to compare the measured values displayed by the JC-80 with a standard measurement. Nutating disc flow-meters checked against a weighing meter were used as a standard for liquid flow measurement, and liquid-in-glass thermometers were used as a temperature standard. Additional temperature calibrations were made between inlet and outlet temperature sensors for the same piece of equipment to calibrate temperature differential measurements. The standard flow-meters were placed so as to be in series with the JC-80 flow-meters for the calibration run. Correction factors derived from the calibrations were second order, involving two constants for each sensor. The correction factors were applied to the input data by the reduction program before calculations were made.

Mechanical Systems Status: It was important to make a determination of the status of the mechanical equipment during each hour that data was collected. If a piece of equipment was not operating, then the flow and temperature values associated with the equipment could have been meaningless. The reduction program set status variables for each hour by checking kilowatt-hour readings, flowrates, and binary information from equipment on/off controllers. Due to limitations in the data acquisition software, it was possible to only record binary information once per hour. Since the equipment monitored usually changed changed state only 2 to 3 times per day, it was assumed that a piece of 
equipment was on during the entire hour if either the previous or present value of the binary point indicated an on status. Status was checked for major air and water transport loops, major pieces of equipment, special modes of operation, heating or cooling status for fan coils and heat pumps, floor occupation, and day or night status. In addition, certain status variables were set based on manual observations not included in the JC-80 instrumentation, such as the presence of water or ethylene glycol/water solution in the solar collectors or the existence of winter or summer operation of the building.

Natural Gas Use: Natural gas consumption at the building boundary was reported on the JC-80 data tapes as counts from a pulse generator on the main gas meter. The count value was converted to $\mathrm{m}^{3}$ by using a gas meter factor and then to equivalent thermal energy using a constant conversion factor of $10.356 \mathrm{kWh} / \mathrm{m}^{3}$. The natural gas used was consumed by one of three types of equipment: the service water heater, the engine-generator, or the boilers. The water heater and engine generator gas usages, which were relatively small, were measured by gasflow transducers located at the equipment. The gas consumed at the boilers was calculated by subtracting the engine-generator and service water heater gas use from the main gas meter reading.

Boiler Performance: The original water flow and temperature sensors located in the boiler piping were determined to be unusable due to a large number of elbows, tees, pumps, and valves packed into the piping around the boilers. Therefore the output of the gas boilers were approximated by calculation. Four gas boilers in a modular configuration exist at the building, as shown in figure 1. The boilers are piped in parallel, each boiler having its own boiler water pump which does not run unless the boiler is producing useful energy. The electrical consumption of each pump was measured separately, and thus if a boiler pump had been used in any hour its electrical consumption was greater than zero. The number of gas boilers operating in any hour was the same as the number of boiler pumps operating. If the boilers operating during a given hour were operating for the full hour at full-load and steady-state conditions, they would consume a rated input amount of gas and have a constant steady-state efficiency. In the actual building the boilers operate at varying conditions from full load to zero load, since the boilers may cycle on and off during an hour. In addition, the four boilers may be operating at different load points (due to the modular concept). The boiler efficiency at part-load conditions is a function of the load point and this function is similar for most conventional boiler designs. Measurements were taken at NBS on a modular boiler system [6], and were used as the basis for a prediction of boiler efficiency as a function of load point at the NCFOB. A one-time measurement of the boiler steady-state efficiency was made for each of the boilers at the NCFOB using stack gas temperature and $\mathrm{CO}_{2}$ measurements and the average boiler efficiency was determined to be 80 percent. The rated full-load gas input for each boiler at the NCFOB was determined to be $61.3 \mathrm{~kW}$. The percentage of ful1-load input was obtained by dividing the measured natural gas consumption at the boilers by the product of the number of boilers operating and the rated full-load input for one boiler. The part-load boiler efficiency for the modular boiler system was determined using:

$$
\text { eff }=\left(1-0.583 \quad e^{(-7.616 \% f 1 i)}\right) \text { eff } s s
$$


where eff is part-load efficiency, \% fli is percent of full load input, and eff $f_{s s}$ is steady-state full-load efficiency. This equation was fitted from experimental measurements described in reference [6]. The calculated boiler system output was then the product of the part-load boiler efficiency and the measured natural gas input to the boilers. This output calculation neglected jacket losses from the boiler. However, since boilers were piped in parallel with individual pumps and the pumps did not operate when the boiler was inactive, jacket losses were assumed to be low due to the small size of the boilers.

Heat Pump System Heating and Cooling Requirements: The heating and cooling requirements, or respectively, the energy delivered by or absorbed by the heat pump terminal units, was calculated by the data reduction program. There are 56 heat pump units located on the first three floors of the NCFOB and the original concept for the data system was to individually instrument the heat pump units with temperature, flow, and electric energy sensors. After installation of the JC-80 system, it was determined that many of the sensors for the heat pump system, particularly the flow-meters in the relatively small diameter water piping leading to the heat pumps, did not give consistent or accurate readings. Therefore, in the reduction algorithms, an approximation technique was used to calculate the capacity of the heat pump system in a given hour from the electrical energy input and a knowledge of the statuses of the individual heat pump units in the heat pump system. Manufacturers' data, available for each type of heat pump unit, specified the fan power consumption, steady-state heating and cooling load compressor input, and steady-state heating and cooling output capacity for a given source water temperature. Heat pump units in a typical installation will not operate at steady-state conditions at all times since the units may cycle on and off to meet a load smaller than the rated full load. Tests were performed at NBS on a unitary water-source heat pump at steady-state and part-load conditions [7]. The data from this heat pump was taken under part-load conditions at several cycling rates and water source temperatures. Using the test data, the percentage of full-load output capacity was found to be a linear function of the percentage of full-load compressor input. This result was used to predict heat pump capacity at the NCFOB.

For the calculation of heating and cooling requirements, the heat pump system was divided into six zones--a perimeter and core zone for each of the three floors. Each of the zones contained from two to thirty-two heat pumps and in general, the heat pumps were all of different steady-state full-load capacities. Usable sensor measurements included the on/off and cooling/heating mode status of each of the heat pumps and a single value of hourly electric energy consumption for all of the heat pumps in a zone. The electric energy measurement was the sum of energy to heat pump compressors and unit fans. To determine the estimated output capacity for each hour in each zone, the following procedure was used:

1. The status of each heat pump was checked to determine if the unit was on or off. The rated fan energy consumption for all units that were on was summed to give a total rated fan energy consumption. Subtracting this number from the total electric energy consumption gave the total zone compressor energy consumption. 
2. A full-load steady-state compressor input and capacity output for the zone were calculated by summing the rated compressor inputs and capacity outputs for each of the individual heat pumps that were in either a heating or cooling mode. It is possible for some units to have fans running but no compressor operation during an hour. Cooling capacity was given a negative value.

3. The part-load factor for each zone was calculated by dividing the actual zone compressor input by the rated full-load steady-state compressor input.

4. Finally, the output capacity for the zone was taken as the product of the part-load factor and the rated full-load steady state capacity.

During the heating season, the thermal energy needed from the heat pump water loop by the heat pump units in a zone was calculated by subtracting the electric energy input from the heating capacity for each hour. The total energy to be supplied by the central plant to the water loop was taken as the sum of the energy needed by the zones. Two other quantities computed for the heat pump system were the electric energy to heat pumps in the cooling mode and electric energy to heat pumps in the heating mode.

Simultaneous heating and cooling within a zone may have taken place occasionally during brief periods in spring and fall. With one exception, this was not taken into account in the heat pump calculation procedure, so that if simultaneous heating and cooling did take place the calculated requirements would be slightly smaller than the actual since heating and cooling requirements canceled each other in the calculations. The exception concerned the NCFOB computer room which required some cooling all year. A special calculation included this cooling load even if other heat pumps in the zone were heating.

Hot Water Heating System Heating Requirements: As in the case of the boiler and hot water systems, an approximation technique had to be used to calculate the hot water heating system requirements for the upper four floors. Sensors were installed on each floor to monitor supply flow rate and temperature and return temperature for the hot water system lines leading to radiation coils and unit heaters. The flow measurements in the relatively small diameter piping were considered to be unacceptable.

The total output of the natural gas boilers was used to supply energy in the winter to both the heat pump system and the hot water heating systems. The amount of energy delivered to the heat pump system by the boilers was assumed to be equal to the heat pump water loop thermal energy requirements calculated for the heat pumps. It was then assumed that the remaining boiler output was used to supply the hot water heating system. This assumption does not take into account the loss of energy through the insulation on the water piping. It was not possible, given the shortcomings of the instrumentation, to calculate individual floor or zone heating requirements for the upper four floors. 
Chilled Water System Cooling Requirements: Original chilled water system sensors placed on the inlets and outlets to the terminal equipment were found to be unusable and cooling requirements for the upper four floors served by the central plant-based chilled water system were approximated by the output of the two central chillers at the NCFOB. The installed instrumentation on the electric chiller in the central plant consists of a kilowatt-hour meter measuring electric energy consumption by the chiller, inlet and outlet temperature sensors on the evaporator and condenser, and flow-meters on the evaporator and condenser. The absorption chiller instrumentation was the same, except that the electric energy measurement was replaced by inlet and outlet temperature and flow measurements for the chiller generator. These sensors were judged to be usable for calculating chiller output.

The energy extracted from or added to a water loop by an individual piece of equipment is given by the following general equation:

$$
\mathrm{q}_{\mathrm{w}}=\delta_{\mathrm{w}} * \mathrm{c}_{\mathrm{p}} * \dot{\mathrm{m}}_{\mathrm{w}} *\left(\mathrm{t}_{\text {in }}-\mathrm{t}_{\text {out }}\right)
$$

where $\delta_{\mathrm{w}}$ is the density of water in $\mathrm{kg} / \mathrm{m}^{3}$ at the location where the flow rate is measured, $\dot{m}_{W}$ is the flow rate in $\mathrm{m}^{3} / \mathrm{s}, c_{p}$ is the specific heat of water in $\mathrm{J} /\left(\mathrm{kg} \cdot{ }^{\circ} \mathrm{C}\right)$ and $\mathrm{t}_{\text {in }}$ and $\mathrm{t}_{\text {out }}$ are the inlet and outlet temperatures, respectively. Water density was determined by an empirical equation as a function of temperature and specific heat was taken as one of three values depending on the range of temperatures within which the water temperature fell. The effect of chemical additives to the water systems was neglected. The energy extracted from the chilled water loop by each chiller was determined by using equation (2) and values from the chiller sensors. The sum of the two chiller outputs was assumed to be equal to the load on the chilled water system by the chilled water coil in the VAV air handling unit and the fan coil units in cooling mode. It was not possible to calculate floor by floor or zone cooling loads for the upper four floors.

Service Hot Water: The service hot water system is based on a small storage tank with three sets of supply and return piping connected to it. One set of pipes brings hot water from a gas-fired hot water heater preheat tank. A second set delivers energy from the basement hot water storage tanks. The remaining pipes lead to the service hot water supply loop which circulates through the building. Make-up water is introduced in the return line when a draw is made on the system. The service hot water load is determined using the supply temperature, return temperature, and system flow in equation (2).

Building Environment: Values of service hot water supply temperature, average wind speed, and storage tank temperatures were taken directly from input information. Algorithms were used to calculate average daytime and nighttime outside dry-bulb temperatures and daytime humidity. Occupied building and unoccupied building space temperatures and occupied humidity were determined for each floor by averaging north, south, east, and west perimeter and core zone temperatures. 
Electrical Energy Use: Figure 4 is a schematic of the electric power distribution system at the NCFOB. Ninety-eight kilowat-hour meters, shown as circles in figure 4, measure the electric energy delivered by the building switchboard circuits and remote electrical panels to the building loads. The main power bus enters the building in the basement and connects to a basement switchboard. The main bus duct riser transfers power to another switchboard in the penthouse. Branch circuits off the main riser supply receptacles and lighting circuits on the building floors. The penthouse switchboard consists of a normal section and an emergency section. The emergency section supplies loads that are considered essential, such as elevators, lights in stairways, and the pneumatic control system air compressor. If utility power fails, these circuits can be supplied by the engine-generator set. The normal section of the switchboard supplies loads such as the chiller and motor control center from which major electric motors are supplied power. All major pieces of equipment in the penthouse had their electric energy consumption monitored.

Two types of electric lighting loads were monitored at the NCFOB. These are normal and essential lighting loads. The determination of lighting energy for each floor was accomplished by summing values from kilowatt-hour meters measuring lighting loads. This was possible since lighting circuits were almost never mixed with non-lighting circuits in metered electrical panels.

Summation algorithms were used to determine the electrical energy used by the HVAC systems and by miscellaneous loads in the NCFOB, using readings from appropriate meters. Miscellaneous loads were defined as loads on receptacles plus loads by miscellaneous pieces of non-lighting and non-HVAC equipment such as sump pumps and snow melters. Receptacle and office equipment loads were determined for each floor with the total miscellaneous load defined as floorby-floor loads plus the other miscellaneous building loads.

Total Energy Use: Total electrical energy use was obtained from the kilowat-hour value of the building main meter. Total natural gas use was taken from the value calculated from the building main gas meter readings. For each hour, the sum of the two totals for electric energy and natural gas represented the total building energy use for the hour, excluding fuel oil use. Due to a lack of adequate computer-connected instrumentation, manual readings were taken for the fuel oil boilers. During the year of monitoring the building, the oil boilers were seldom used ( $12 \mathrm{~h}$, total). Total HVAC energy, again excluding fuel oil, was the sum of natural gas use and HVAC electric power. For comparison to the HVAC energy, the total HVAC requirements were summed from calculated cooling, heating, and service hot water requirements.

Solar Collectors: If the NCFOB solar system was operating during an hour being examined, the data reduction program determined the thermal output of the solar collectors on the building roof. Also calculated were collector system temperature levels and solar irradiation in the collector plane. Inlet and outlet temperature sensors and flow meters installed in the collector array supply and return piping were used to provide values for the calculations on the solar system. A heat exchanger is located between the solar array piping and the building piping to isolate the antifreeze solution used in the winter. Calculations were made to determine both collector output from the array and output 
from the array and heat exchanger together. Equation (2) was used as the basis for calculating thermal output.

During the monitoring period, the solar system was used only to supply energy to the service hot water system. The contribution of solar to the service hot water load was calculated using values from sensors in the service hot water system in equation (2).

Parameter Averaging, Totalization, and Storage: The 160 output values generated by the previously described algorithms were average values for one hour only. To produce total energy values for a month-long period required that approximately 720 hourly values for a month be summed. When a monthly average of hourly data was desired for a particular parameter, the total was divided by the number of hours in a month. Average and total values for day-long periods were generated in a similar manner. Four types of averages were used beside the standard average. A daytime average value was obtained by only adding hourly output values to the totalization when the hour of data was for a daytime hour. The final total was divided by the number of daylight hours in the totalization time period. Similar averages were calculated for certain points, using nighttime hours, occupied hours, and unoccupied hours as bases.

The output values from the data reduction were stored in three computer magnetic disc storage files at NBS in a special unformatted form. A variable record size input/output ( $I / O$ ) routine was used which is faster than Fortran I/O and has special record search capabilities.

Hourly output parameters were stored in one of two larger computer files each containing approximately six to seven months of data. The 160 output parameters for each hour were written into a single 202-word record (a word contains 36 binary bits on the UNIVAC), with the first word serving as an identifier containing the hour and day for the data. Before a month-long block of data, a one-word identifier record containing the month and year was written, allowing a block of data for a particular month to be located. Daily averaged and totaled values were stored in the same two files in a 6201-word record containing data for the entire month, with a one word identifier giving the month and year.

Totalized and average values on a monthly basis were stored in a smaller computer file in 202-word records. An identifier word contained the month and year for location purposes.

Data Retrieval and Analysis: Two types of special programs were used to retrieve data from storage. One type of program was designed to print out tables of selected parameters as a functon of the hour, day, or month. The other program type was used to generate data for use in plotting routines. These two types of programs allowed analysis to be performed on the data collected by the JC- 80 system at the NCFOB.

The main table-producing program reads a list of instructions in order to access the correct data. The instruction list contains the time basis desired and the beginning time or date for the data. Also in the instruction list is 
a number describing the general type of data desired. Figure 5 shows a sample instruction list with a description of the six data types available.

The Appendix contains sample printouts from this program on a monthly basis.

The plotting data generation routines have the same basic structure as the table program but the data instruction list contains the number of time periods desired as well as the time basis, and also has space for up to 10 index numbers identifying calculated parameters. The output of the plotting data routines is a data file or array containing columns of numbers, the first column containing the time and the other columns containing the desired data parameters. Data retrieved using the plotting data program described were used by software plotting packages to examine trends and relationships between data parameters on hourly, daily, or monthly bases. 


\section{RESULTS -- MONTHLY PERFORMANCE PARAMETERS}

During the process of reducing the 13 months of data collected on the acquisition system, monthly parameters were compiled from the data. A full listing of the monthly values calculated may be found in the Appendix, along with a definition of each quantity calculated. The number of parameters is too large to discuss here in detail. Study of the assumptions outlined in chapter 4 will determine the usefulness of the data for specific purposes.

It should be noted that the performance data compiled is not useful for comparison of HVAC systems on one floor with those on another floor for three reasons: First, instrumentation problems did not allow the collection of detailed data for each floor; collected data did not fully describe the performance of individual pieces of equipment because equipment output was not adequately measured in many cases; finally, the HVAC and lighting system design was too complex to allow simple comparisons of energy consumption between floors.

\subsection{VALIDATION OF MONTHLY VALUES}

A check of some of the results from the data acquisition system is possible using the monthly results because manual readings of a number of $\mathrm{kWh}$ and gas meters were taken concurrently with the data collection by the acquisition system. The manual readings were taken weekly and were compiled into a set of parameters comparable to some of the parameters produced by the reduction program. Figure 6 shows a comparison of measurements of total energy consumed at the building boundary, as determined both from the JC- 80 readings and the manual readings. Any disagreement between the two data sources is an indication of instrument error (in gas and electrical measurements) and the validity of the replacement technique used to deal with missing data. Figure 6 shows that the agreement for total energy is good, with a some exceptions which will be explained as more detailed information is examined.

Figure 7 shows the natural gas consumption for the NCFOB and validates the main gas meter measurements by the data system. The main gas meter used was actually the utility meter.

Detailed Monthly Electric Energy Use: Because of a large number of manually readable $\mathrm{kWh}$ meters (98), the best detailed comparison between the data system measurements and the manual readings is available for electric energy values. Figure 8 shows the total electrical energy use and a comparison for the manual and automated readings.

Figures 9 through 16 display comparisons between manual and automated readings for several categories of electric energy use. Figures 9 and 10 show floorby-floor lighting energy. The most outstanding feature of this data is the relatively high constancy of loads. The curves for the 1st floor lighting illustrate the effect when a data system sensor fails and indicates zero energy use. This causes a discrepancy between manual and automated readings and several failures of this type can cause the small discrepancies in total usage in figure 6. Figure 11 is a plot of electrical energy use for lighting on 
essential circuits. These circuits are supported by the emergency generator during power failures.

Figures 12 and 13 display floor-by-floor usage of energy for miscellaneous office loads which, like the lighting loads, remain relatively constant. In figure 13 there is a large discrepancy for the 4th floor. This is due to one of the sensors on the 4 th floor being inoperative for the entire period of data collection and assumed values being used for this sensor.

Figure 14 shows electrical data for fan coils and for the solar pumps. Fan coil loads are constant, with the exception of the 5 th floor, where there is a large heating-only fan coil whose use was discontinued in warmer weather. The solar pump data represent a variable load which depends on the amount of solar irradiation. The agreement between manual and data system is not as good as for the constant loads, but improves considerably at the end of the year when more hours of original data were available.

Heat pump electric energy consumption is shown in figure 15 and is a seasonally varying load. First floor heat pump energy consumption is larger than for the upper floors because of a 24-hour occupied area (guard office and computer room), larger floor area, and the presence of main entrance doors on this floor. There are some discrepancies for the upper two floors between manual and $\mathrm{JC}-80$ values.

Other important mechanical system electrical loads are shown in figure 16. Energy to fans is constant until the warmer months when fan usage is increased to implement nighttime flushing of the building and thus reduce cooling requirements. The chiller and evaporative coolers represent equipment used only in summer. The controls and miscellaneous category includes electrical energy for pumps, and shows an increase in summer.

\subsection{ANNUAL TOTAL ENERGY CONSUMPTION}

In order to make comparisions between buildings, it is useful to express building gross energy consumption on a per unit area basis. It is important that all buildings involved have their areas calculated in a consistent manner and that all references to a single building use the same area. The GSA Public Buildings Service (PBS) has developed a method of calculating building area which it uses in comparing its own buildings and as a basis for energy consumption goals [8]. This method identifies three types of building area: office space, mechanical equipment space, and garage areas. Since garage and mechanical areas use energy for lighting, elevator service and ventilation, GSA/PBS felt that it was important to include such areas in the total but not on the same level as fully conditioned office areas. The GSA/PBS equivalent gross floor area is then defined as one quarter of the mechanical and garage areas plus the total office area.

In order to be consistent with the GSA/PBS areas, NBS used an area for the NCFOB of $10900 \mathrm{~m}^{2}$. This includes $9072 \mathrm{~m}^{2}$ of office space, $643 \mathrm{~m}^{2}$ of mechanical space, and $6672 \mathrm{~m}^{2}$ of garage. In the design stage, GSA established an energy consumption goal of $627 \mathrm{MJ} / \mathrm{m}^{2}$.yr for the NCFOB and for other energy conserving buildings 
to follow. This figure used the equivalent gross floor area described.

The annual energy consumption of the NCFOB has been falling since the first month of building operation. Annual consumption for the fourth operating year (September 1979 to August 1980) was $527 \mathrm{MJ} / \mathrm{m}^{2} \cdot \mathrm{yr}, 15$ percent below the GSA goal. Part of the success in being below the goal is due to the lower thermostat settings required by the Emergency Building Temperature Restrictions (EBTR) regulations.*

An annual energy use figure which was calculated for the Norris Cotton Building is the expression of energy use per unit area and per number of occupied hours. The value of this figure is that it prevents buildings which are not operated all day from having apparently low energy usage per unit area. For the NCFOB, occupied hours are tabulated in the Appendix as an output of the data reduction for each month. These occupied-hours figures include all hours when the building was occupied for HVAC purposes (including hours when no people are present such as during nighttime flushing operations in the summer). Taking the maximum number of hours for any floor during the month as the occupied hours for the building, the NCFOB was occupied a total of 3667 hours during the 4 th operating year. This is a use factor of approximately 42 percent. Dividing the total energy use by the area and the occupied hours yields a figure of $156 \mathrm{~kJ} /$ ( $\mathrm{m}^{2}$ - occupied hour).

* Federal Register, July 16, 1979 (44 FR 41205). 


\section{RESULTS -- DAILY PROFILES OF NON-HVAC ENERGY}

Building energy use can be divided into two broad categories--HVAC and lighting-miscellaneous. HVAC energy is used to provide all heating, cooling, ventilation, and service hot water, and varies as a function of the time of year. Lighting-miscellaneous energy is used to provide energy to all other functions of the building, such as lighting, elevators and electric receptacles for operating typewriters, copiers and other office equipment.

Monthly totals of energy for lighting and miscellaneous have already been presented in chapter 5. In figures 17 and 18, hourly energy use profiles are presented for the total building lighting and miscellaneous energy, respectively, over a three day period. In both figures, the first day presented is a weekend day and the other two days are weekdays. Figure 17 shows total energy for lighting used in each hour of the day in $\mathrm{kWh} / \mathrm{h}$ or average hourly $\mathrm{kW}$. Data from two three-day periods is presented, one set from near the winter solstice and the other from near the summer solstice. Also presented is the percentage of the building occupied to show the normal working hours of the building. Figure 17 illustrates that there is little difference from summer to winter in this building since little daylighting is used and lighting is always on when the building is occupied.

Figure 18 shows the hourly energy used for miscellaneous office electric loads such as typewriters, copiers, and similar equipment. This figure also indicates the occupied hours of the building. As in figure 17, data from summer and winter months are given and there is very little difference between the curves for the two sets of data. Three distinct times of day may be observed in figure 18. There is a slight dip around noon corresponding to lunchtime and morning and afternoon working sessions to either side of lunch. The usage of office equipment appears to be higher in the morning than the afternoon. 


\section{RESULTS -- BUILDING ENVELOPE PERFORMANCE}

The most important features of the envelope of the Norris Cotton Federal Office Building are the use of massive masonry wall construction, application of external wall insulation, and incorporation of very small windows in the building shell design. An important application of the hourly data collected by the data acquisition system is to determine the effectiveness of these techniques as used in the NCFOB. If building data such as interior temperatures are studied, it becomes obvious that in this building, steady-state models cannot be used to evaluate the performance of the envelope because steady-state conditions are rarely reached. The equipment in the NCFOB is slightly undersized by conventional criteria, and there were many cases where space temperatures floated below or above thermostat settings and did not remain constant over the period when the building was occupied. The use of night setbacks also introduced variation in the space temperature.

Many computer-based building models are available to predict the space temperatures and energy use of a building given assumptions of building parameters such as window shading factors and transmission loss coefficients. However, such models are not suited to determining building parameters from actual data.

\subsection{CONCEPT OF EQUIVALENT THERMAL PARAMETERS}

Extremely detailed transient heat transfer analysis might serve to determine building characteristics but the computations involved would be overwhelming. Kusuda [9] and Sonderreger [10] have used a technique of simplified transient analysis using equivalent thermal parameters (ETP) to describe the behavior of buildings. The concept of ETP's makes the assumption that a building can be modeled as a simple system consisting of a single uniform indoor air temperature, an outdoor air temperature, a building mass with a uniform temperature and constant heat capacitance, and thermal resistances connecting the mass, indoor air, and outside air. Figure 19 shows the equivalent electrical analog circuit for this simple model. A differential equation involving time can be developed to describe this system. Sonderegger has used a technique of solving the differential equation describing the simple model using actual measured data from a residential structure and determining values for the thermal resistances and capacitance shown in figure 19. A similar technique was used by Kimura for a commercial building [11].

The solution of the ETP model can be accomplished using discrete data and a finite difference equation derived from the differential equation. Ideally the technique requires instantaneous temperature and heat rate data taken at regular intervals. The data collected for the NCFOB by the JC- 80 included only average hourly space temperatures and outdoor temperatures and energy totals for each hour. However, it was felt that the data could be used to model the NCFOB using the ETP concept.

One of the basic equations describing the model in figure 19 is:

$$
Q=H s(T-T s)+H(T-T o)
$$


where $\mathrm{T}$ is the inside temperature, $\mathrm{Ts}$ is the temperature of the building mass, To is the outside air temperature, Hs is the heat transfer coefficient between the building air and the mass, $H$ is the heat transfer coefficient between the building air and the outside, and $Q$ is the net energy added to or removed from the space including internal gains, mechanical cooling, and space heating. This equation is an energy balance for the building. The second equation describing the model describes the transient behavior of the system:

$$
C \frac{\mathrm{dTs}}{\mathrm{dt}}=\mathrm{Hs}(\mathrm{T}-\mathrm{Ts})
$$

where $C$ is the equivalent thermal capacity of the system, not necessarily equal to the total thermal capacity. Since $T s$ is difficult to measure, it may be eliminated from the analysis by combining the two above equations into a single differential equation:

$$
\mathrm{C}(1+\mathrm{H} / \mathrm{Hs}) \dot{\mathrm{T}}=\mathrm{C}(\dot{\mathrm{Q}} / \mathrm{Hs}+\mathrm{H} \dot{\mathrm{T}} / \mathrm{Hs})-\mathrm{HT}+\mathrm{HTO}+\mathrm{Q}
$$

where the dot above a variable denotes differentiation with respect to time. A similar development was used by Sonderreger [10]. If an effective thermal mass, $C^{*}$, is defined as:

$$
\mathrm{C}^{*}=\mathrm{C}(1+\mathrm{H} / \mathrm{Hs})
$$

then the final differential equation is:

$$
\dot{\mathrm{T}}=(H \dot{\mathrm{T}} \mathrm{O}+\dot{\mathrm{Q}}) /(\mathrm{H}+\mathrm{Hs})+\mathrm{H}(\mathrm{To}-\mathrm{T}) / \mathrm{C}^{*}+\mathrm{Q} / \mathrm{C}^{*}
$$

To convert equation (7) to a finite difference equation, the characteristics of the experimental data must be taken into account. The time increment for the discrete measured data from the JC-80 was one hour and thus the differentials are approximated by the change in the value of temperature or heat rate between hourly measurements. For temperature readings, the value of the temperature at each hour is actually an average of the temperature over the previous hour. For linear changes in temperature the average is equal to the temperature at the midpoint of the hour. For non-linear temperature change the average is an approximation of the mid-hour temperature. For heat flow, the available measurement is an integrated energy entering or leaving the building and this approximates an average heat rate at the midpoint of the hour. The differentials in equation (7) are approximated by first interpolating the on-the-hour measurements to calculate values half-way between the measured values and then subtracting the interpolated values to obtain a linearized value for the slope of the temperature or heat rate curves. In equation form this is:

$$
\dot{T}=\left(T_{t+1 / 2}-T_{t-1 / 2}\right) / \Delta t=\left(\Delta T_{t}\right) / \Delta t
$$

where $\Delta t$ is the time step and $t \pm 1 / 2$ represent times halfway between measurement times. 
By substituting expressions of the form of equation (8) for all differentials in equation ( 7 ) and manipulating the equation to isolate $T_{t+1 / 2}$, equation

(7) may be converted to a difference equation of the following form:

$$
\mathrm{T}_{\mathrm{t}+1 / 2}=\mathrm{aT}_{\mathrm{t}-1 / 2}+\mathrm{b}_{1} \mathrm{To}_{\mathrm{t}}+\mathrm{b}_{2} \Delta \mathrm{To}_{\mathrm{t}}+\mathrm{c}_{1} \mathrm{Q}_{\mathrm{t}}+\mathrm{c}_{2} \Delta \mathrm{Q}_{\mathrm{t}}
$$

where

$$
\begin{aligned}
& \mathrm{a}=\left(1 / \Delta \mathrm{t}-\mathrm{H} / 2 \mathrm{C}^{*}\right) /\left(1 / \Delta \mathrm{t}+\mathrm{H} / 2 \mathrm{C}^{*}\right), \\
& \mathrm{b}_{1}=\left(\mathrm{H} / \mathrm{C}^{*}\right) /\left(1 / \Delta \mathrm{t}+\mathrm{H} / 2 \mathrm{C}^{*}\right), \\
& \mathrm{b}_{2}=(\mathrm{H} / \Delta \mathrm{t}(\mathrm{H}+\mathrm{Hs})) /\left(1 / \Delta \mathrm{t}+\mathrm{H} / 2 \mathrm{C}^{*}\right), \\
& \mathrm{c}_{1}=\left(1 / \mathrm{C}^{*}\right) /\left(1 / \Delta \mathrm{t}+\mathrm{H} / 2 \mathrm{C}^{*}\right), \\
& \mathrm{c}_{2}=(1 / \Delta \mathrm{t}(\mathrm{H}+\mathrm{Hs})) /\left(1 / \Delta \mathrm{t}+\mathrm{H} / 2 \mathrm{C}^{*}\right) .
\end{aligned}
$$

$\Delta Q$ and $\Delta T_{0}$ represent the change in $Q$ and $T_{0}$ between $t-1 / 2$ and $t+1 / 2$, and $\Delta t$ is the time step.

The $Q$ and $\Delta Q$ terms in equation (9) represent the sum of several heat sources and sinks. The Q terms may be broken down into heat generated within or mechanically removed from the building and heat generated by solar irradiation passing through the building windows. Although the windows in the NCFOB are small, solar irradiation was included in the analysis to see if the effects of solar had any significance. Equation (9) may be expanded to include solar by substituting:

$$
Q=Q+A S
$$

where Q becomes all non-solar heat sources and sinks, A is an effective solar window area and $S$ is the solar irradiation in energy per unit time and per unit area, in the $Q$ and $\Delta Q$ terms. This results in an equation of the form:

$\mathrm{T}_{\mathrm{t}+1 / 2}=\mathrm{aT}_{\mathrm{t}-1 / 2}+\mathrm{b}_{1} \mathrm{To}_{\mathrm{t}}+\mathrm{b}_{2} \Delta \mathrm{To}_{\mathrm{t}}+\mathrm{c}_{1} \mathrm{Q}_{\mathrm{t}}+\mathrm{c}_{2} \Delta \mathrm{Q}_{\mathrm{t}}+\mathrm{d}_{1} \mathrm{~S}_{\mathrm{t}}+\mathrm{d}_{2} \Delta \mathrm{S}_{\mathrm{t}}$

where

$$
\begin{aligned}
& \mathrm{d}_{1}=c_{1} * A \\
& d_{2}=c_{2} * A .
\end{aligned}
$$

To determine values for the thermal resistances and capacitances of the model, a set of the experimental data can be used with a least squares regression to determine what coefficients in equation (16) would result in the best agreement between the temperatures predicted by the equation and the measured temperatures. Once the coefficients are known the ETP's can be determined by algebraic techniques from the coefficients. 


\subsection{APPLICATION OF EQUIVALENT THERMAL PARAMETERS CONCEPT}

Although the data replacement technique described in chapter 4 was useful for producing complete monthly totals and also daily totals, the technique produces small discontinuities in the hourly data at the beginning and end of the replaced block. Since the ETP technique is a transient analysis, only sets of NCFOB data that were continuous were used to evaluate the constants in equation (16). Table 2 in chapter 4 shows that there were a large number of gaps in the continuous data collection and thus only ten sets of data were selected for use in the ETP analysis. These ten sets were selected based on the criteria that they consist of at least five continuous days.

The categories of data used in the analysis had to be carefully selected to agree with the concept of the terms used in equations (3) and (4). The indoor temperature terms for the measured data were calculated as an average of five space temperature measurements on each of the seven floors of office space. Although there was variation in the temperatures from floor to floor and core to perimeter, the temperature was assumed to be uniform to preserve the simplicity of the analysis. The outdoor temperature was a single measurement taken at the roof of the building.

The energy term $Q$ was assumed to be a combination of a number of measured parameters. During the winter, the heat energy added to the building space is the sum of the energy added by the HVAC system, the internal gains due to the presence of people, and the internal gains from lighting and office equipment. The energy from the HVAC system had been calculated, as described in chapter 4, during the data reduction and could be used directly. The internal gain from lights was assumed to be equal to the electric energy consumed for lighting. Energy to lighting in the basements and non-office areas was excluded. Misce1laneous office electric energy was used as the internal gain from office equipment. The only quantity not measured was the gain from people. To approximate the internal gain from people, an assumed daily occupancy profile was used. This profile was based on a full occupancy of 280 persons, each producing approximately $120 \mathrm{~W}$ of energy. Occupancy was assumed to begin at 7 am and reach the full value by 8 am, continue until 4 pm at full occupancy and then decline to unoccupied by $5 \mathrm{pm}$.

The solar irradiation term was taken from a measurement of tilted irradiation at 60 degrees in the vicinity of the roof-mounted solar collectors.

Horizontal irradiation was not available.

To illustrate the techniques used to obtain the equivalent thermal parameters for the Norris Cotton Building, a detailed example will be presented. One time period selected for analysis was a time period from February 8 through 14, 1980. During this period, 139 continuous hours of data were taken. The weather during the period was cold with temperatures ranging from $0^{\circ} \mathrm{C}$ to $-10^{\circ} \mathrm{C}$ and solar radiation levels were high. To fit the data collected for this time span to the model represented by equation (16), the data were arranged to correspond as closely as possible to the terms of the equation, as described above. A linear regression was done using a computer program to determine the coefficients in equation (16). The model equation has seven variables and a constant 
term was included in the determination to improve the fit of data to the model even though the theory does not predict the existence of a constant term.

Table 3 shows the output of the computer program used to perform linear regression [12]. The second column of the table contains the computed coefficient for each variable and the third column shows the computed standard deviation for each coefficient. The fourth column of table 3 contains a number, called the t-ratio, used to test the statistical significance of the coefficient. If any coefficient were equal to zero, then the corresponding variable would have no statistical effect on the dependent variable. If the coefficient is assumed to be zero, then the t-ratio is defined as the difference between the computed coefficient from the regression and the assumed value, zero, divided by the standard deviation for the coefficient. If the t-ratio is less than approximately 2 or 3 , then the coefficient may be considered to be equal to zero. If the t-ratio is greater than 2 or 3 , then the variable corresponding to the coefficient is statistically significant and has an effect on the dependent variable. It may be observed in table 3 that several variables are not very significant for this data set, most notably the solar irradiation terms. The lack of significance for the solar irradiation is not surprising because of the very small window area for the building. The constant term, the $\mathrm{T}_{0}$ term, the $\Delta \mathrm{Q}$ term and the $\Delta$ To term have low significance in this case. These results might be expected, since the close coupling between the mass and the building space implies a large heat transfer coefficient between mass and space and in equation (7) the $\dot{Q}$ and To terms are divided by this coefficient.

To determine the quality of the fit between the model with the calculated coefficients and the measured data, the residuals, defined as the differences between the model predictions and the measured values at all the time steps of the data, were examined. The residual standard deviation is defined as:

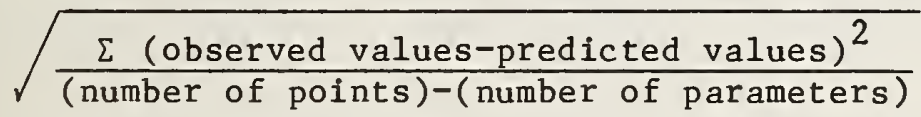

The calculated residual standard deviation was $0.045^{\circ} \mathrm{C}$, a value much smaller than the probable instrument error. The distribution of the residuals about the mean was observed to follow a normal distribution, indicating a good agreement between model and measured data.

Table 3 showed that the coefficients $a, b_{2}$, and $c_{1}$ could be considered significant. Regressions were not repeated using only significant parameters. The assumption was made that the coefficients would not change appreciably. Thus equations (10), (12), and (13) form a set of simultaneous equations for determination of the equivalent thermal parameters $C^{*}, H$, and Hs. Since a and $c_{1}$ had the highest t-ratios, equations (10) and (13) were combined first to yield the following relationships:

$$
H=(1-a) / c_{1}
$$

and

$$
C^{*}=\left(2-c_{1} H\right) / 2 c_{1}
$$


If the coefficients from table 3 are substituted in the above equations, the result is that the heat transfer coefficient between the outside air and the inside air, $\mathrm{H}$, is calculated to be $18.6 \mathrm{~kW} /{ }^{\circ} \mathrm{C}$; the effective thermal capacity, $\mathrm{C}^{*}$, is calculated to be $728 \mathrm{kWh} /{ }^{\circ} \mathrm{C}$; and using equation (12), the transfer coefficient between the space and the mass, Hs, is calculated as approximately $500 \mathrm{~kW} /{ }^{\circ} \mathrm{C}$.

In order to determine if the above values for the equivalent thermal parameters are reasonable, the parameters may be estimated from information about the building envelope. The thermal loss coefficient, $\mathrm{H}$, should have three components for this building. One component, the transmission loss, may be estimated from the design values for the wall and roof constructions under steady-state conditions [13]. If this is done the transmission loss coefficient is determined to be $3.5 \mathrm{~kW} /{ }^{\circ} \mathrm{C}$. The second component is infiltration loss and may be empirically estimated using an air exchange rate that was measured at the building with a tracer gas technique [4]. The measured average air exchange rate with building air circulation system operating but outside air dampers closed was determined to be 0.54 air change/hour. With a building volume of $31150 \mathrm{~m}^{2}$ and an outside air temperature of approximately $0^{\circ} \mathrm{C}$, this amounts to an infiltration loss coefficient of approximately $9.5 \mathrm{~kW} /{ }^{\circ} \mathrm{C}$. The final component of the thermal loss is the effect of forced ventilation of the building using outside air. It is assumed that opening the outside air dampers does not affect the component of total air exchange rate due to effects other than mechanical ventilation. The design minimum outside air rate of $5829 \mathrm{l} / \mathrm{s}(12,350 \mathrm{cfm})$ was used along with an assumed efficiency of 70 percent for a heat recovery heat exchanger in the air system for the upper four floors to yield a ventilation air loss coefficient of approximately $5.8 \mathrm{~kW} /{ }^{\circ} \mathrm{C}$. Combining the three estimated components yields an estimated loss coefficient of $18.8 \mathrm{~kW} /{ }^{\circ} \mathrm{C}$ which compares well with the value determined from the regression analysis.

The thermal capacity of the building is more difficult to estimate than the loss coefficient. Typically, the total capacity of the building walls will not be used in hour-to-hour variations in room temperature during heating [14]. Using half of the wall thickness, the capacity of the building walls was estimated to be $280 \mathrm{kWh} /{ }^{\circ} \mathrm{C}$, and the capacity of the floors to be approximately 450 $\mathrm{kWh} /{ }^{\circ} \mathrm{C}$. The resulting estimate is in the vicinity of $750 \mathrm{kWh} /{ }^{\circ} \mathrm{C}$ not including the capacity of the building furnishings. The regression calculated value of $728 \mathrm{kWh} /{ }^{\circ} \mathrm{C}$ is not unreasonable. The value for the heat transfer coefficient between the mass and the building space calculated from the regression analysis when divided by the floor area is $45 \mathrm{~W} / \mathrm{m}^{2}{ }^{\circ} \mathrm{C}$ which is large but is not unreasonable given the lack of insulation between the air in the building and the walls and floors.

A comparison betwen the measured inside temperature and the temperature predicted using the calculated equivalent thermal parameters for the period of February 8-14, 1980 is shown in figure 20. The original fit between measured data and model using the full set of coefficients from table 3 was much closer than shown in the figure, illustrating the effect of assuming all non-significant constants to be equal to zero. The fit is still acceptable, however. The figure shows a weekend period followed by three working days. No heating is provided during the weekend and the inside temperature steadily drops. During the working days the mechanical equipment works to bring the temperature back 
up. The figure shows that the space temperature never reached the set point on Monday but gets closer to the set point on succeeding days. In this case, the building mass works against the mechanical system and slows the achievement of the space temperature setpoint.

Figure 21 shows the swings in outside temperature during the time period and the smaller swings of indoor temperature relative to the outdoor temperature. Also shown in figure 21 is a calculated structure temperature which turns out to be quite close to the indoor air temperature. The calculation of structure temperature is highly sensitive to the heat transfer coefficient between the structure and the indoor air, Hs, and errors in the determination of Hs, which was determined from a weak coefficient, have a large effect on the magnitude of the structure temperature. Keeping in mind that the difference between the structure temperature and the indoor temperature is of the same order of magnitude as the probable measurement error in the temperatures, the structure temperature is predicted as being slightly higher than the inside temperature. The simplicity of the model presents some problems in physical interpretation of the results but figure 21 seems to indicate that the mass participating in the heat transfer during this time period may have been mostly the floors and interior furnishings since it is known that the wall temperatures in most cases in the winter were less than the space temperature. Figure 21 illustrates that the difference between inside and outside temperature is much larger than the amplitude of the indoor temperature variations. This means that the massive walls should not cause any phase differences between indoor and outdoor temperature oscillations in this case.

The total energy added to the building space during the February 8 to 14 time period is plotted in figure 22. These values include both mechanical system heating requirements and internal gains. The figure shows that during the weekend, little energy was added but during the weekdays daytime energy addition was much greater than on weekends.

\subsection{RESULTS OF EQUIVALENT THERMAL PARAMETERS ANALYSIS}

A total of ten periods of continuous data were analyzed to determine the equivalent thermal parameters for the Norris Cotton Building. of the ten, only four sets of data were judged to fit the simple ETP model acceptably and the results from these four sets are shown in table 4. Of the unacceptable six sets of data, four resulted in a relatively large and significant constant term being generated by the least squares regression. Since the model cannot explain the physical significance of the constant term, the data did not fit the model. The problem with these sets may have resulted from error in some of the measurements or the model may not have taken into account significant energy transfers existing in the real building during the time period. Due to physical mechanisms not reflected in the simple model, a variable such as $T$ may not have statistically significant regression coefficients. If the coefficient of this variable is small, the fit will have a constant term to account for any heat loss caused by the average indoor-outdoor temperature difference. The two remaining unacceptable data sets resulted in unreasonable or negative coefficients from the least squares regression. 
Of the four data sets that fit the model, the results of the least squares regression were consistent between sets. Table 4 shows that two sets were from winter months and two from summer and fall months. The indoor-outdoor air heat transfer coefficient, $H$, was found to be larger for the summer months than for the winter months. This can be explained because during the summer, the heat loss includes removal of heat from the building by nighttime flushing with outside air and economizer operation. The analysis predicts that these summer operations approximately double heat losses over those experienced during winter operation.

Table 4 shows that there is a slight increase in the effective thermal capacity during the summer months indicating that more of the building mass is being used. This is as would be expected since no space conditioning is used during unoccupied hours in the summer and more of the building mass could be expected to approach the ambient temperature. Figure 23 shows the outdoor, indoor, and calculated structure temperature for the time period of June 20 to 29, 1980 . This figure is comparable to figure 21 except that figure 23 is for summer operation. It may be observed that the structure temperature tracks the inside temperature closely. The start of mechanical cooling is obvious in the figure as the inside and the structure temperatures decrease toward a set point. 
8. RESULTS -- MECHANICAL SYSTEMS

The performance of the mechanical equipment at the Norris Cotton Federal office Building can be examined at two levels, equipment performance and overall system performance.

\subsection{EQUIPMENT PERFORMANCE}

The mechanical systems at the NCFOB utilize several types of equipment and the hourly data can be used to evaluate, to some extent, the performance of various types of equipment. In chapter 4, the assumptions used to calculate the performance parameters for the building were stated. For most of the mechanical equipment, input energy quantities were satisfactorily measured, but to determine equipment output or efficiency the equipment was essentially simulated.

Four major types of equipment were evaluated using the hourly average data. These were the natural gas boilers, the heat pumps, the electric chiller, and the solar system. The efficiencies of the four modular boilers acting together were examined to verify the part-load performance curve assumed in the calculations and determine the operating point of the boiler system in different months. Figure 24 is a plot of boiler efficiency calculated by the data reduction program during three months of the year versus the boiler output. A relationship between efficiency and load of this type was assumed for the data reduction calculations of boiler performance and figure 24 verifies that the assumed curve was correctly used in the calculations. The points on the figure lie along one of four curves, depending on how many boilers were operating at the time. If the efficiencies were plotted versus the boiler output divided by the full load output of the number of boilers operating, the curves would all coincide. Three different types of points are displayed in figure 24, one type for each month of data. The figure shows that in the colder month, February, most of the points are on the higher end of the four boiler curve, while in the warmest month, April, most of the points lie on the lower end of the one or two boiler curve. This figure points out that the use of modular boilers was successful since the boiler loading varied during the year and a single large boiler would have had lower efficiency at lower loads in spring and fall (a large boiler might be represented by the 4 boiler curve).

For the heat pump system, the coefficient of performance (COP) for individual units was taken from manufacturers data. The hourly data produced by the data reduction program allows the heat pump system to be viewed as a whole and the distribution of load point to be examined. Figure 25 shows the calculated COP for the heat pump system during the month of February 1980. The COP in this case is the sum of all calculated hourly output divided by the input electric energy to the heat pumps, including energy to the unit fans. During this month the heat pump load is almost entirely for heating and the loop water temperature was constant. The COP is plotted versus the load and the maximum heating requirement indicated on the figure represents the full load heating capacity of the heat pump system. The general shape of the data in figure 25 is similar to the curves in figure 24 for the boilers because of the effects of part-load operation on the heat pump system performance. The most obvious feature of the figure is the division of the points into two groupings. The upper grouping 
represents the operation of heat pumps during unoccupied periods. When the building is unoccupied, only a few of the heat pumps are operating and these are operating at relatively high part-load points. Thus the apparent COP of the units is higher as a function of load. The lower curve, then, is for the occupied period when all of the heat pumps are operating with at least their fans running. Note that the occupied period points are distributed evenly along the part-load curve.

Figure 26 represents the calculated COP of the heat pump system during the cooling season for the month of July 1980. As for figure 25, 1oop water temperature was constant during the month, but at a higher temperature than in winter. Again the maximum value of requirements represents the total steadystate cooling capacity for the heat pump system. For this month of cooling operation it appears that most of the points are clustered in the lower end of the part-load curve. The explanation for this is that since the heating loads predominate in this climate, the heating capacity of the heat pumps determines the size of the unit. For a given unit the ratio of heating to cooling capacity is relatively fixed, and thus the heat pumps end up being somewhat oversized with regard to cooling capacity. The points in figure 26 generally lie along a single curve, unlike the points in figure 25 , because during the cooling season no cooling is performed during the unoccupied hours except under unusual conditions.

The central plant electric chiller input and output were both measured and no approximations were made for the output of the chiller. Figure 27 is a plot of the measured coefficient of performance (COP) for the electric chiller as a function of the evaporator output. This figure shows that most of the chiller operation is at around the same load point. However, this point is not the same as the rating of the chiller $(211 \mathrm{~kW})$ but is nearly half of the rated capacity. It is not clear if this discrepancy is real or due to measurement error. The rated conditions for the electric chiller were examined, and it was noted that the measured evaporator flow rate was approximately half of the rated flow rate. This low flow rate could be due to some measurement error or could be correct and represent a problem in the chilled water circuit which is reducing the flow rate.

The solar system at the Norris Cotton Building and the use made of the solar heated water were described in chapter 2. During the year of monitoring by the JC-80, the solar system provided energy for service hot water and met most of that load. Very little energy was supplied to the hot water heating system at the building.

The solar array on the roof was operated all year during daylight hours even if the energy collected could not be put to any use. The performance of the array was monitored and the information collected is useful in illustrating the performance of solar collectors in an array on an actual installation that has been in service for several years. Figure 28 is a plot of solar collector efficiency based on the gross area of the array plotted versus a term to represent the operating level of the collectors as recommended by ASHRAE standard 93-77. The operating level term is the inlet temperature to the collector array minus the ambient dry bulb temperature divided by the solar irradiation 
per unit area on the collector array. The data points in the figure are hourly averages taken from three different months. Points taken when the solar pumps were not operating at full speed for the entire hour were not plotted in figure 28. There is a large amount of scatter visible in the data since the points were not taken under laboratory conditions but represent a large number of environmental conditions which would tend to shift the efficiency curve around on the plot. The points from February and the points from April generally lie in the same area of the plot. The line on the figure represents an average performance curve for the array based on laboratory tests of individual collectors of the same types as those in the array. The average array performance is determined by weighting individual performance test results by the area of the collector types in the array and by using the assumption that the flow rates in the array are the same as for the collectors during the lab tests. The existence of higher or lower flow rates in the individual rows of the collector array than were used in the lab tests would result in a shifted performance curve.

The efficiency points for the array during August are in general much lower than the winter or spring points. During the summer, irradiation and ambient temperature levels are much higher than in the winter. If there are collectors in the array with restricted flow, local boiling in parts of the collector array can result. If this problem is excessive, the array can become steambound, resulting in a much lower efficiency curve. It is likely that this has occurred at the Norris Cotton Building since steam has sometimes been observed being discharged at relief valves in the array.

\subsection{TOTAL MECHANICAL SYSTEMS PERFORMANCE}

In large buildings, equipment exists which supplies required ventilation and transfers thermal energy, produced from the fuel, to heat or cool the building space. This equipment, which includes pumps, controls, and fans, requires energy to operate in addition to the fuel used to satisfy the building loads. Such energy usage may be termed energy distribution energy or "operating energy." It is important to look at both the operating energy and the fuel energy in studying large buildings.

Figure 29 is a plot of the total fuel energy used per hour, including electric energy to the compressors in the heat pumps, versus the heating requirements calculated by the method in section 4.3 using data from February 1980. The data in figure $29 \mathrm{fall}$ into a straight line with little scatter, due to the assumptions about equipment performance and the assumption that there is no transmission loss from pipes and ducts in transferring energy from the central plant to the building conditioned space. As the heating requirements approach zero, the fuel use also decreases toward zero.

The measured operating energy per hour for the same period of data collection as in figure 29 is shown in figure 30. The operating energy is plotted versus calculated heating requirements but there appears to be very little relationship between load and operating energy, as expected. There are two groups of data in figure 30, the upper group with a magnitude of about three times the lower group. The upper group represents occupied building operation with all 
ventilation fans operating and the lower group is for unoccupied operation with only minimal operating energy.

Figure 31 is similar to figure 29 but represents fuel energy data from July 1980 during the cooling season. The fuel energy for cooling, mostly electric energy to the compressors in the heat pumps and the chiller, is plotted versus the calculated hourly cooling requirements. As in the case of the heating season data, the points lie in a straight line with little scatter because the cooling requirements were calculated from manufacturer equipment capacity data and measured input energy.

The operating energy for July 1980 is shown in figure 32, which is analagous to figure 30. The operating energy points are plotted versus the cooling requirements, and as with the heating points, fall into two groups, the occupied hours and the unoccupied hours. During the summer, usually no space conditioning is used during the unoccupied hours and thus the cooling requirements are very small. The unoccupied operating energy points all cluster at lower cooling requirements for this reason. The upper group of points, representing the occupied hours, shows a very slight increase with increased cooling requirements.

The concept of efficiency is useful in measuring the performance of a total mechanical system. For heating season operation the hourly average efficiency of the mechanical system was defined as the calculated heating requirements for an hour divided by the measured total energy used for heating, where the total energy for heating includes operating energy but does not include non-HVAC energy such as for lighting. The hourly efficiency can be plotted versus the heating requirements to produce a part-load heating efficiency curve and this is done in figure 33 for data from the month of February 1980. As in previous figures, two groups of points occur, corresponding to unoccupied and occupied operation. The system efficiency approaches 70 percent during occupied hours, a figure which includes the effects of boiler efficiency, heat pump COP, and relative amounts of fuel and operating energy. The calculation of efficiency assumes that all piping and duct losses from the HVAC system are not really lost but help satisfy heating requirements by convection and radiation of lost heat into occupied spaces. The efficiencies for unoccupied heating in figure 33 are higher for a given load because the operating energy is much less than during occupied hours when all pumps and fans are operating.

Figure 34 is similar to figure 33 except that instead of efficiency, the concept of cooling factor is used. Cooling factor is used here to mean the calculated cooling requirements for one hour divided by the measured total energy used in the same hour for cooling, including operating energy. The occupied cooling factor approaches about 1.2 at larger loads. This is less than the COP's of individual pieces of equipment such as heat pumps and the electric chiller because the operating energy brings down the net cooling factor. The unoccupied data points are generally at low loads and low cooling factors. 


\section{CONCLUSIONS}

1. An automated data acquisition system was operated at the NCFOB compiling 7441 complete hours of data out of a possible 9504. The longest uninterrupted period was 17.75 days in September 1980 and the longest outage was 10 days in September 1979.

2. A number of major problems were experienced in the checkout and operation of the minicomputer control/data acquisition system at the NCFOB due to three major causes: proprietary system software which was difficult to evaluate; lack of contractual agreements between NBS, the commercial supplier of the system, and the building operator; and the fact that the system was a commercial design, lacking laboratory accuracy and the capability for on-site system changes.

3. A technique of replacing missing or unusable hours of data with data from similar hours and changing the date on the replacement hours was successfully utilized. The technique did result in discontinuities when the data was used for transient analysis.

4. Hourly average data from the control/data acquisition system was used to calculate monthly, daily, and hourly building energy performance parameters. Parameters based on electrical energy measurements were considered the most reliable.

5. The complexity of the HVAC system design and failure of the instrumentation to produce originally-planned measurements, prevented the collected data from being used to make detailed floor-by-floor comparisons of HVAC equipment.

6. Using simplified transient heat transfer analysis, equivalent thermal parameters were determined from actual continuous hourly data. The calculated parameters compared well with estimated values. This technique is useful for determining dynamic heat transfer coefficients in large buildings with simple measurements.

7. Based on the equivalent thermal parameter analysis, the small windows in the building were found to admit an insignificant amount of solar energy.

8. Based on the equivalent thermal parameter analysis, the insulation design of the Norris Cotton Building was found to be effective in producing a low transmission loss for the building. During the heating season however, the large mass, closely coupled with the interior space, was found to inhibit the return to desired temperatures after an unoccupied period when the space temperature set point had been setback.

9. Reduced data from boiler fuel consumption and boiler operating hours showed that the use of modular boilers resulted in higher boiler efficiencies over the use of a single large boiler.

10. Reduced data on heat pump system performance show that hourly COP's of the heat pump system are lower in summer than winter. The units are sized for the 
large heating loads in winter and not the smaller cooling loads in summer and therefore operate at a lower, less efficient part-load point in summer.

11. Hourly average total mechanical system heating efficiency calculated from assumptions about equipment performance approached a maximum of 70 percent at large loads in the month of February 1980 during occupied hours. This figure includes operating energy and fuel energy. Average heating efficiency for February was 30 percent.

12. The hourly average mechanical system cooling performance factor calculated from measurement and assumptions of equipment performance was observed to approach a maximum of 1.2 for large cooling loads in July 1980. This figure includes operating energy and fuel energy. Average cooling factor for July was 0.91 . 


\section{REFERENCES}

[1] Isaak, N.; Isaak, A. Designing an Energy Efficient Building. General Services Administration/Public Buildings Service spec. publ. 1975 September, $43 \mathrm{p}$.

[2] Hill, J. E.; May, W. B.; Richtmyer, T. E.; et al. Performance of the Norris Cotton Federal Office Building for the First Three Years of Operation. Nat. Bur. Stand. (U.S.) Bldg. Sci. Ser. 133; 1981 June, 125 p.

[3] Elder, J.; Tibbott, R. L. User Acceptance of an Energy Efficient Office Building - A Study of the Norris Cotton Federal Office Building. Nat. Bur. Stand. (U.S.) Bldg. Sci. Ser. 130; 1981 January, 122 p.

[4] Hunt, C. M. Ventilation Measurements in the Norris Cotton Federal Office Building in Manchester, New Hampshire. ASHRAE Transactions. Vo1. 85, part $1,1979$.

[5] Richtmyer, T. E.; May, W. B.; Hunt, C. M.; Hill, J. E. Thermal Performance of the Norris Cotton Federal office Building in Manchester, New Hampshire. Proceedings of the DoE/ASHRAE Conference on Thermal Performance of Exterior Envelopes of Buildings; 1979 December; Orlando, FL.

[6] Kelly, G. E.; Didion, D. A. Energy Conservation Potential of Modular Gas-Fired Boiler Systems. Nat. Bur. Stand. (U.S.) Bldg. Sci. Ser. 79; 1975 December, 54 p.

[7] Mulroy, W. J.; Kelly, G. E. Laboratory Tests of a Residential Unitary Water-Source Heat Pump. Nat. Bur. Stand. (U.S.) NBSIR in preparation; 1981.

[8] General Services Administration/Public Buildings Service. Energy Conservation Design Guidelines for New Office Buildings. 2nd Edition, 1977,324 p.

[9] Kusuda, T.; Tsuchiya, T.; Powe11, F. J. Prediction of Indoor Temperature by Using Equivalent Thermal Mass Response Factors. Proceedings of the 5 th Symposium on Temperature. Nat. Bur. Stand. (U.S.), Washington, D.C. 1971 .

[10] Sonderegger, R. Diagnostic Tests Determining the Thermal Response of a House. ASHRAE Transactions. Vo1. 84, part 1, 1978.

[11] Kimura, K.; Ishino, H.; Komiya, H.; Matsura, J. Study on the Comparative Verification of Various Methods of Air Conditioning Load Calculation by Field Measurements, Second Symposium on the Use of Computers for Environmental Engineering Related to Buildings, 1974 June.

[12] Hogben, D.; Peavy, S. T.; Varner, R. N. Omnitab II User's Reference Manual. Nat. Bur. Stand. (U.S.) Tech. Note 552; 1971 October, 264 p. 
13. May, W. B.; Spielvogel, L. G. Analysis of Computer Simulated Thermal Performance of the Norris Cotton Federal Office Bullding. Nat. Bur. Stand. (U.S.) NBSIR 80-2093; 1980 November, 62 p.

14. Børresen, B. A. Heat Storage in Walls. Building Service Engineer (British). Vo1. 41, 1973 December, p. 17 . 


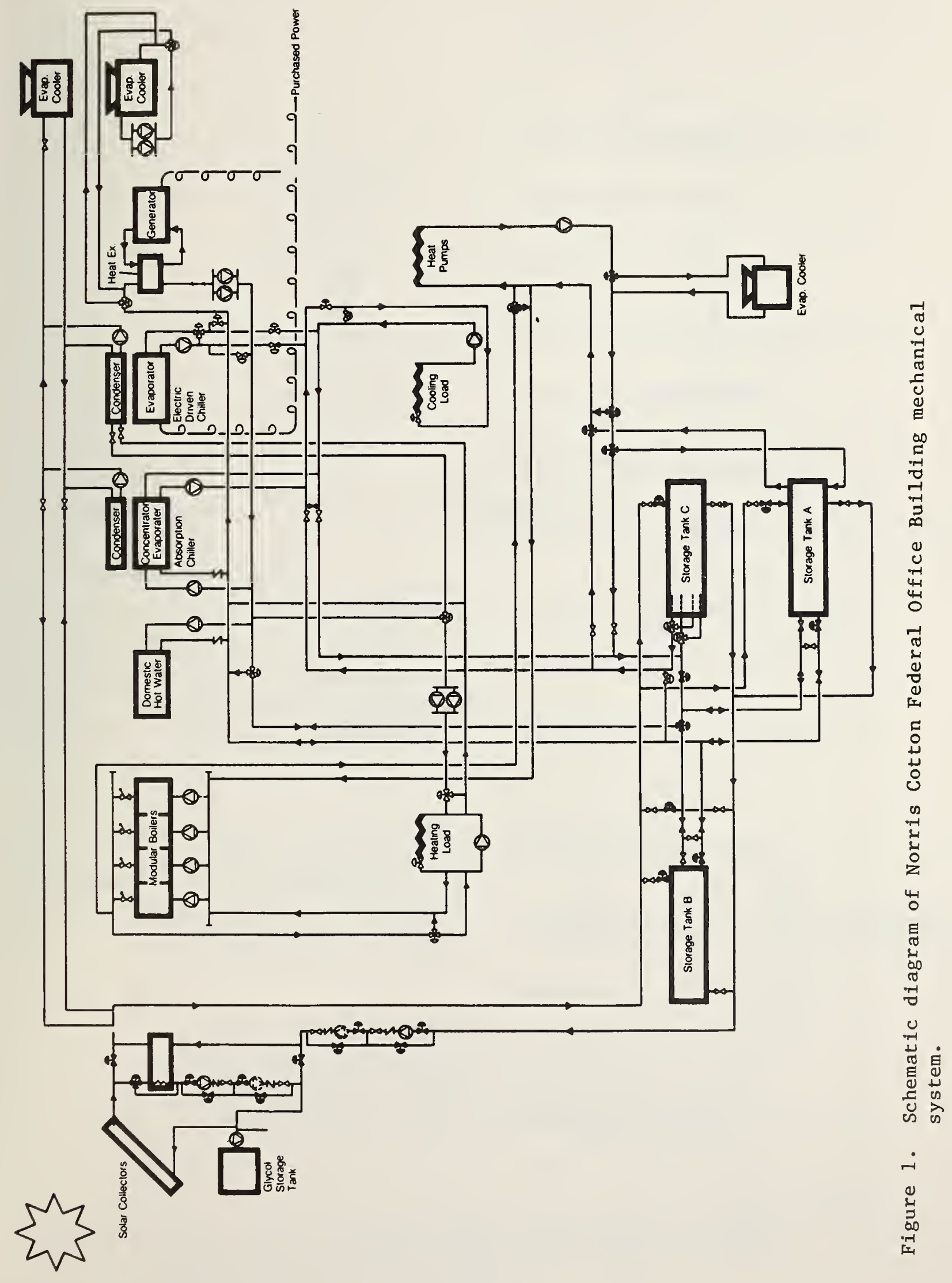




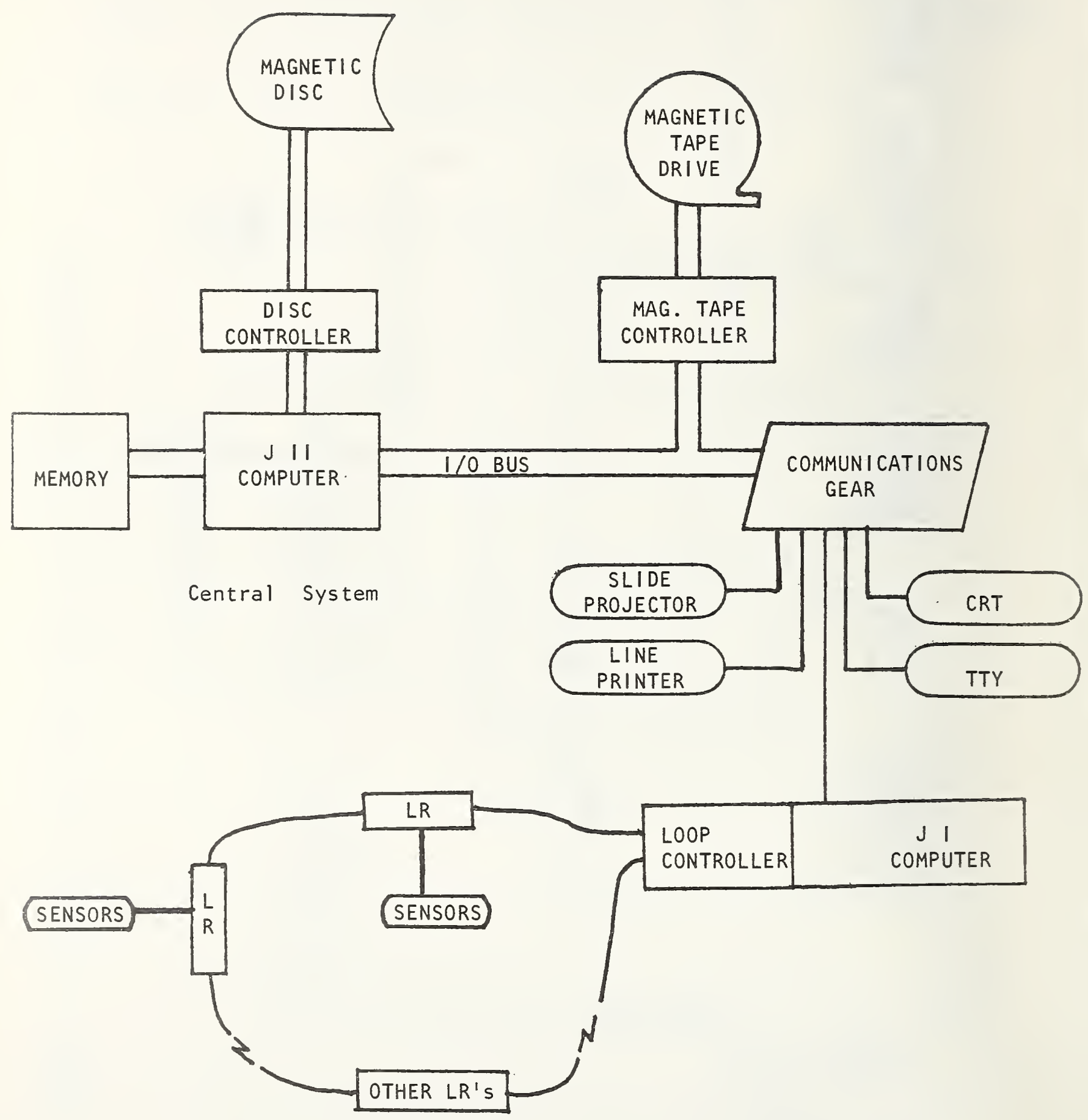

Figure 2. Diagram of JC-80/55 minicomputer control system configuration at Norris Cotton Federal Office Building. 


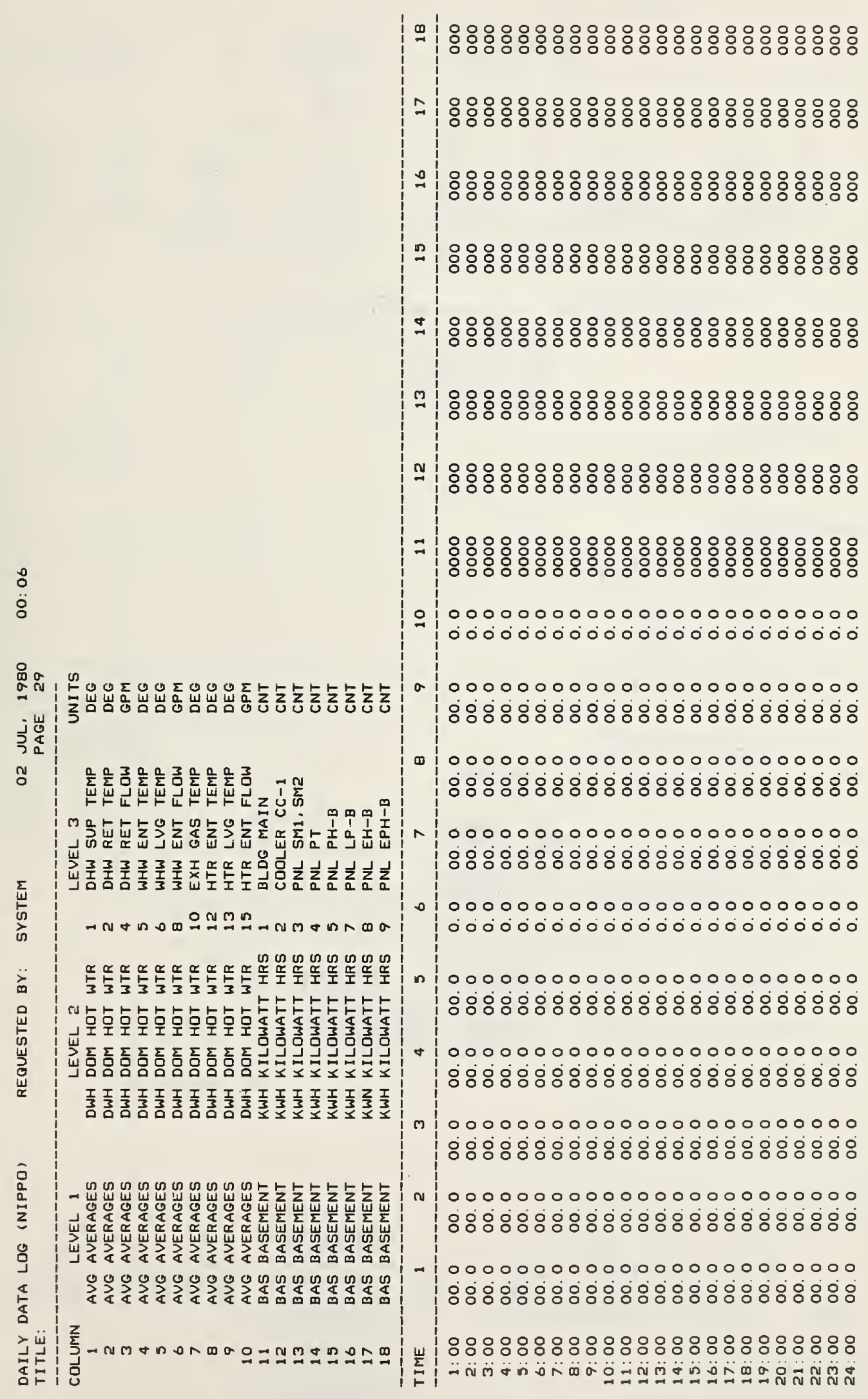

Figure 3. Format of data contained on magnetic tapes generated at the Norris Cotton Federal office Building. 


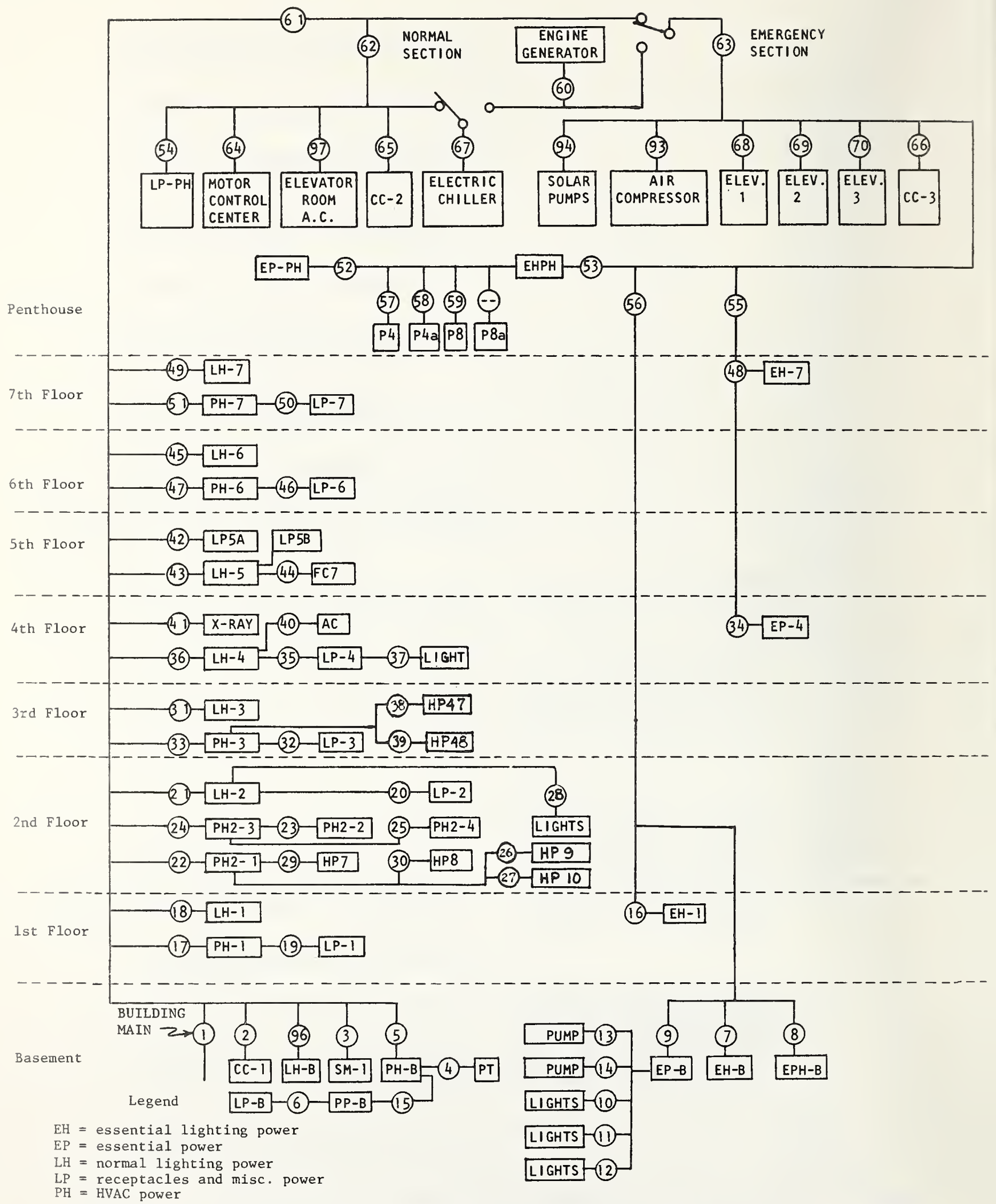

Figure 4. Diagram of electric power distribution system at Norris Cotton Federal office Building. Circled numbers indicate kilowatt-hour meters. 


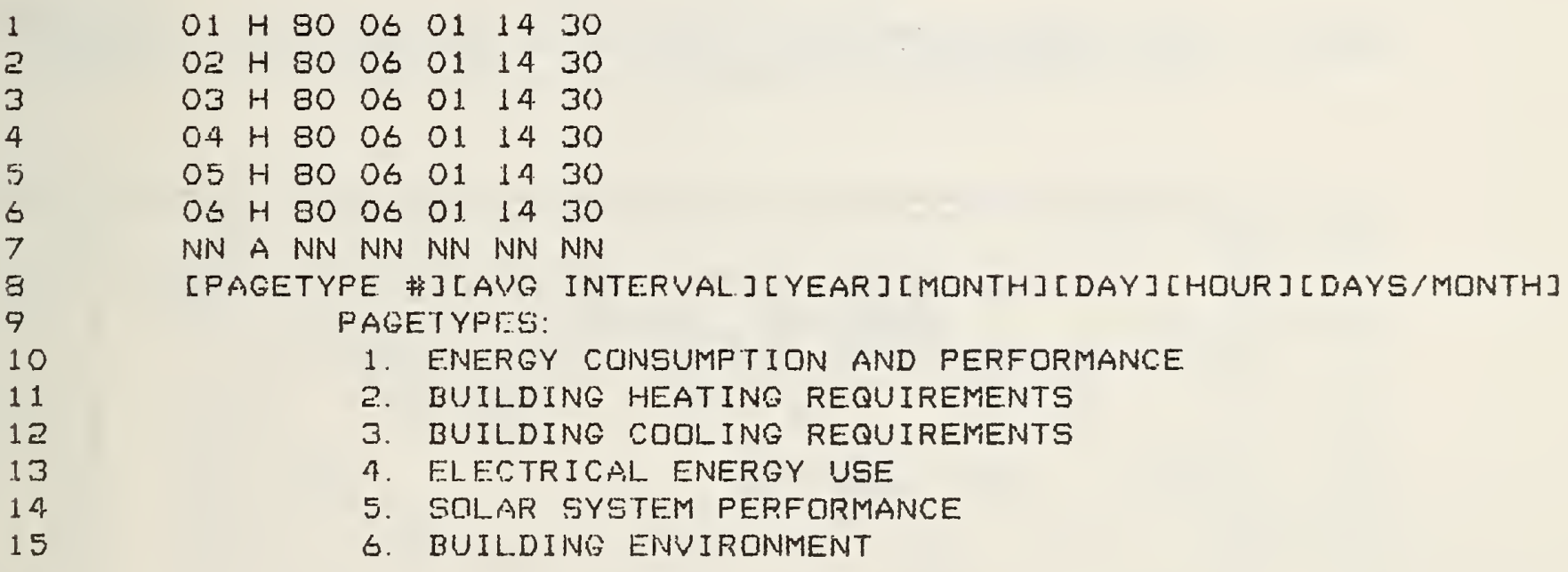

Figure 5. Sample instruction file for table-producing data retrieval program. 


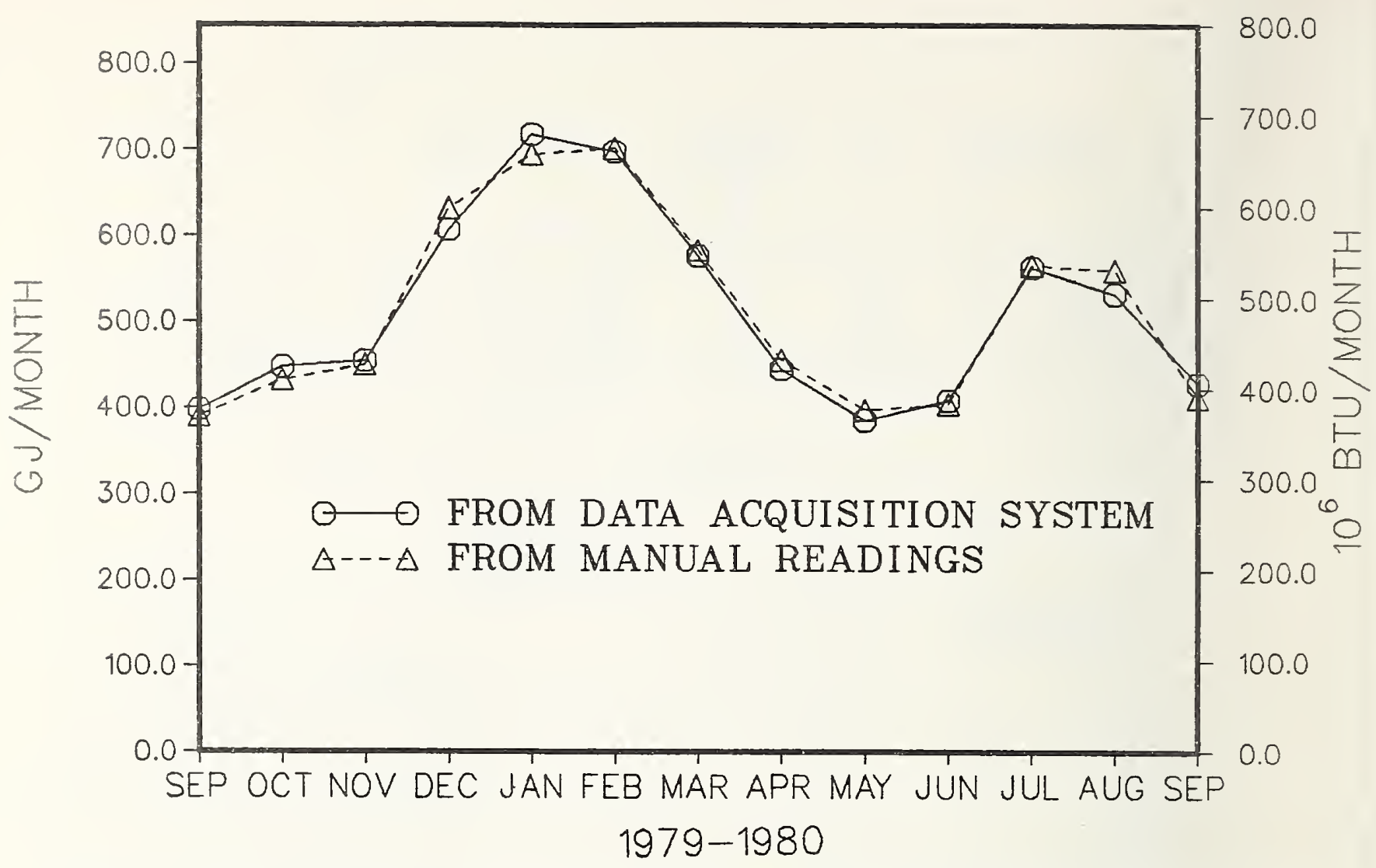

Figure 6. Total energy consumption at the NCFOB building boundary as calculated from $\mathrm{JC}-80$ and manual readings

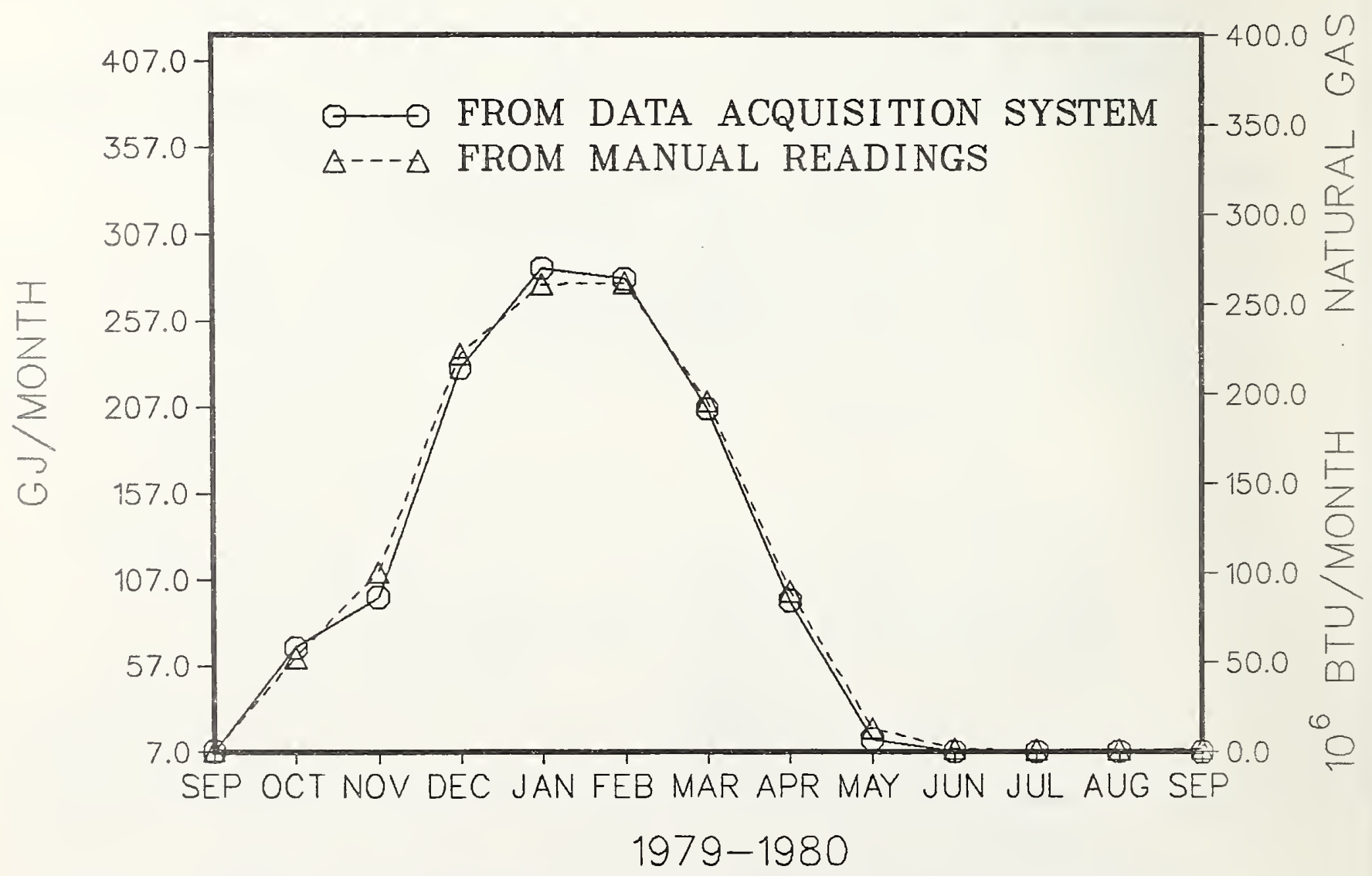

Figure 7. Natural gas consumption at NCFOB as calculated from JC-80 and manual readings. 


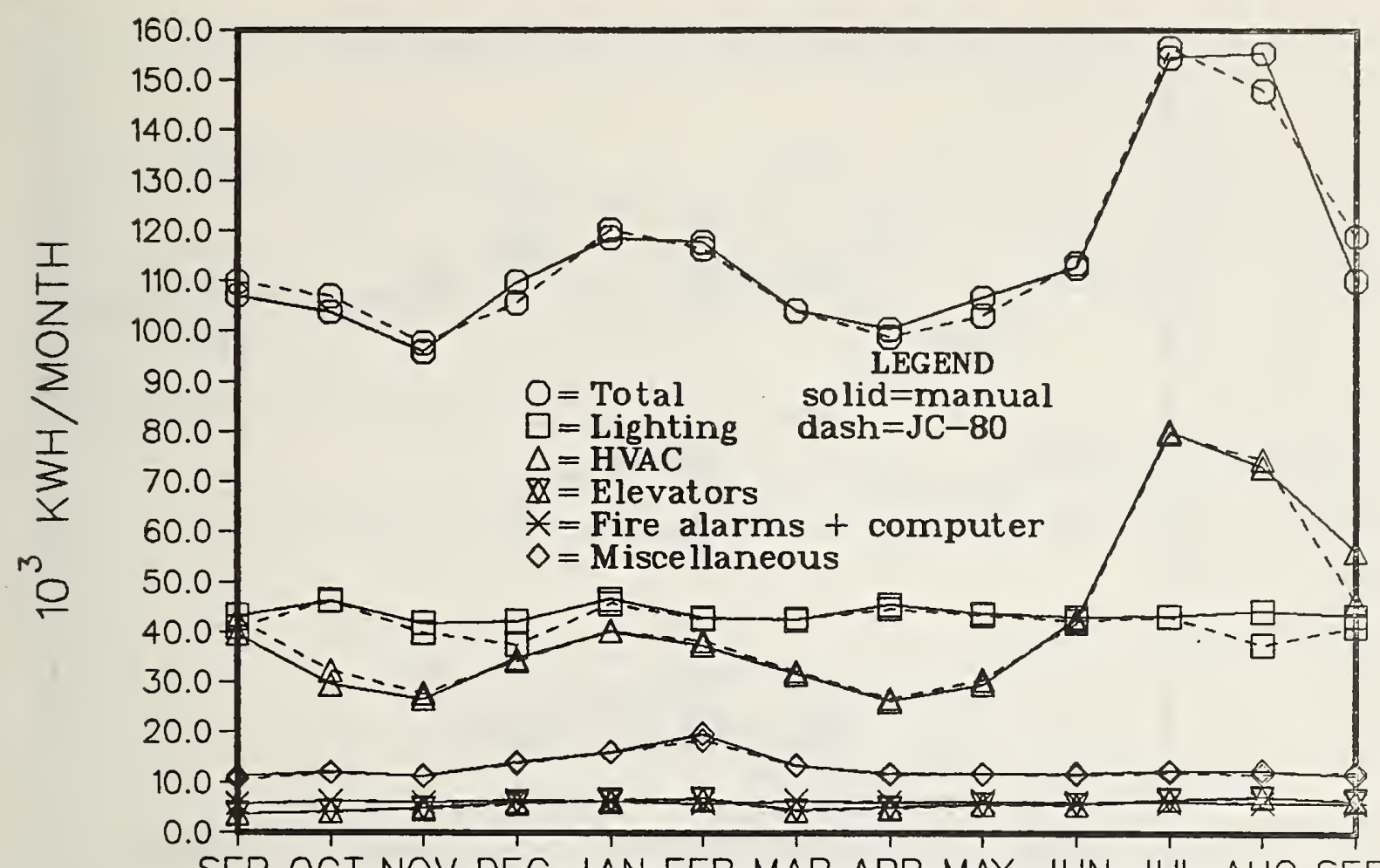

SEP OCT NOV DEC JAN FEB MAR APR MAY JUN JUL AUG SEP $1979-80$

Figure 8. Major categories of electrical energy consumption for the NCFOB as calculated from $\mathrm{JC}-80$ and manual readings

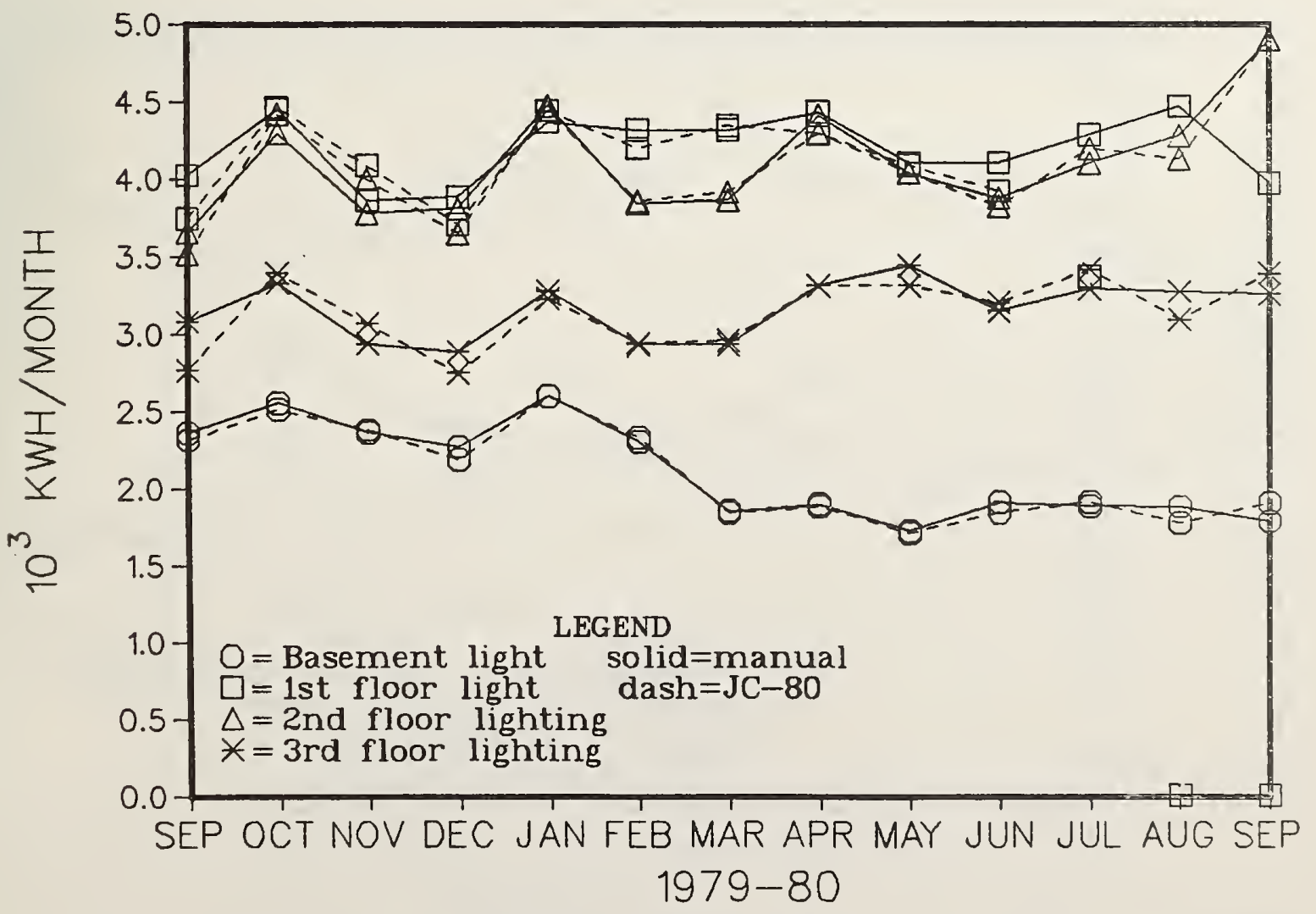

Figure 9. Electrical energy use for lighting on lower floors of NCFOB as calculated from JC-80 and manual readings. 


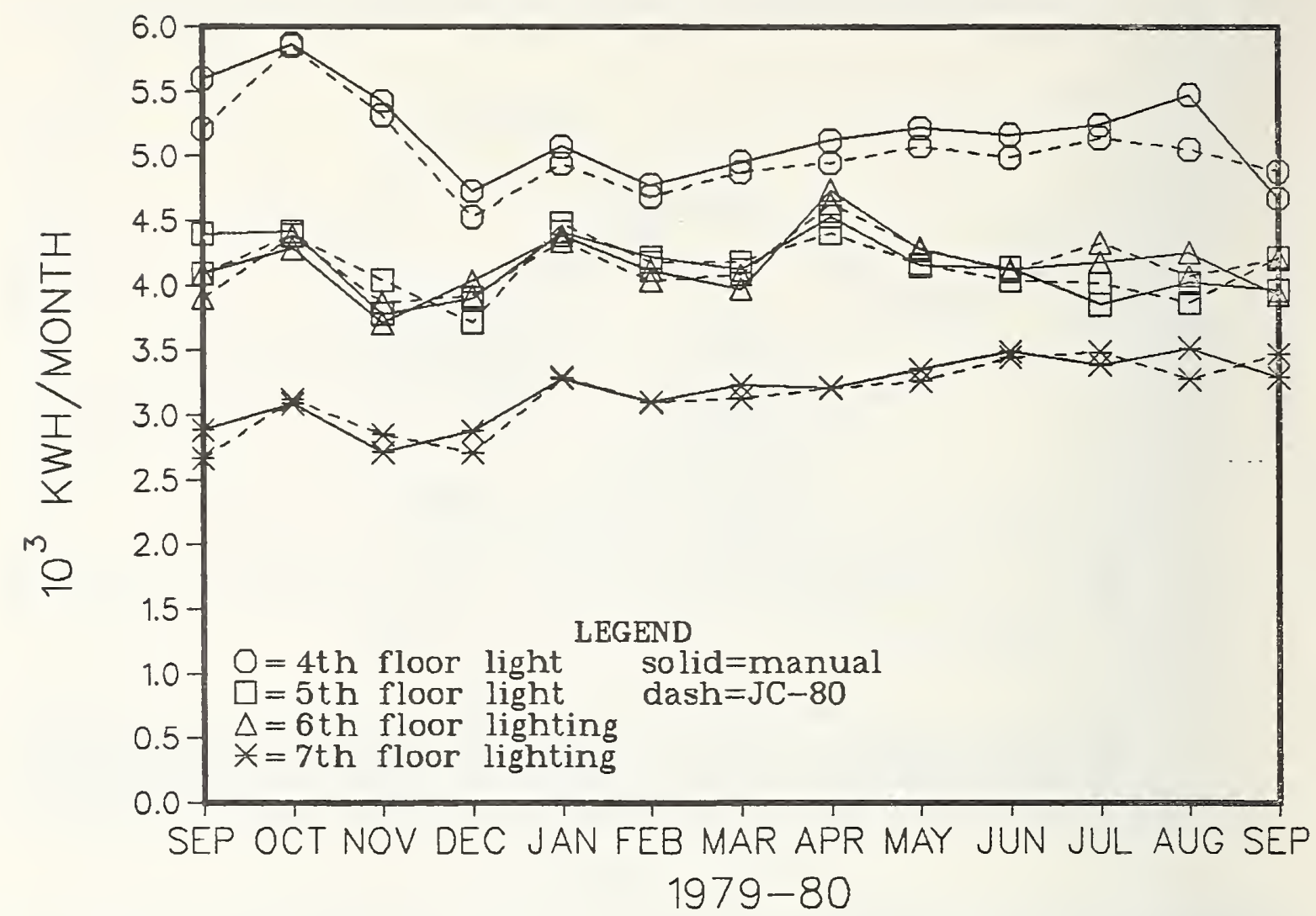

Figure 10. Electrical energy use for lighting on upper floors of NCFOB as calculated from $\mathrm{JC}-80$ and manual readings.

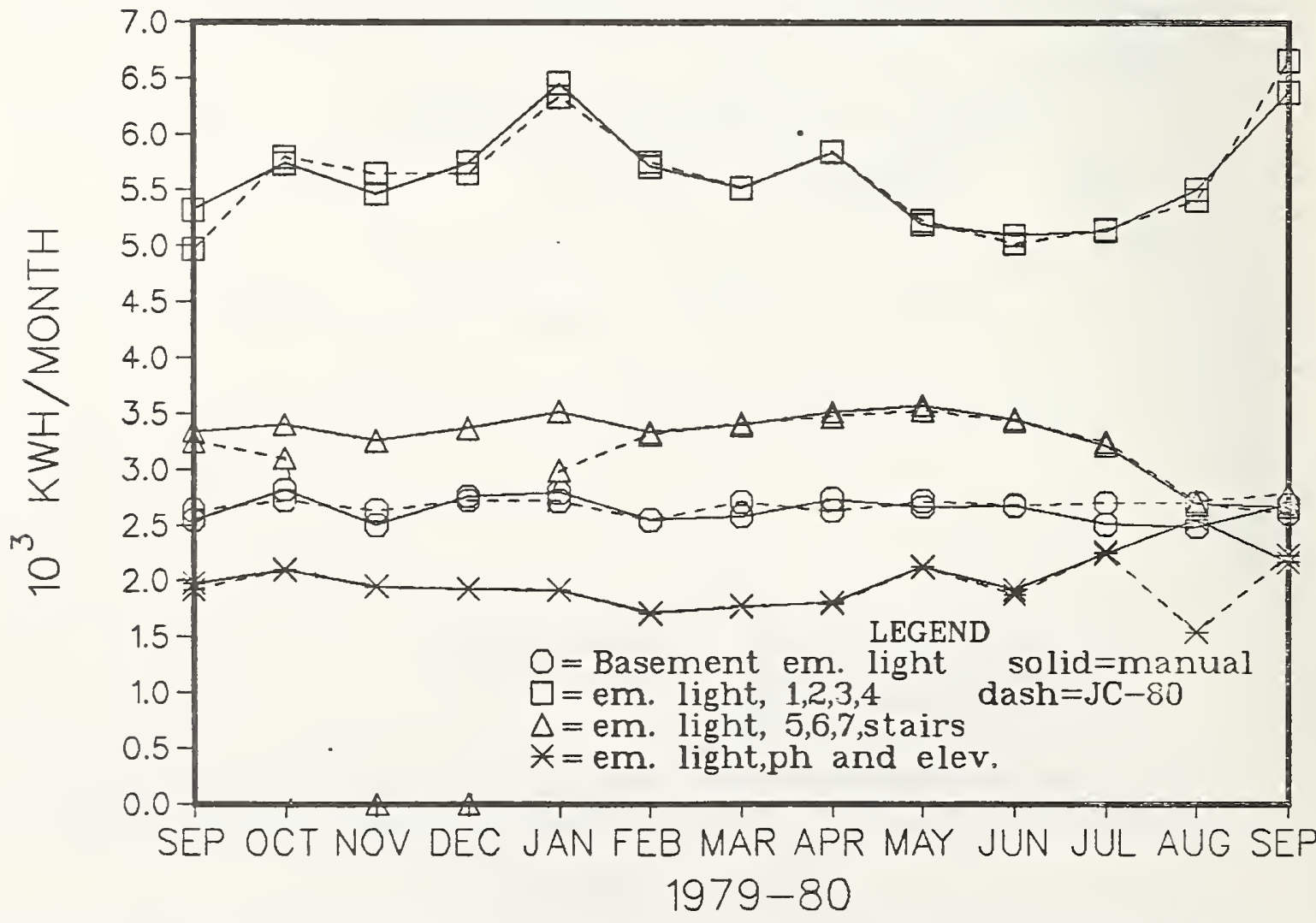

Figure 11. Electrical energy use for lighting on essential circuits of NCFOB as calculated from $\mathrm{JC}-80$ and manual readings. 


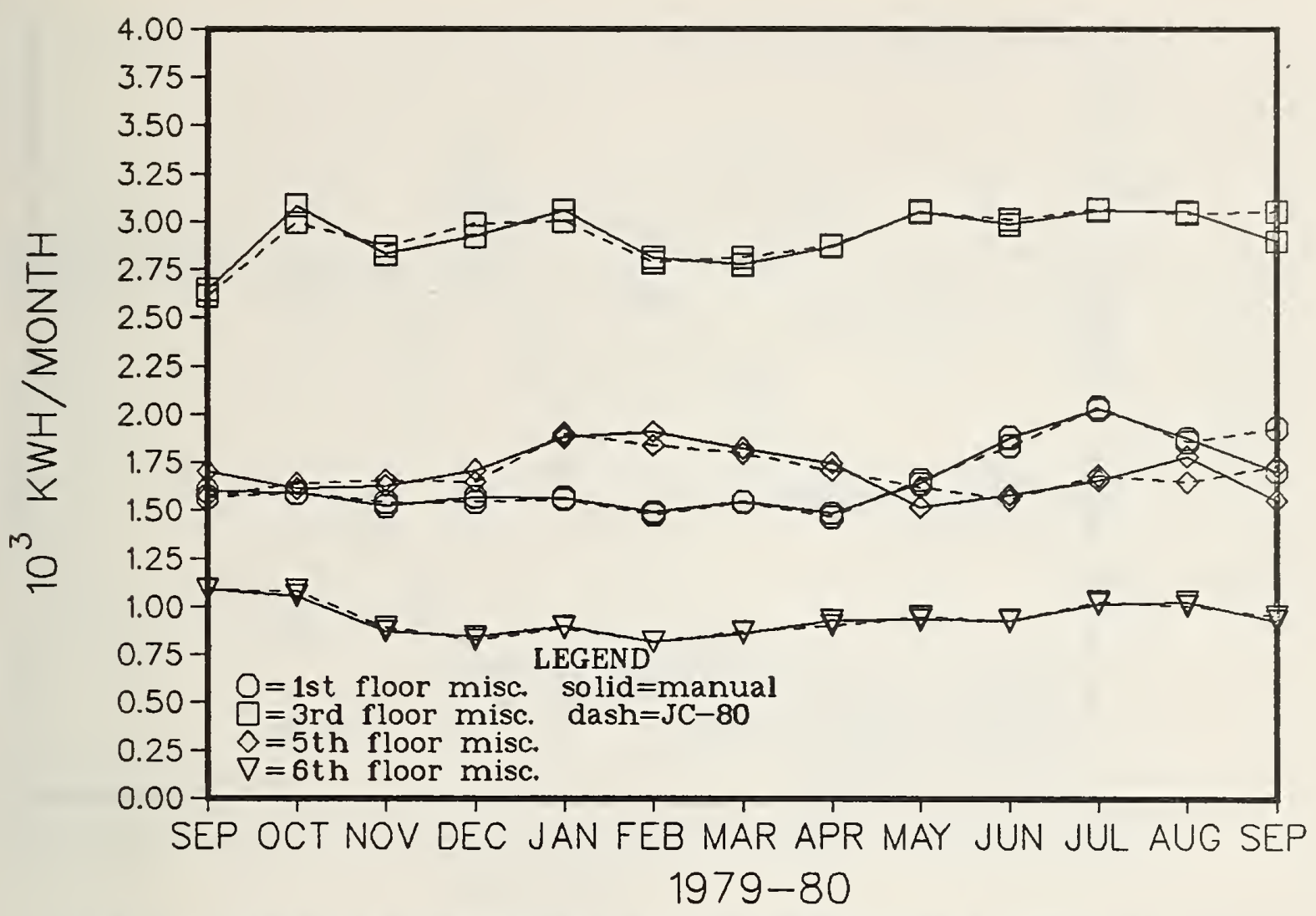

Figure 12. Miscellaneous office electrical energy use at NCFOB as calculated from $\mathrm{JC}-80$ and manual readings.

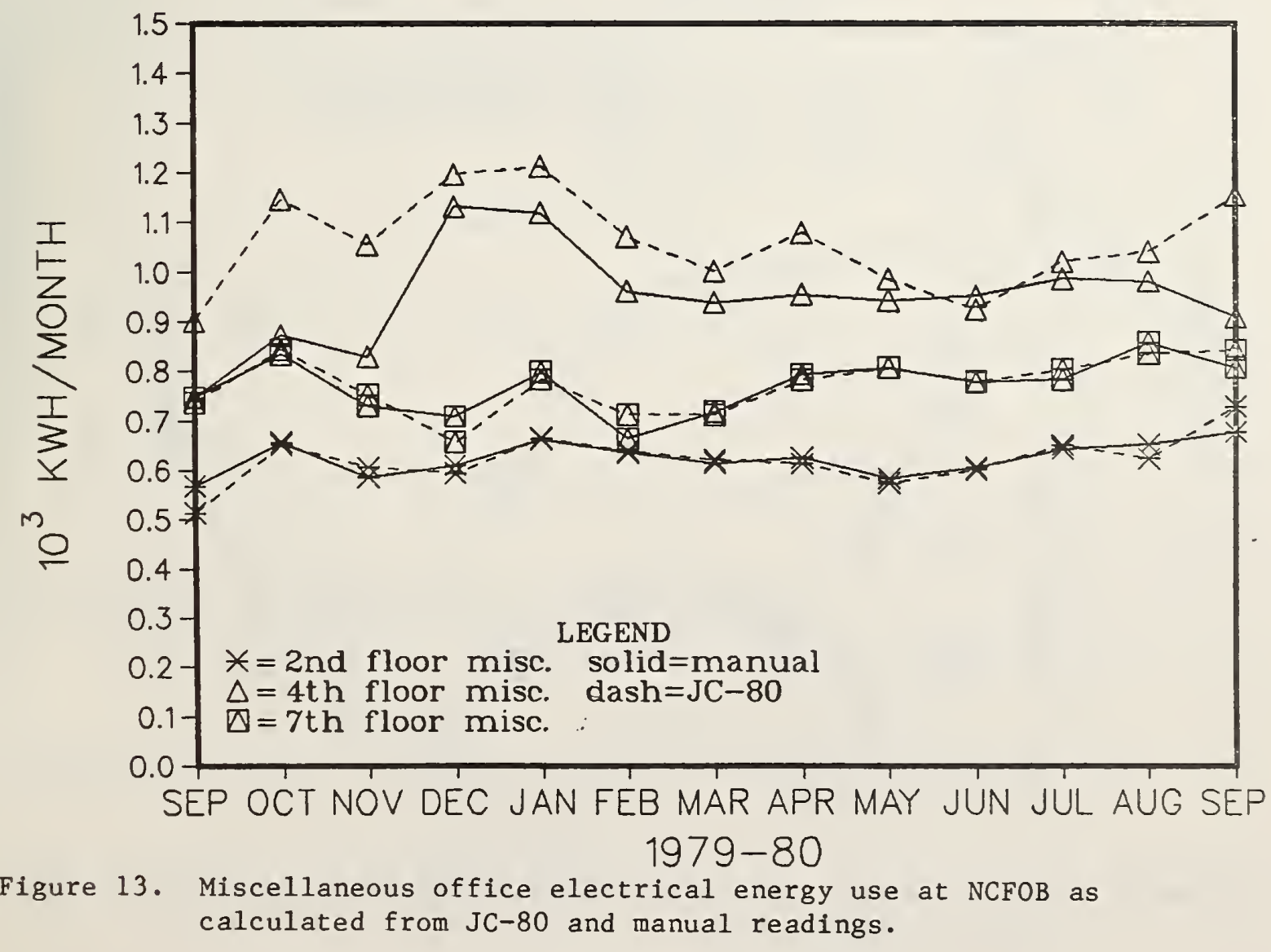




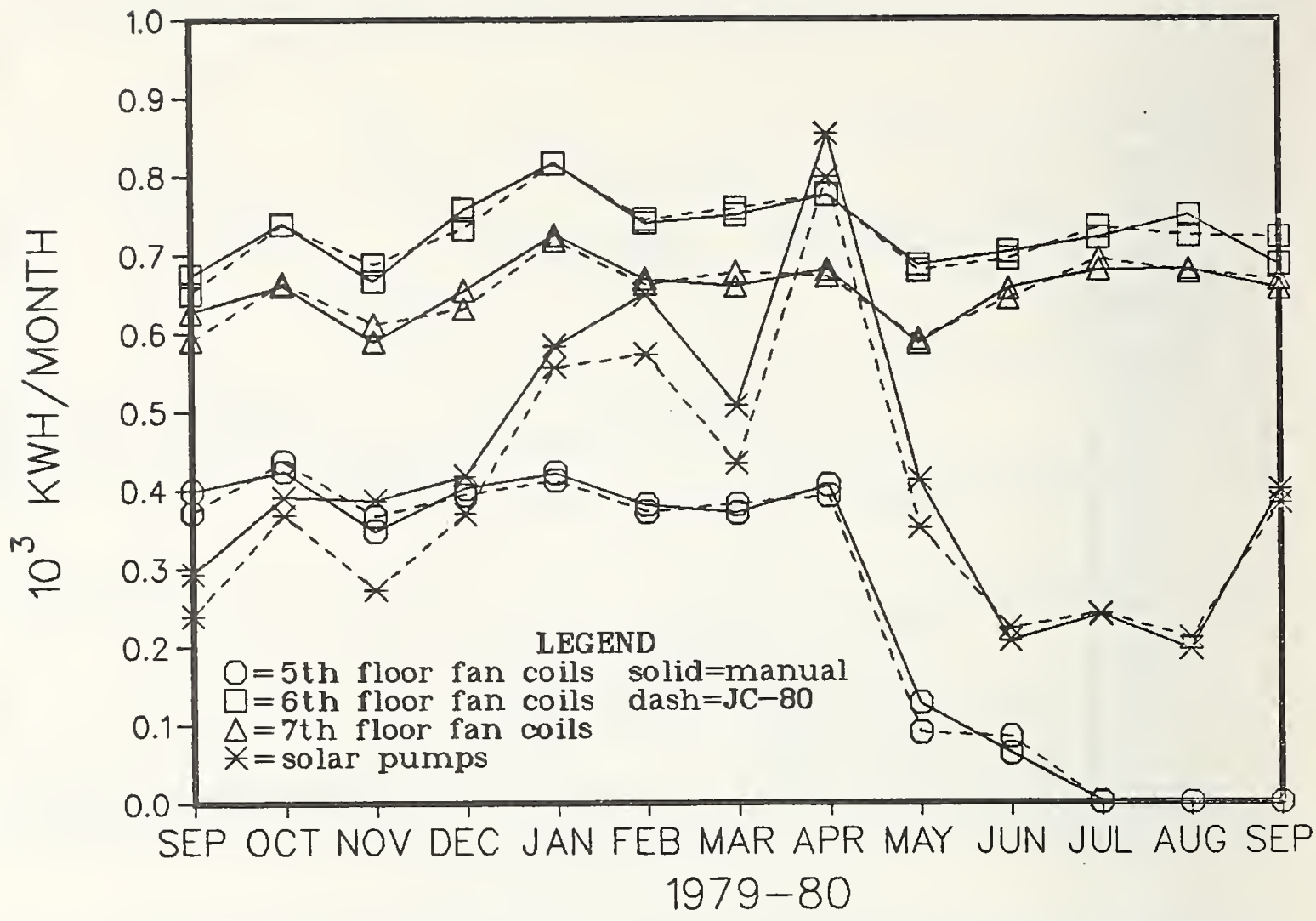

Figure 14. Electric energy used by $f a n$ coils and solar pumps at NCFOB as calculated from JC-80 and manual data.

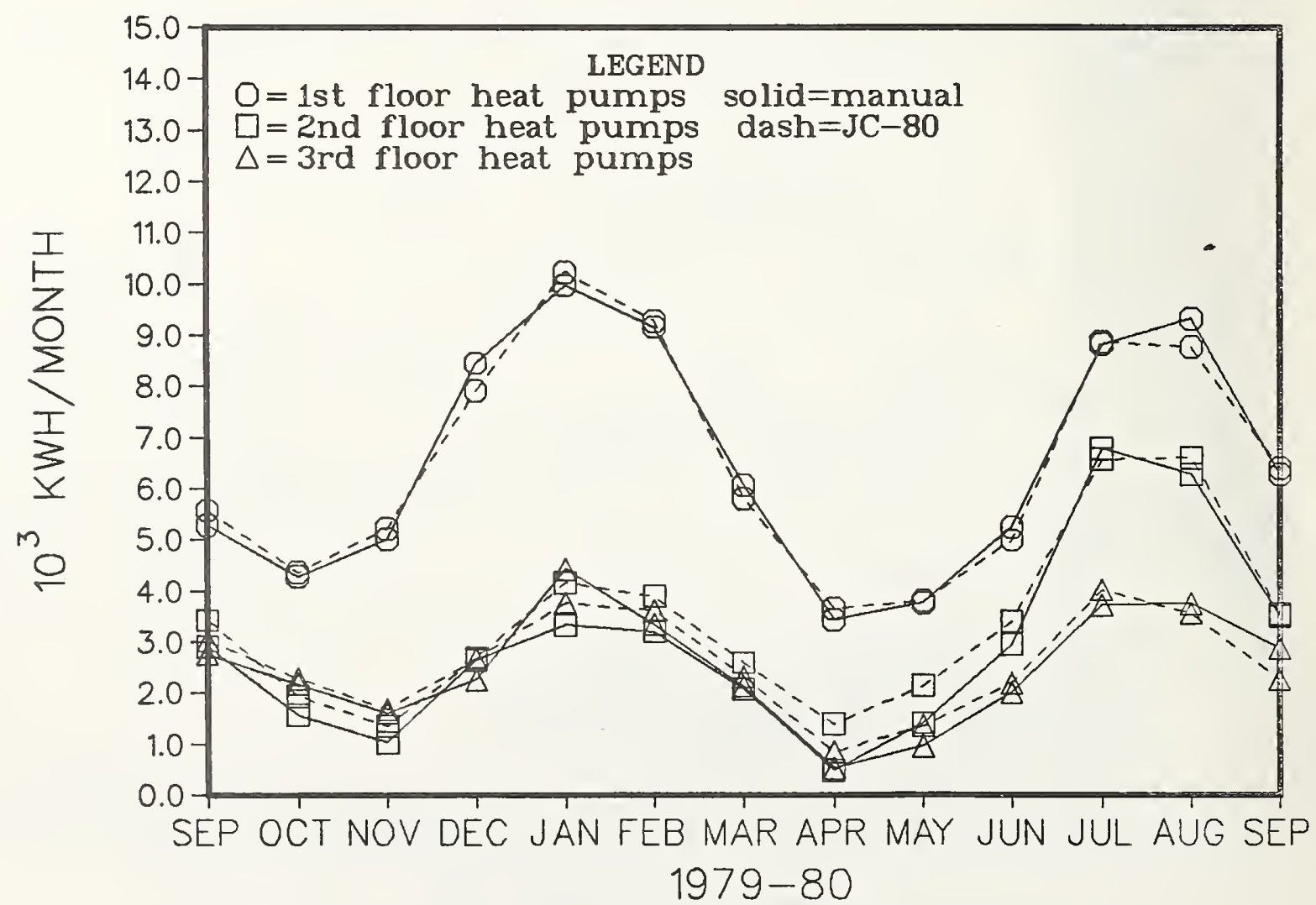

Figure 15. Electric energy use by heat pumps at NCFOB as calculated from $\mathrm{JC}-80$ and manual data. 


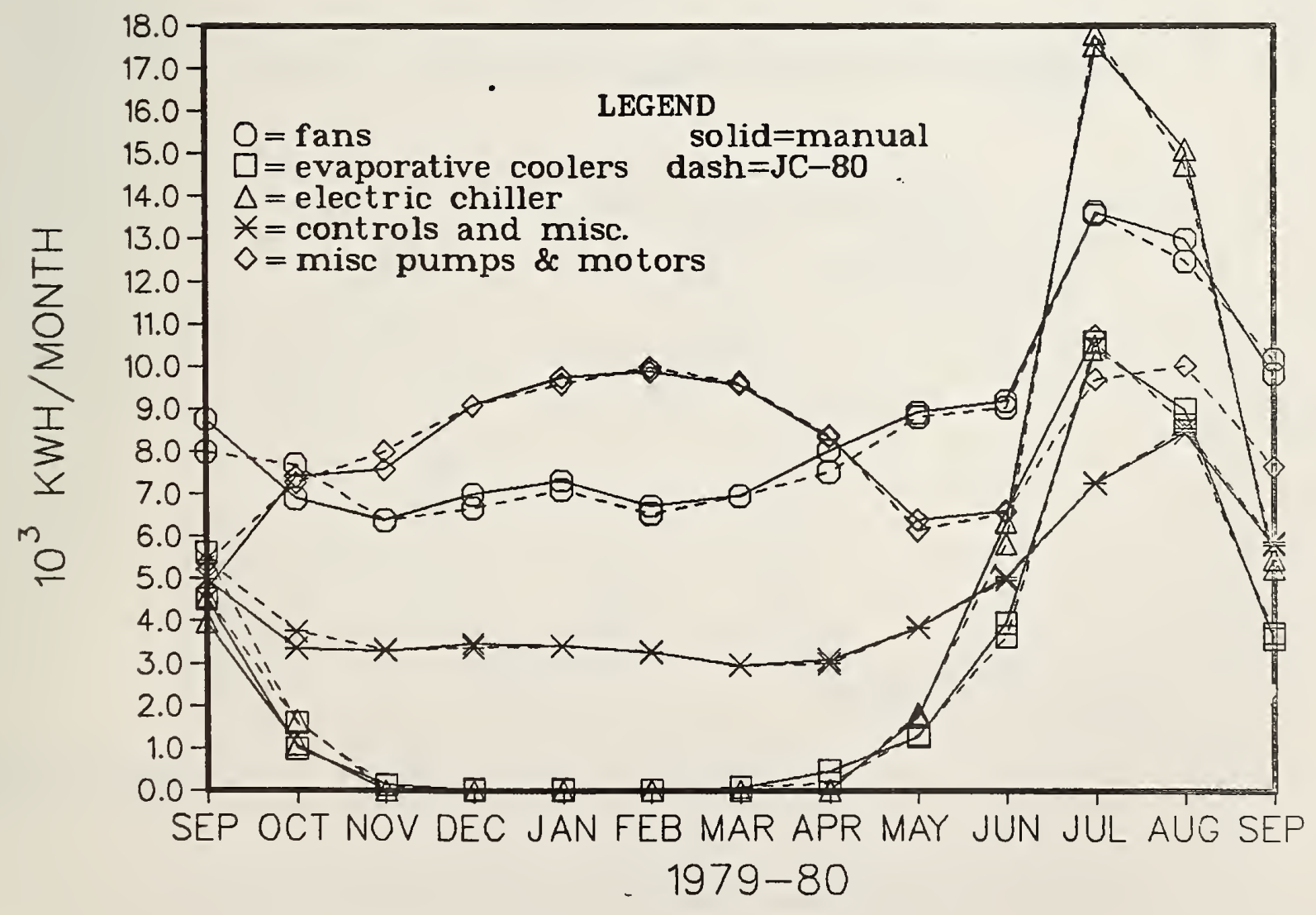

Figure 16. Mechanical equipment electrical loads at NCFOB as calculated from JC-80 and manual data. 


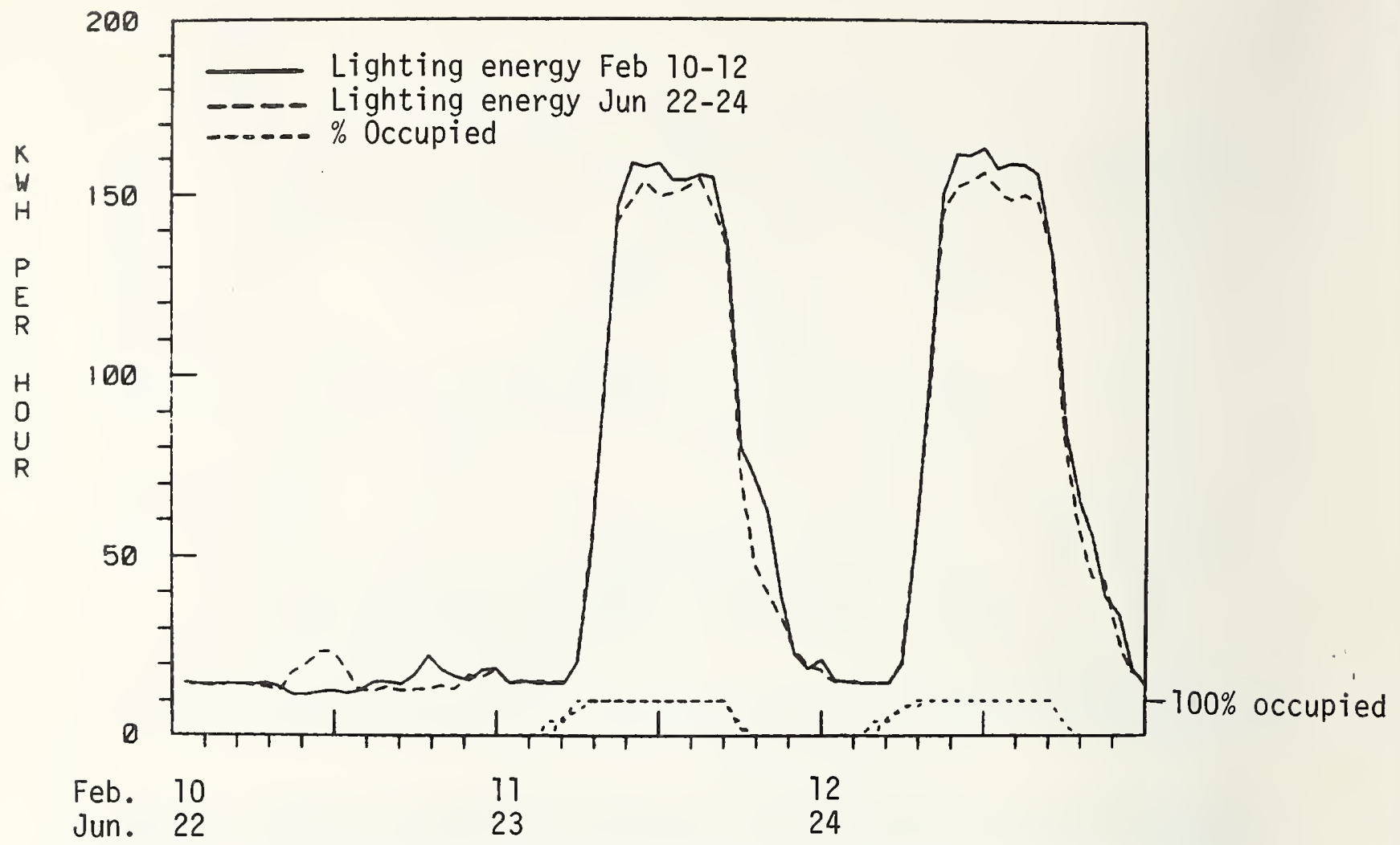

Figure 17. Demand profile of total energy for lighting at NCFOB.

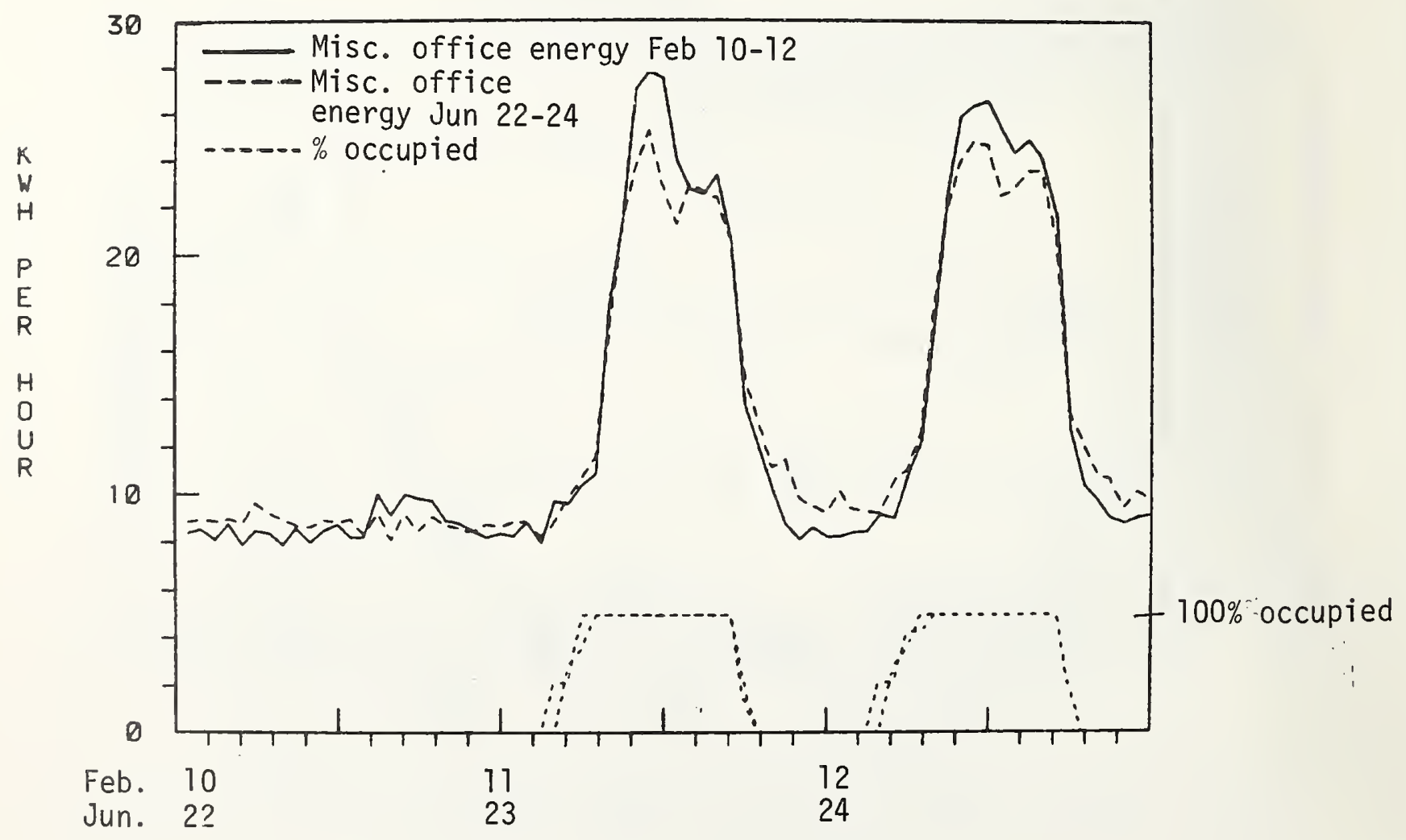

Figure 18. Demand profile of office miscellaneous electric loads at NCFOB . 


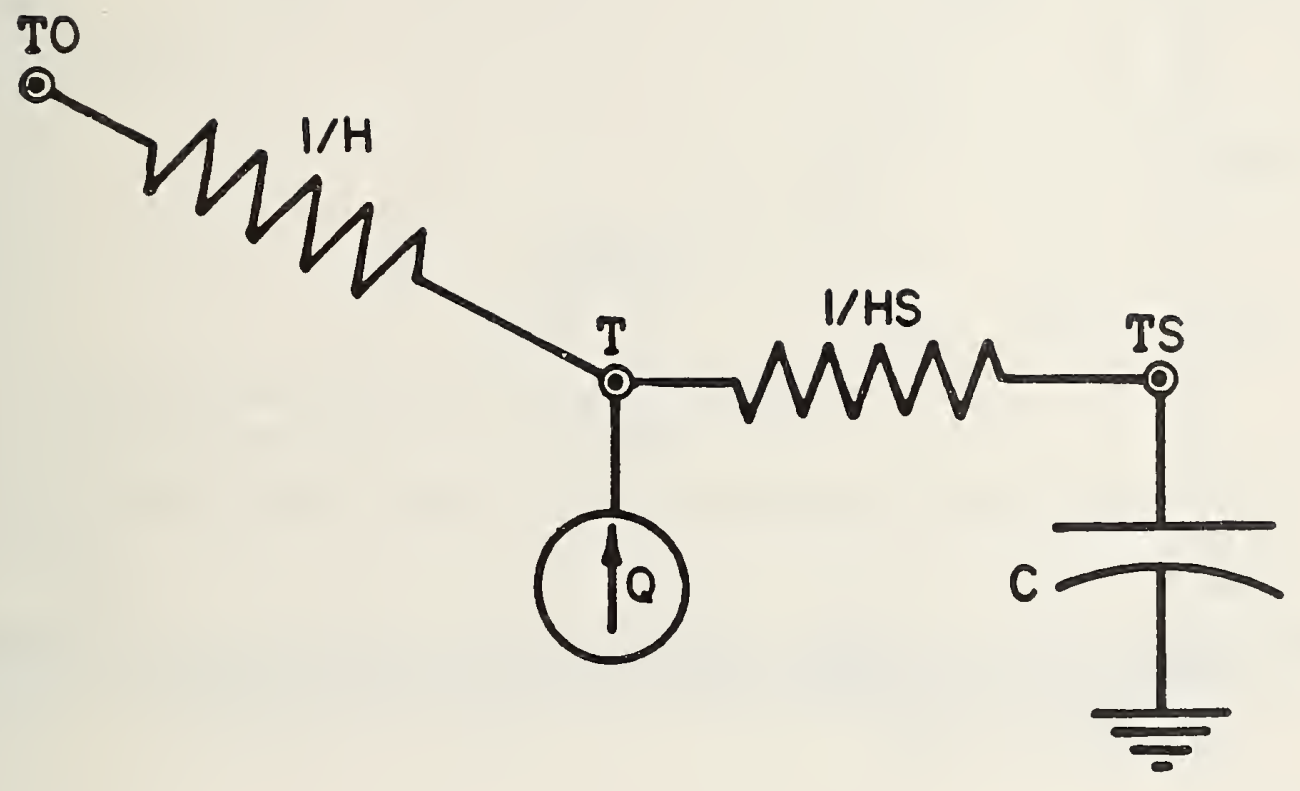

Figure 19. Electrical circuit analogy for equivalent thermal parameter model. 


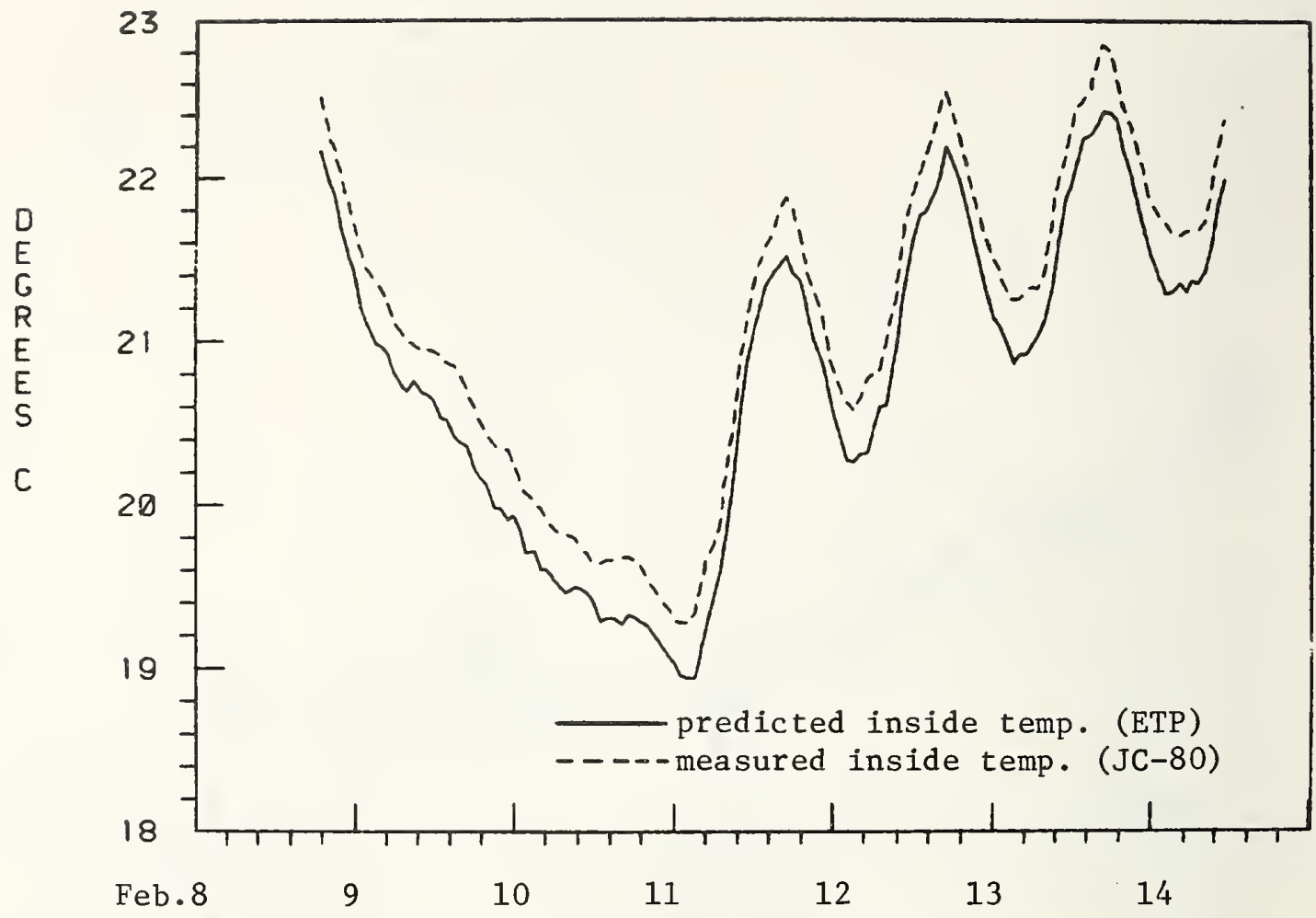

Figure 20. Comparison of average inside temperature at Norris Cotton Federal Office Building measured by JC-80 and calculated by ETP analysis for February 1980.

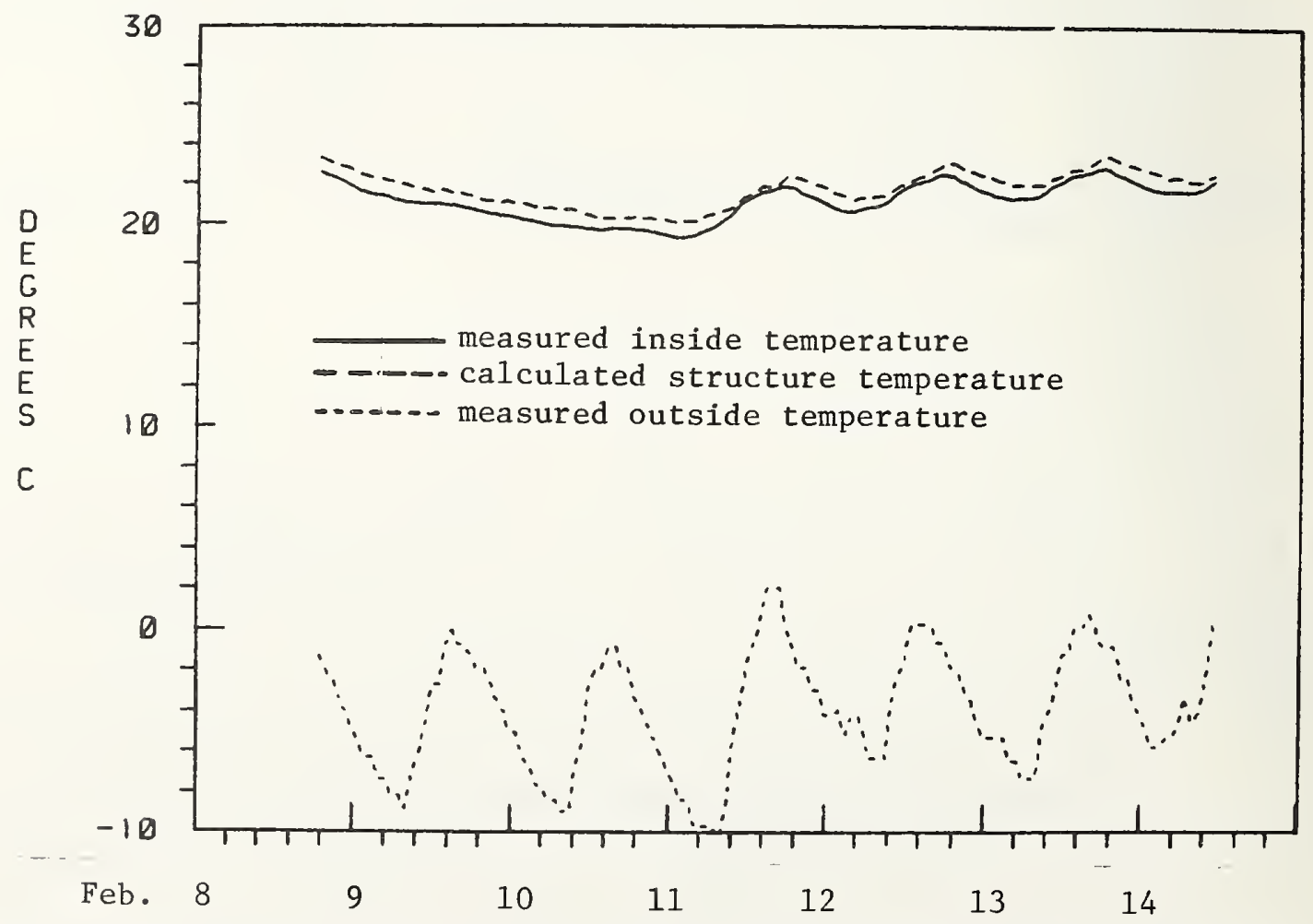

Figure 21. Measured outdoor, indoor and structure temperatures calculated by ETP analysis for Norris Cotton Federal Office Building during February 1980. 


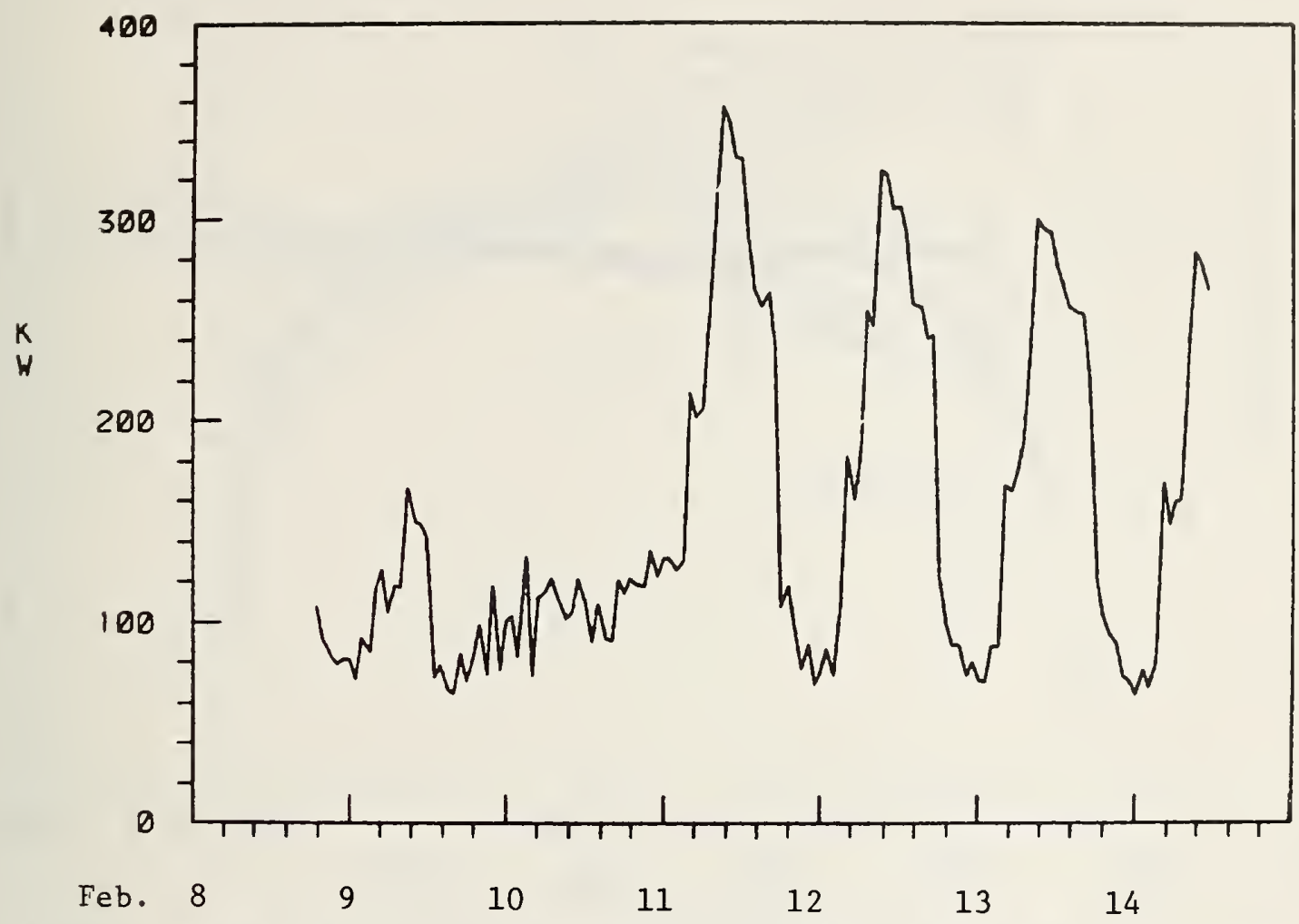

Figure 22. Measured addition of internal and heating energy to building space of Norris Cotton Federal office Building during February 8-14, 1980.

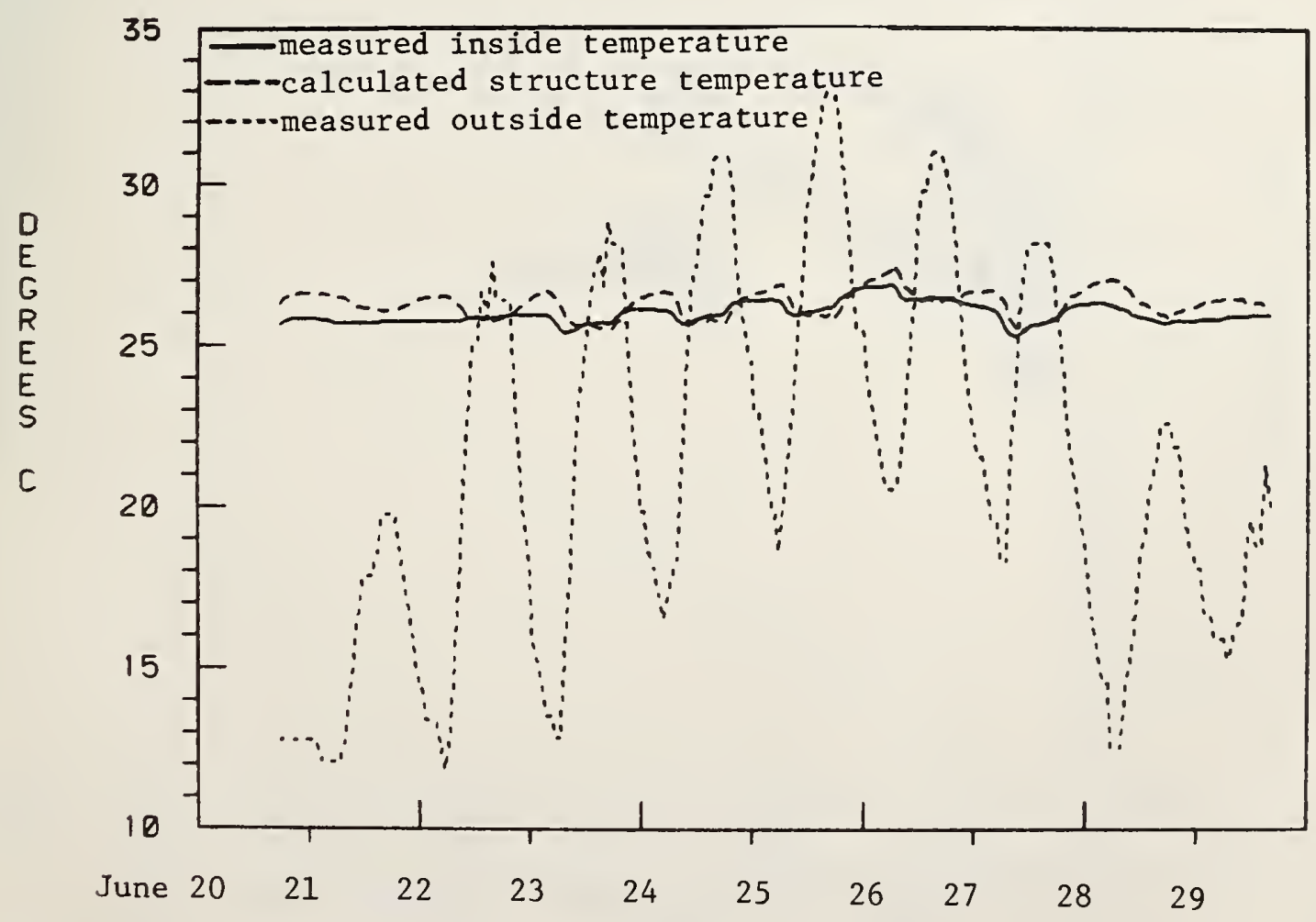

Figure 23. Measured outside and inside temperatures and structure temperatures calculated by ETP analysis for Norris Cotton Federal office Building during June 20-29, 1980. 


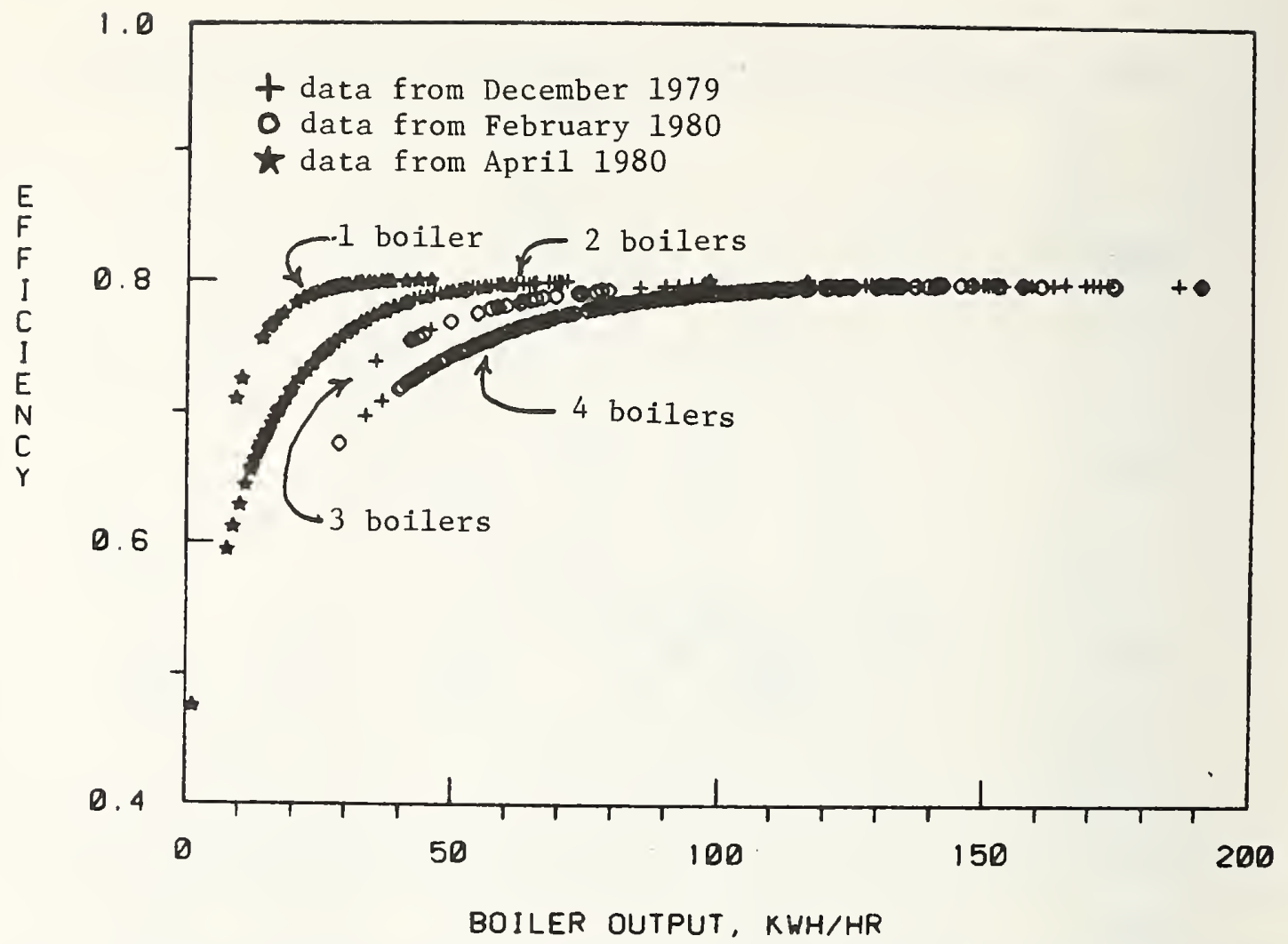

Figure 24. Natural gas boiler efficiency as a function of boiler output at the Norris Cotton Federal office Building.

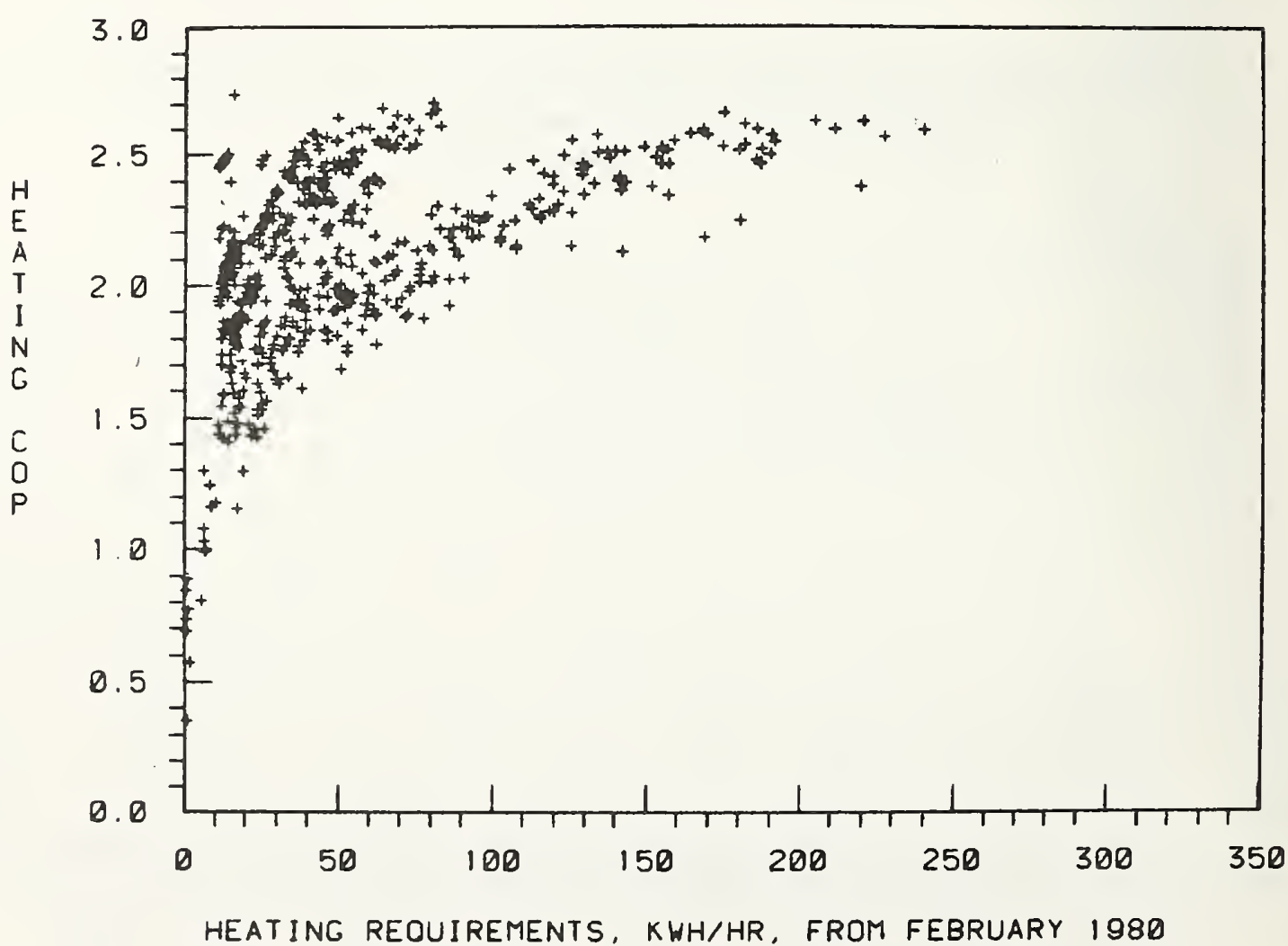

Figure 25. Heating performance of heat pump system at Norris Cotton Federal office Building during February 1980. 


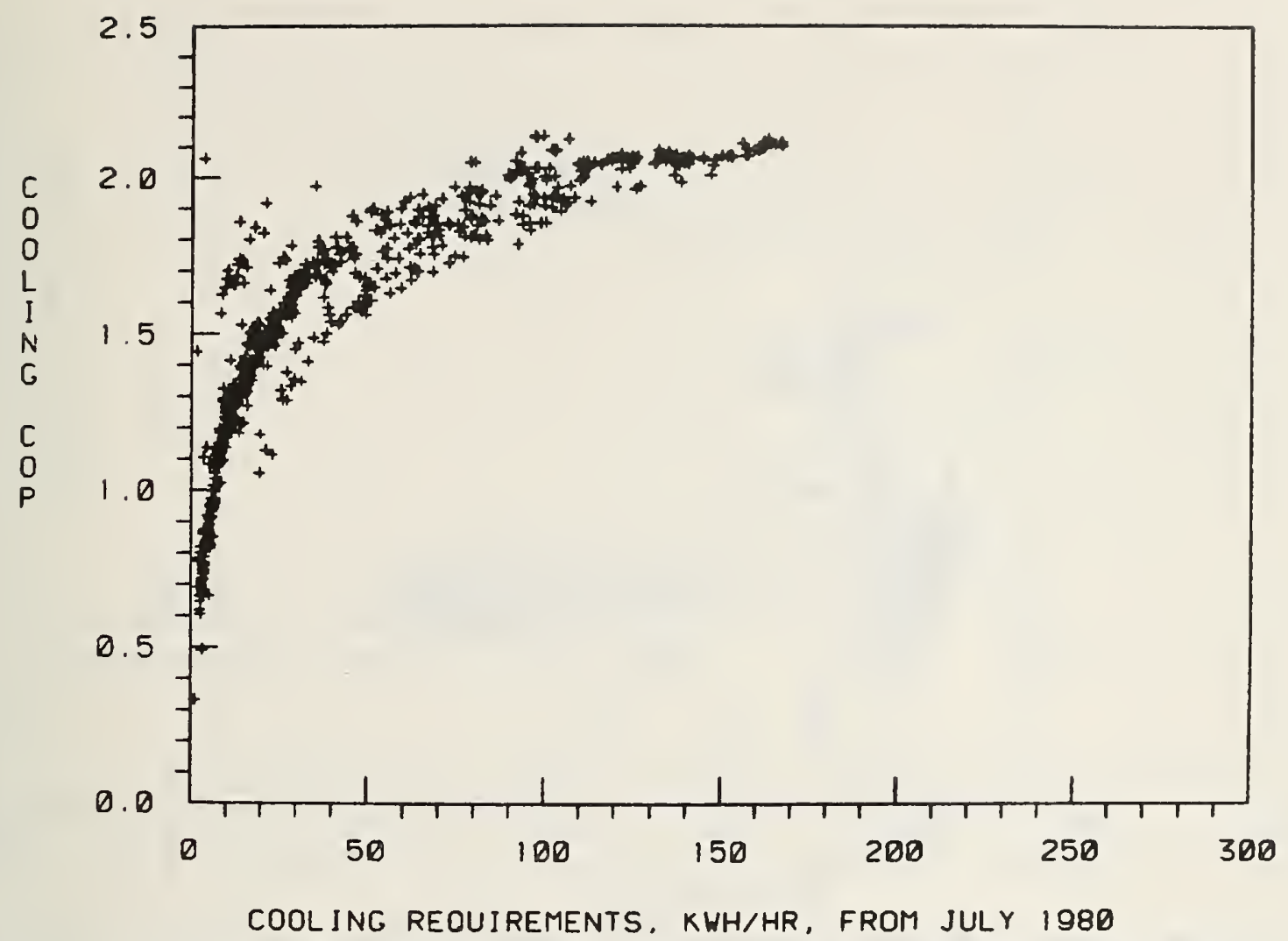

Figure 26. Cooling performance of heat pump system at Norris Cotton Federal office Building during July 1980.

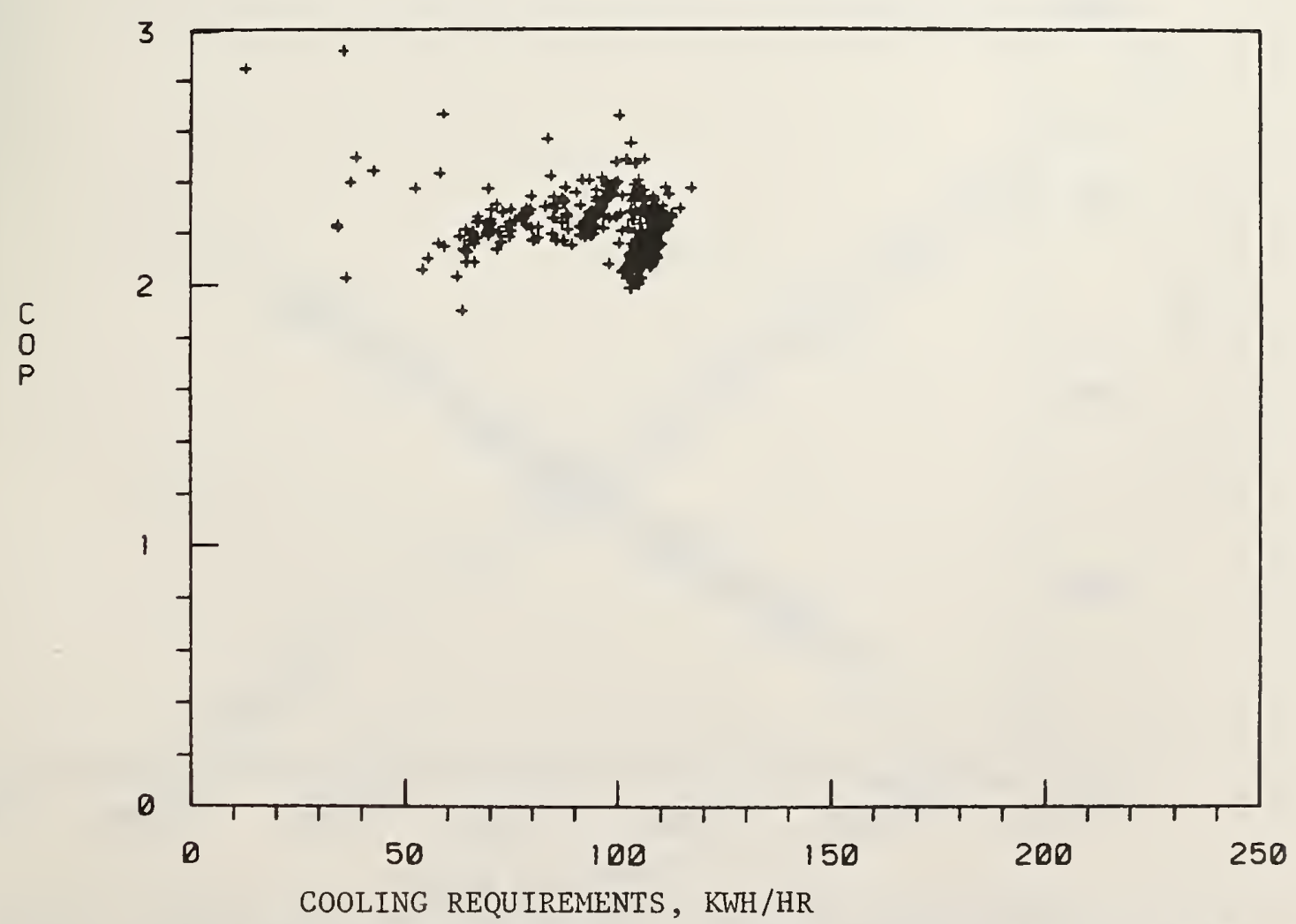

Figure 27. Measured performance of electric chiller at Norris Cotton Federal office Building during July 1980. 


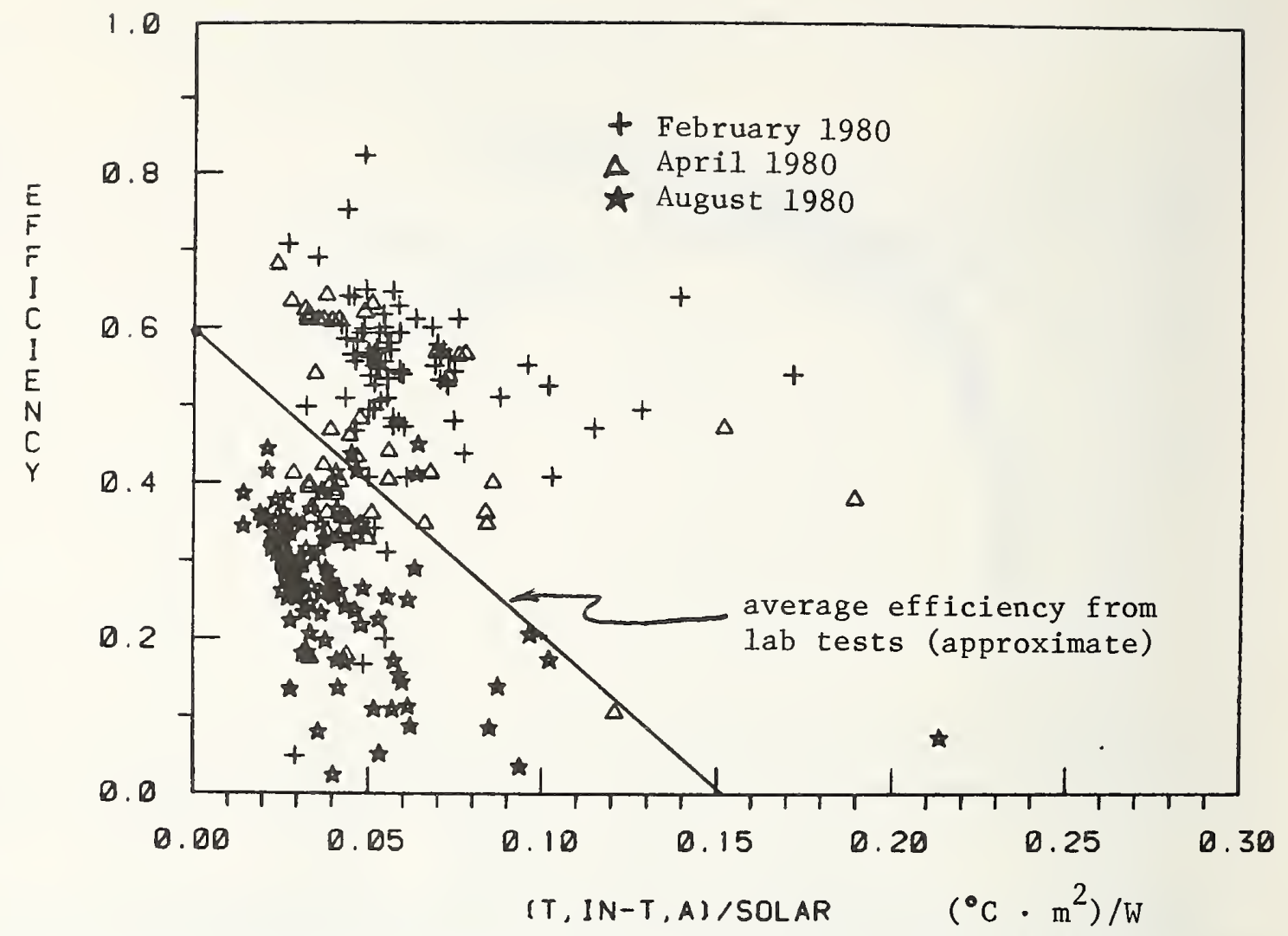

Figure 28. Solar collector array efficiency at Norris Cotton Federal Office Building.

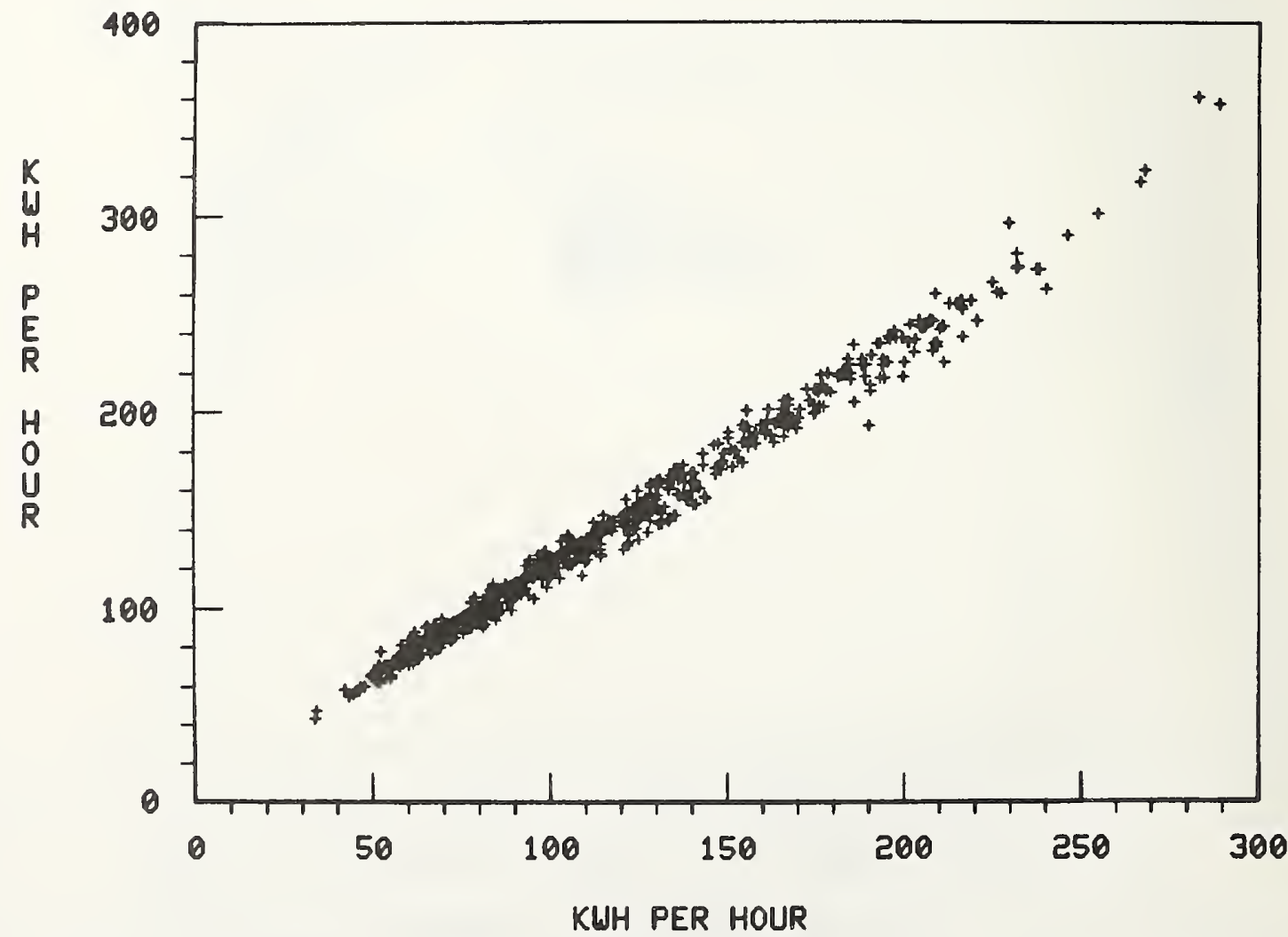

Figure 29. Fuel energy for heating versus calculated heating requirements at Norris Cotton Federal office Building during February 1980. 


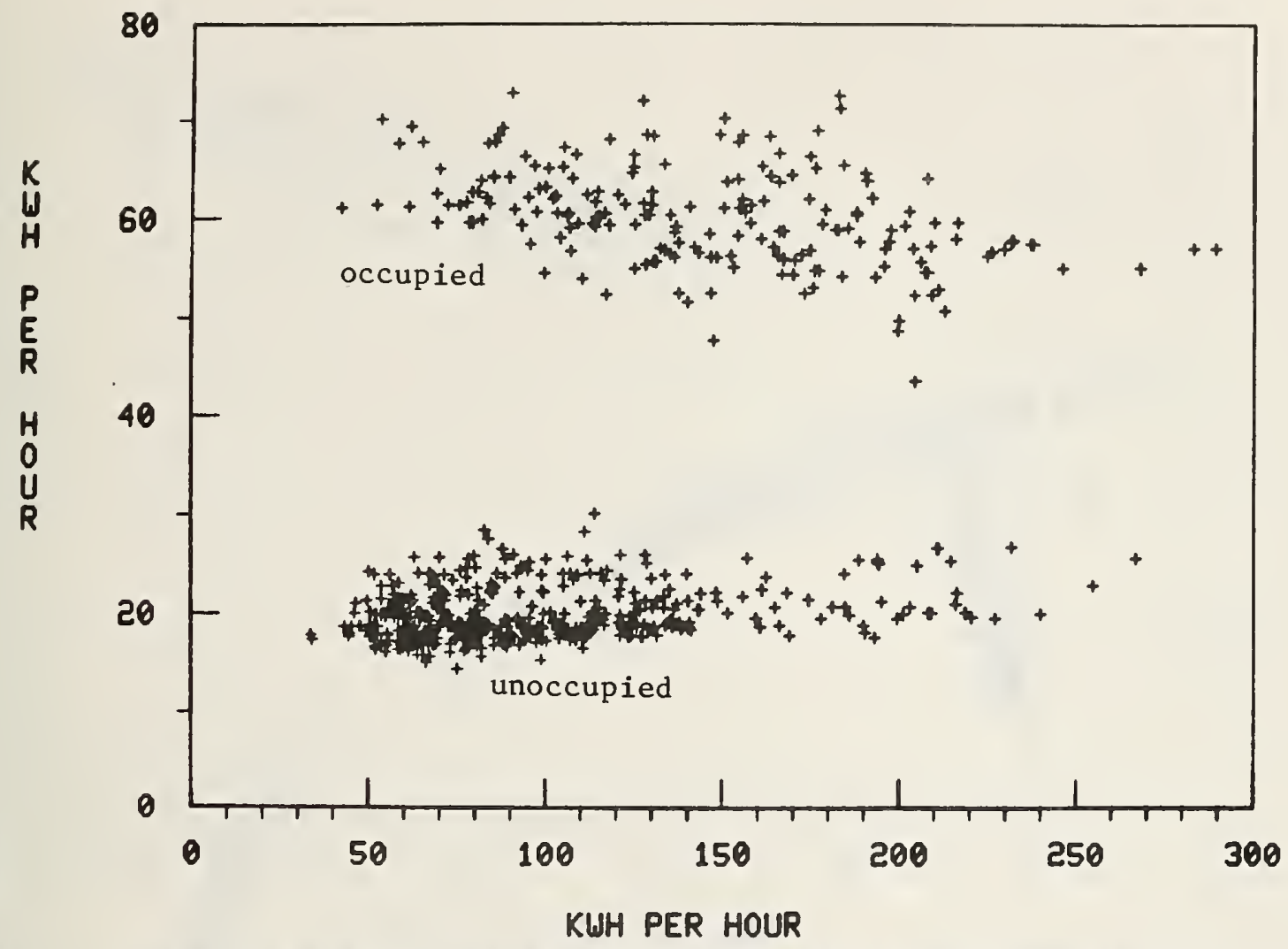

Figure 30. Operating energy versus calculated heating requirements during February 1980 at the Norris Cotton Federal office Building.

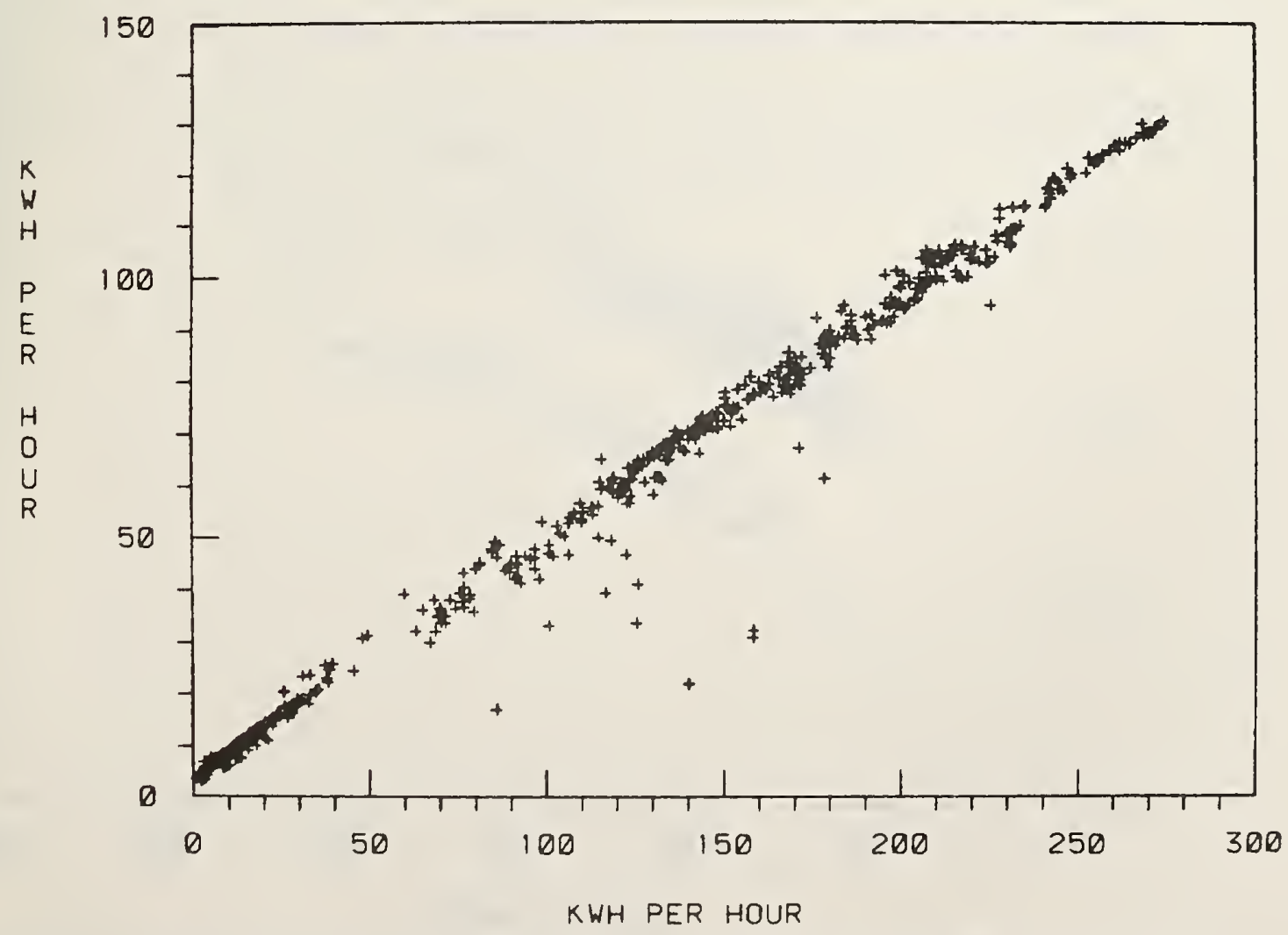

Figure 31. Fuel energy for cooling versus cooling requirements at the Norris Cotton Federal office Building during July 1980. 


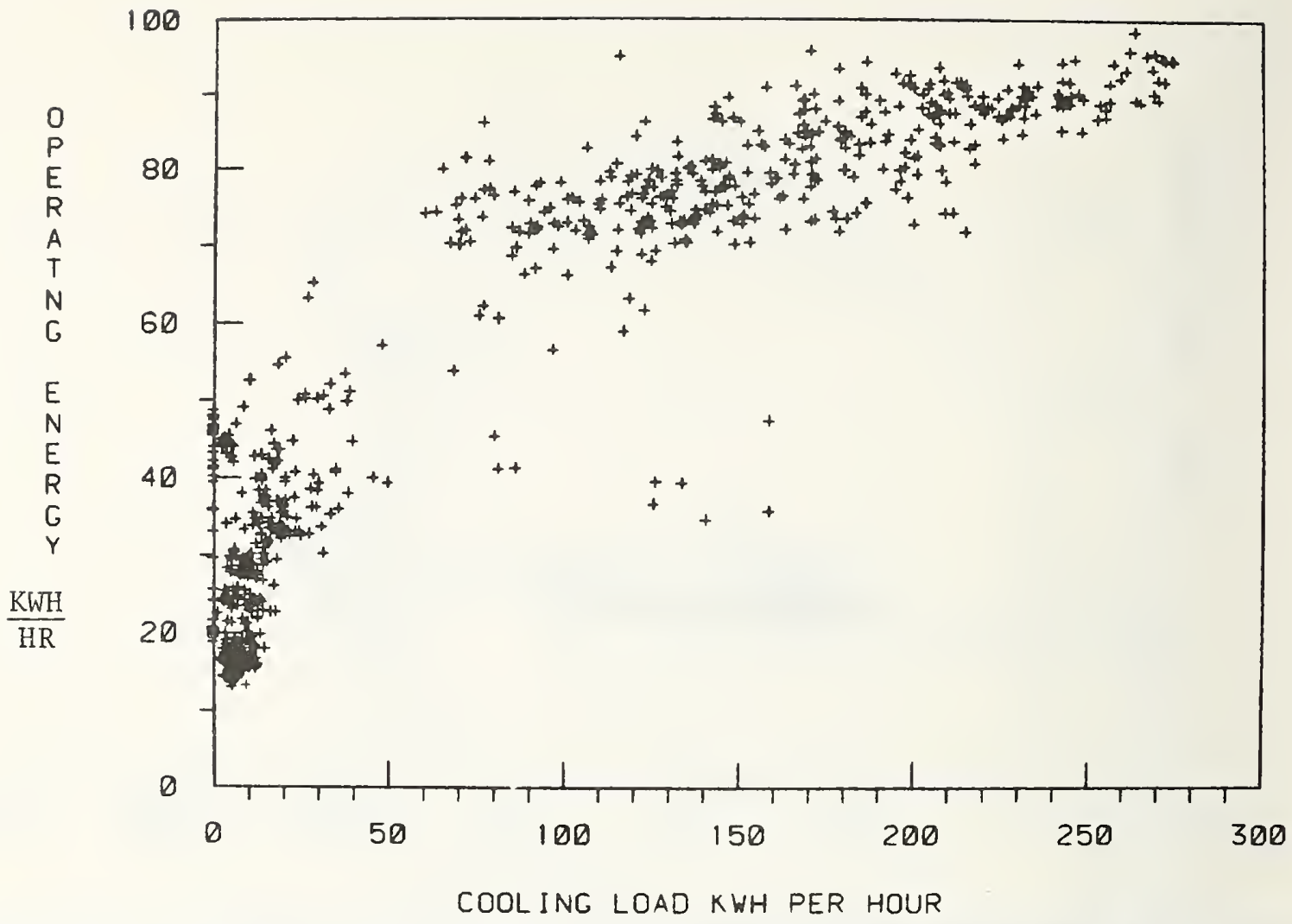

Figure 32. Operating energy versus calculated cooling requirements during July 1980 at Norris Cotton Federal office Building.

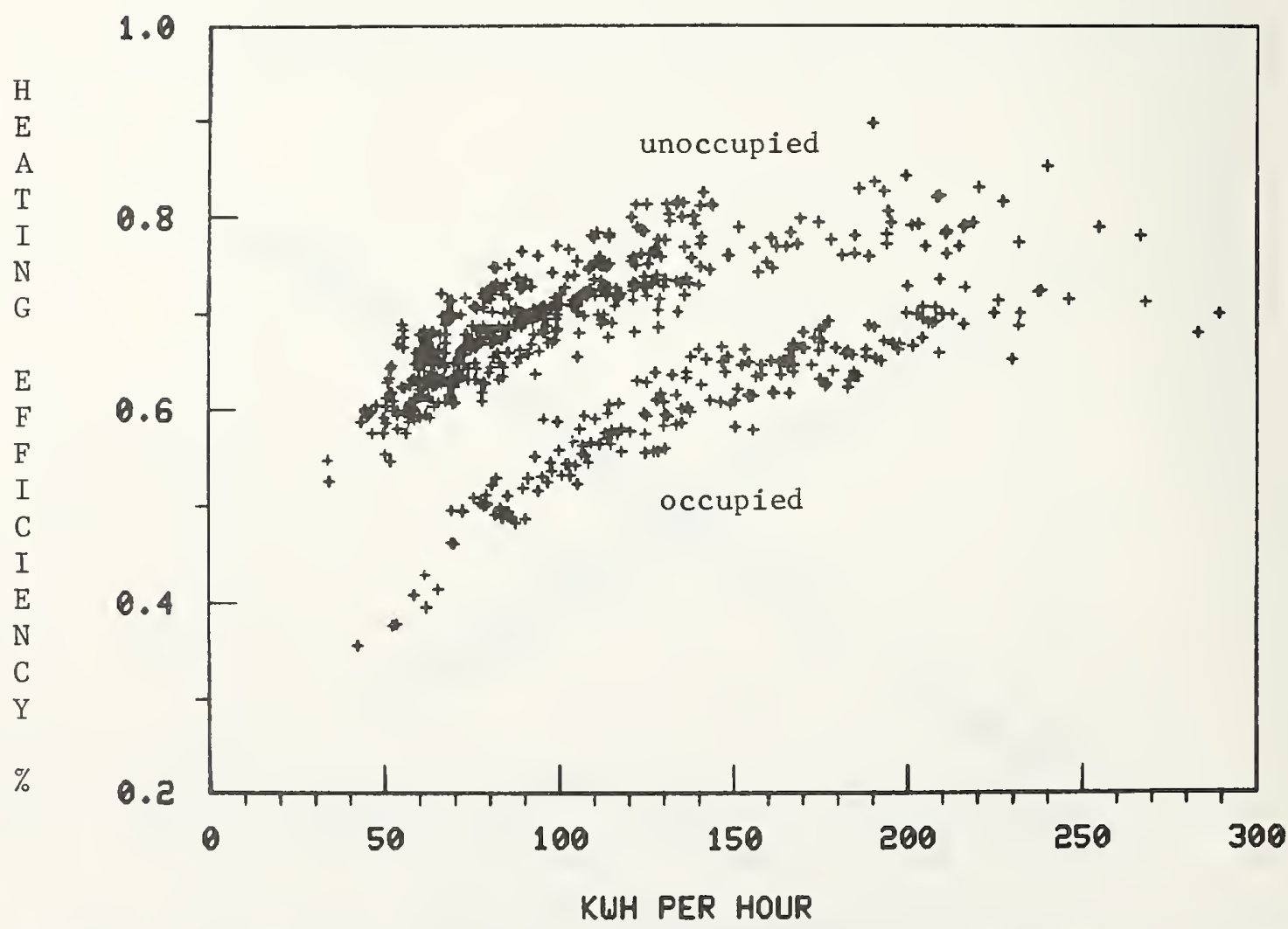

Figure 33. Total mechanical system efficiency for heating versus calculated heating requirements at Norris Cotton Federal office Building during February 1980. 


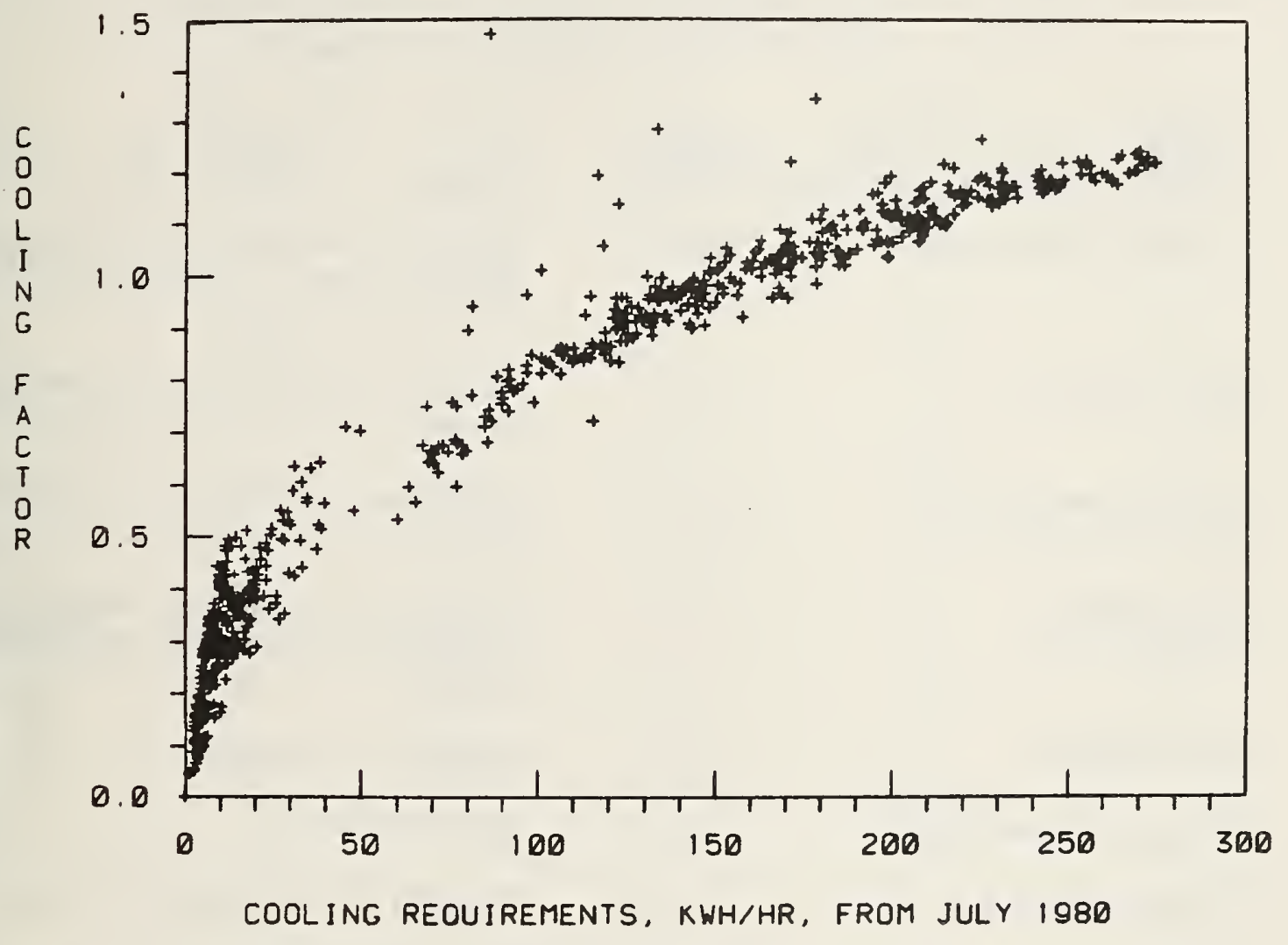

Figure 34. Total mechanical system performance factor for cooling versus calculated cooling requirements at Norris Cotton Federal office Building during July 1980 
Table 1. Analog sensor types used by JC-80 system at the Norris Cotton Federal office Bullding

Sensor type

Liquid flowmeters

Air flowmeters

Liquid temperature

air temperature

Air dewpoint

temperature

Air humidity

Flue gas temperature

Natural gas flow

Illumination

Solar radiation

Electric energy
Quantity

79

55

286

49

6

7

7

15

5

98
Description

Impact tube combined with reversed static tube. Pressure differential fed into transducer.

Array of pitot tubes to determine average air velocity in ducts.

Nichrome wire-wound resistance temperature element.

Nichrome wire-wound resistance temperature element combined with dewcell.

Humidity elements .

Thermocouples.

Positive displacement meter.

Photoelectric cells

Pyranometer

Contact closure in kilowatt-hour meter. 
Table 2. Description of data loss from Norris Cotton Federal office Building data acquisition system

\begin{tabular}{|c|c|c|c|c|c|}
\hline Month & $\begin{array}{c}\text { Number of } \\
\text { hours } \\
\text { in month }\end{array}$ & $\begin{array}{l}\% \text { of } \\
\text { hours } \\
\text { usable }\end{array}$ & $\begin{array}{c}\% \text { of } \\
\text { hours } \\
\text { replaced } \\
\end{array}$ & $\begin{array}{c}\text { Longest } \\
\text { uninterrupted } \\
\text { period (days) }\end{array}$ & $\begin{array}{l}\text { Longest } \\
\text { outage } \\
\text { (days) }\end{array}$ \\
\hline September 79 & 720 & 50.1 & 49.9 & 6.25 & 10.00 \\
\hline October 79 & 744 & 61.3 & 38.7 & 8.29 & 9.71 \\
\hline November 79 & 720 & 74.9 & 25.1 & 4.54 & 1.58 \\
\hline December 79 & 744 & 76.1 & 23.9 & 6.50 & 2.00 \\
\hline January 80 & 744 & 77.2 & 22.8 & 5.79 & 2.38 \\
\hline February 80 & 696 & 82.6 & 17.4 & 5.83 & 1.00 \\
\hline March 80 & 744 & 88.0 & 12.0 & 4.38 & 0.67 \\
\hline April 80 & 720 & 80.0 & 20.0 & 10.67 & 4.42 \\
\hline May 80 & 744 & 75.3 & 24.7 & 9.33 & 5.71 \\
\hline June 80 & 720 & 81.8 & 18.2 & 9.08 & 4.21 \\
\hline July 80 & 744 & 95.3 & 4.7 & 10.58 & 1.00 \\
\hline August 80 & 744 & 80.9 & 19.1 & 14.42 & 5.00 \\
\hline September 80 & 720 & 94.3 & 5.7 & 17.75 & 1.00 \\
\hline --- & --- & ----- & --- & $\cdots$ & ----- \\
\hline Average & & 78.3 & 21.7 & & \\
\hline
\end{tabular}


Table 3. Estimates from least squares fit to equivalent thermal parameter model using data from February 9-15, 1980

\section{Independent variable}

$\mathrm{T}$

To

$\Delta \mathrm{To}$

Q

$\Delta \mathrm{Q}$

S

$\Delta S$

Constant

\section{Coefficient}

$a=0.974175$

$\mathrm{b}_{1}=-0.001665$

$b_{2}=0.035435$

$c_{1}=0.001390$

$c_{2}=-0.000141$

$d_{1}=-0.051665$

$\mathrm{d}_{2}=-0.135498$

$e=0.333352$

\section{Standard Deviation Coefficient of coefficient t-Ratio}

0.005072

192.05

0.002371

$-0.70$

0.009251

3.83

0.000061

22.74

0.000209

$-0.68$

0.024551

$-2.10$

0.048453

$-2.80$

2.97
Residual standard deviation ; based on degrees of freedom

$$
=0.044668171
$$

$137-8=129$ 
Table 4. Results from equivalent thermal parameters analysis of four data sets

\begin{tabular}{|c|c|c|c|c|}
\hline hours in data set & $\begin{array}{c}\text { Dec } 22-28 \\
154 \\
\end{array}$ & $\begin{array}{c}\text { Feb } 09-15 \\
139 \\
\end{array}$ & $\begin{array}{c}\text { Jun } 21-30 \\
217 \\
\end{array}$ & $\begin{array}{c}\text { Sep } 06-24 \\
425 \\
\end{array}$ \\
\hline$a$, coeff. of $T_{t-1 / 2}$ & 0.983793 & 0.974175 & 0.969487 & 0.973435 \\
\hline$b_{1}$, coeff. of $T_{0}$ & 0.0077678 & NS & 0.008986 & 0.008956 \\
\hline$b_{2}$, coeff. of $\Delta T_{0}$ & NS & 0.035435 & NS & NS \\
\hline$c_{1}, \operatorname{coeff}$ of $Q$ & 0.001110 & 0.001391 & 0.001021 & 0.001007 \\
\hline$c_{2}$, coeff. of $\Delta Q$ & NS & NS & NS & -0.001014 \\
\hline$d_{1}$, coeff. of $s$ & NS & NS & NS & NS \\
\hline $\mathrm{d}_{2}, \operatorname{coeff}$. of $\Delta \mathrm{S}$ & NS & NS & NS & NS \\
\hline e, constant & NS & 0.333 & NS & NS \\
\hline $\mathrm{H}, \mathrm{kW} /{ }^{\circ} \mathrm{C}$ & 14.6 & 18.6 & 29.9 & 26.4 \\
\hline $\mathrm{C}^{*}, \mathrm{kWh} /{ }^{\circ} \mathrm{C}$ & 893.3 & 728.4 & 994.9 & 1006.0 \\
\hline
\end{tabular}

NS - not significant 
A full listing of the Norris Cotton Federal Office Building (NCFOB) energy data for a given period of time consists of six 132 column computer pages. Each page displays a different category of data as a function of time. Data can be for hourly, daily, or monthly time periods with six to seven time periods worth of data on one page. The tables at the end of this appendix contain monthly data for the 13 months of data collection.

All of the six data pages have certain features in common. At the top of each page is a title describing the type of data. Below the title is information describing the time span of the data and the type of time period. Data are contained in six to seven vertical columns with column headings indicating the time period for the data in the column. The energy parameter names for the data on the page are located at the left of the page.

The data values printed on each page are usually in electrical or thermal kilowatt-hours. All other units used are SI units. The numbers are printed in a format that provides at least four significant figures. However, it may not be true that the numbers are correct to four figures.

\section{Data Page 1: Energy Consumption and Performance}

The first of the six pages of data is intended to provide overall energy consumption and energy balance information. A general breakdown of fossil fuel (oil and gas) use and electrical energy use is presented, followed by figures for energy rejected from the building during cooling operations. Also presented are total energy use figures and solar system general performance parameters. The following definitions describe the parameters in detail:

Total Natural Gas Use is the thermal equivalent of the natural gas delivered to the building main during the given time period.

NG to Boilers is the thermal equivalent of natural gas entering the four natural gas modular boilers.

Fuel oil to Boilers is the thermal equivalent of the fuel oil fed to the oil boilers. This value is from manual readings and is available only for monthly periods.

Boiler Energy to Heating is the energy transferred from the oil and gas boilers to the heat pump or hot water systems for heating purposes.

Boiler Energy to Cooling is the energy transferred from the fuel oil boilers to the concentrator of the absorption chiller. Gas boilers are never used for cooling purposes.

NG to Eng/Gen is the thermal equivalent of the natural gas delivered to the gas engine-generator set. 
Eng/Gen to Electric Chiller represents the quantity of electrical energy used by the electric chiller when the chiller is supplied by the engine-generator rather than by purchased power.

Heat Recov. to Cooling is the energy recovered from the water jacket and exhaust stack of the engine-generator and utilized to provide thermal energy to the absorption chiller. This is the sum of waste heat energy supplied to the chiller directly and from storage.

Heat Recov. to Heating is the energy recovered from the water jacket and exhaust stack of the engine-generator and utilized for space heating by the hot water and heat pump systems.

Heat Recov. to D. Hot Water is energy recovered from the engine-generator and used to heat domestic hot water.

Eng/Gen to Auxiliary Power is the electrical energy delivered to loads other than the chiller by the engine-generator. These other loads consist of sections of the motor control center. The motor control center supplies the major pumps and motors and may be driven by the generator when the chiller electrical load is not great enough to generate sufficient waste heat to drive the absorption chiller.

NG to Dom. Hot Water is the equivalent thermal energy for the natural gas used by the conventional domestic hot water heater.

Heater Energy to DHW is the thermal energy added to the main domestic hot water tank by the conventional hot water heater.

Total Electrical Energy Use is the electrical energy measured at the building main power bus.

Electric Energy to Heating is the electrical energy delivered to those heat pumps which are in the heating mode.

Electric Energy to Cooling is the energy delivered to those heat pumps which are in the cooling mode.

Electric Energy to HVAC Systems includes the electrical energy to all heat pumps, pumps, fans, controls and other pieces of equipment associated with heating, cooling and ventilating the building space.

Electric Energy for Lighting is the energy for all lighting, external and internal, at the NCFOB.

Miscellaneous Electrical Loads includes all non-lighting and non-HVAC loads such as receptacle loads, snow-melting equipment, and elevators.

Energy Rejected during Cooling is the thermal energy rejected from the water loops of the building closed-circuit coolers during operation of chillers or heat pumps in a cooling mode. 
CCl(HPS) represents energy rejected by the closed circuit cooler for the heat pump system.

CC2(Condensers) represents energy rejected by the closed circuit cooler which cools the chiller condensers.

CC3 (ENG/GEN) represents energy rejected by the closed circuit cooler which dumps excess waste heat to keep the engine/generator jacket temperature below a safe level.

Total Energy Consumed is the sum of the electrical energy and the equivalent thermal energy of the natural gas and fuel oil used by the building at the building boundary.

HVAC Energy Consumed is the electrical energy used for HVAC purposes plus the thermal equivalent of the natural gas and oil by the building.

Total Building HVAC Load is the sum of the space heating and cooling requirements plus the domestic hot water load. It represents the energy that must be added to or removed from the space to maintain acceptable comfort levels.

Solar Energy Incident is the total solar radiation energy which falls on the tilted solar collector surface on the roof of the building. The total gross collector area is $352.6 \mathrm{~m}^{2}$.

Useful Solar Energy Collected is the thermal energy removed from the solar array and stored in one of the storage tanks. If the temperature at the solar array output is less than the lowest tank temperature the solar loop is run in a bypass mode and no energy is stored. The useful energy value is an estimate based on solar and storage tank temperatures.

Solar Energy Utilized is that part of the thermal energy drawn from storage which was originally obtained from the solar collector array.

Solar to Heating (HWS) is the solar energy drawn from the storage tanks for use in the hot water system.

Solar to Heating (HPS) is the solar energy drawn from the storage tanks for use in the heat pump system.

Solar to Cooling is the solar energy drawn from the storage tanks in the summer for use in the absorption chiller.

Solar to Hot Water is the solar energy drawn from the storage tanks for use in heating domestic hot water.

Solar Utilization Efficiency is the percentage of the total solar energy falling on the collector panels which is utilized in the building mechanical systems for heating or cooling purposes. 
Solar Fraction of HVAC Load is that portion of the energy to HVAC Systems which is provided by energy collected from the solar array.

Total HVAC Performance Factor represents the efficiency of the building mechanical systems in meeting the heating and cooling load. This factor is the HVAC load divided by the total energy consumed for HVAC purposes.

\section{Data Page 2: Building Heating Loads}

Building heating requirements are broken down on the first three floors by floor zone for space loads and ventilation loads. Core zones include the area in the central part of the building where the central air systems are located. Perimeter zones consist of the areas around the outside of each floor near the windows. For the upper four floors the total heating requirements only, are given.

Definitions of specific parameters are included below:

Total Heating Load is the energy added to the building space to maintain comfort levels.

Percent Loads Supplied are the amounts of energy of different types applied to space heating divided by the space heating load. Fossil fuels are used in the boilers to generate thermal energy. Heat recovery is energy recovered from the engine generator. Cooling heat rejection is energy from the chiller condenser applied to heating.

Percent Loads Handled are the percentages of the total load carried by the two primary space heating systems.

Heat Pump System COP is the coefficient of performance for heating calculated for the heat pump system as a whole. In this case the C.0.P. equals the total energy rejected from all heating mode heat pumps of the space divided by the electric power consumption of all heat pumps in the heating mode.

\section{Data Page 3: Building Cooling Loads}

Cooling loads are broken down in the same manner as heating loads (see Data Page 2: Building Heating Loads). Definitions of specific parameters are included below:

Total Cooling Load is the energy removed from the building space to maintain comfort levels.

Cooling Energy Used is the energy required by refrigerating equipment to remove the energy of the total cooling load from the building.

Percent Energy Supplied represents the amounts of different types of energy applied to space cooling divided by the total cooling energy used (see above). Fossil fuel energy includes thermal energy from boilers and electrical energy from the engine generator. Heat recovery is thermal energy obtained from the 
engine generator and used in the absorption chiller. Outside air may be used for cooling when outside air enthalpy is below inside air enthalpy.

Percent Loads Handled are the percentages of the total cooling energy used by each of three major cooling subsystems.

Chilled Water Production by Electric Chiller is the energy removed from the chilled water system by the electric chiller to lower the chilled water temperature.

Chilled Water Production by Absorption Chiller is the energy removed from the chilled water system by the absorption chiller to lower the chilled water temperature.

\section{Data Page 4: Electrical Energy Used}

The information on this page describes the electrical energy usage by the NCFOB. Major loads are the lighting, HVAC and miscellaneous electrical loads. Definitions of the major loads are included in the data page one definitions. other selected definitions are given below:

Electrical Energy for Normal Lighting is the energy to those lights which are not considered essential in case of power fallure. This category includes the bulk of office and lobby lights.

E1. Energy for Essential Lighting is the energy to those lights which are considered essential during a power failure. This category includes stairway and penthouse lights.

Total Heat Pumps and component heat pump loads for each floor represent the electrical energy consumption by all heat pumps in the building or on a floor, regardless of the heat pump mode.

Total, Fan Coils and component fan coil loads for each floor represent the electrical energy consumption by all fan coil units in the bullding or on a floor.

Fans is the total electrical energy consumption for the four central air system fans; two supply and two return fans.

Evaporative Coolers is the electrical energy consumed to operate the three closed circuit coolers in the building.

Electric Chiller is the electrical energy consumed by the electric chiller.

Total, Pumps and Misc. Motors is the public utility generated electrical energy consumed by all of the important pumps and most of the minor fans in the building.

Solar System Pumps is the electrical energy consumed by the two solar system variable speed pumps. 
Controls and Misc. is the electrical energy to a number of devices not included in other categories but which have a function in the HVAC systems. Devices in this category include the pneumatic control system air compressor, pneumatic control panels, furnace controls, elevator machine room air conditioner and miscellaneous fans and pumps not included under the pumps and motor category.

Elevators is the electrical energy consumed by the three elevators in the NCFOB.

Fire, Computer and Emergency Systems is the electrical power used by the JC-80 minicomputer and the fire and other emergency warning systems.

Undocumented Loads are miscellaneous loads not individually metered.

\section{Data Page 5: Solar System Performance}

This page is intended to report the thermal performance of the solar energy system on the NCFOB. There are four rows of solar panels in the solar array, each row containing collectors of a different design. Definitions of the solar system parameters are given below:

Total Energy Incident is the total solar irradiation falling on the gross area of the array in the time period specified.

Useful Solar Energy Collected: See the definition for data page 1.

With Temp. $>70^{\circ} \mathrm{F},\left\langle 110^{\circ} \mathrm{F}\right.$ : quantity of solar energy which is collected at a temperature level greater than $21^{\circ} \mathrm{C}\left(70^{\circ} \mathrm{F}\right)$ but less than $43^{\circ} \mathrm{C}\left(110^{\circ} \mathrm{F}\right)$.

With Temp. $>110^{\circ} \mathrm{F},\left\langle 130^{\circ} \mathrm{F}\right.$ : is the solar energy collected at a temperature level greater than $43^{\circ} \mathrm{C}\left(110^{\circ} \mathrm{F}\right)$.

With Temp. $>130^{\circ} \mathrm{F},<180^{\circ} \mathrm{F}$ : is the solar energy collected at a temperature level greater than $54^{\circ} \mathrm{C}\left(130^{\circ} \mathrm{F}\right)$.

With Temp. $>180^{\circ} \mathrm{F},<220^{\circ} \mathrm{F}$ : is the solar energy collected at a temperature level higher than $82^{\circ} \mathrm{C}\left(180^{\circ} \mathrm{F}\right)$ during the summer.

With Temp. $>220^{\circ} \mathrm{F}$ : is the solar energy collected at a temperature level greater than $104^{\circ} \mathrm{C}\left(220^{\circ} \mathrm{F}\right)$. This energy can sometimes be used in the absorption chiller.

Solar Array Collection Efficiency is the average net energy gain in the collector fluid passing through the solar array divided by the total energy incident on the gross area of the array $\left(352.6 \mathrm{~m}^{2}\right)$.

Total System Collection Efficiency is the useful solar energy collected (see data page 1) divided by the total energy incident on the gross area of the array.

Electrical Energy to Operate System is the electrical energy required to run the solar system pumps and the pump speed controller. 
Solar System COP is the Useful Solar Energy Collected (see definition on data page 1) divided by the electrical energy to operate system (see definition above).

Tank Degree C-Hours are the temperatures of the three storage tanks multiplied by the number of hours in the time period for the data. These values are of primary interest in hourly printouts.

Data Page 6: Building Environment

The sixth page of the performance data is intended to display the conditions of the inside and outside building environment at the NCFOB. Definitions of the reported quantities are included below:

Average Outside Dry Bulb Temp. (Day) is the dry bulb temperature measured on the roof of the NCFOB averaged over the daylight hours.

Average Outside Dry Bulb Temp. (Night) is the dry bulb temperature measured on the roof of the NCFOB averaged over the hours after sunset and before sunrise.

Average Outside Humidity (Day) is the relative humidity of the outside air measured on the roof of the NCFOB averaged over the daylight hours.

Average Windspeed is the magnitude of the wind velocity measured above the roof of the $N C F O B$ averaged over the time period specified for the data.

Inside Space Temperatures are the average dry bulb temperatures for each of the floors in the NCFOB. In most cases the core, north, south, east and west zone temperatures are averaged to obtain the floor average. OCC designates the temperature averaged over the hours that the floor is occupied (see definition below). UNOCC designates the temperature averaged over the hours that the floor is unoccupied.

Space Humidities are the average relative humidities for the main seven floors of the NCFOB. The values are averages over the occupied hours of the floor. The humidity values are derived from the core dewpoint and dry bulb temperatures except for the second floor humidity which is the average of the humidities in the five floor zones.

Occupied Hours for a floor are the number of hours that the floor is in a so-called occupied mode. The occupied/unoccupied modes can be set by the building operator or the JC-80 minicomputer. When in unoccupied mode the air systems are shut down and no cooling is provided. In winter, some minimum temperature is maintained. Unoccupied mode is usually maintained at night or on weekends.

Hot Water Use is the net energy removed from the domestic hot water loop which circulates through the NCFOB.

Average HW Temp. is the average of the domestic hot water temperature measured in the hot water circulating line at the outlet of the domestic hot water storage tank. 


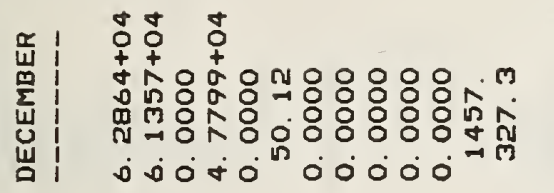

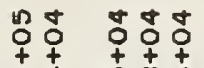

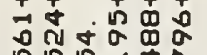

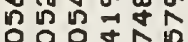
$-\dot{-1}^{-1}$ लं लं

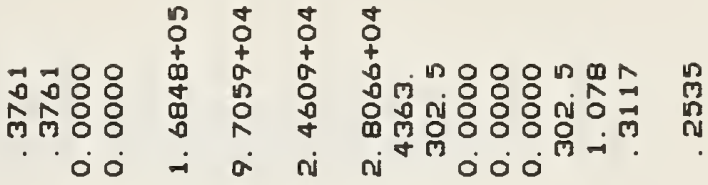

虽主

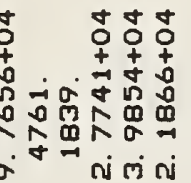

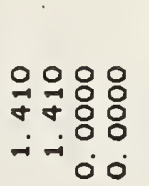

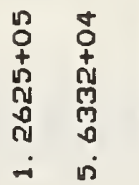

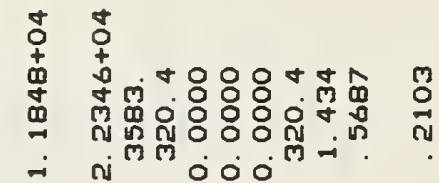

就部

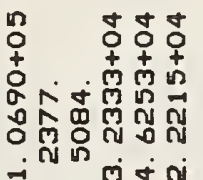
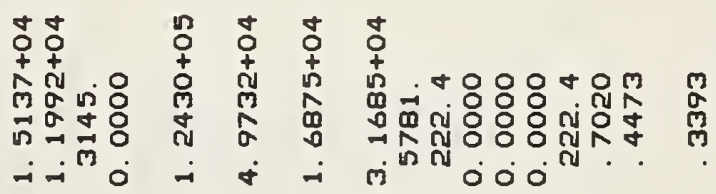

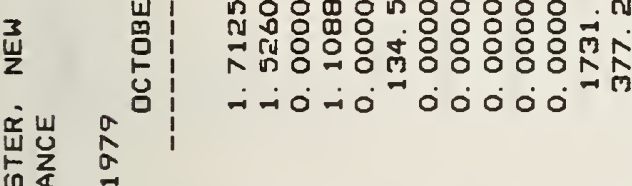

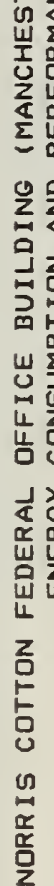

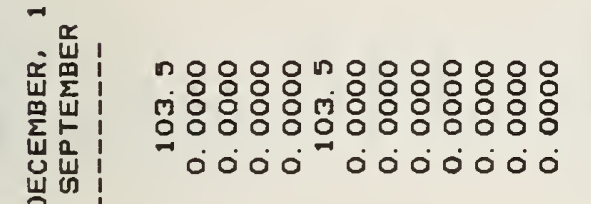

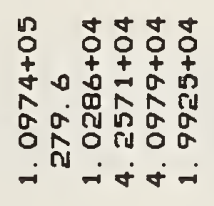

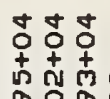

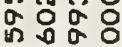

o

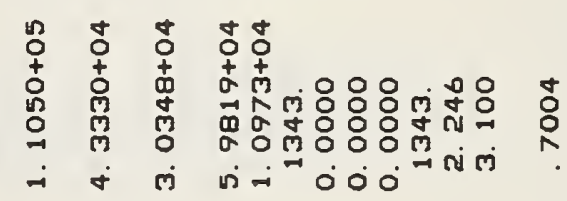

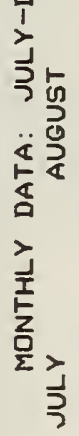

-

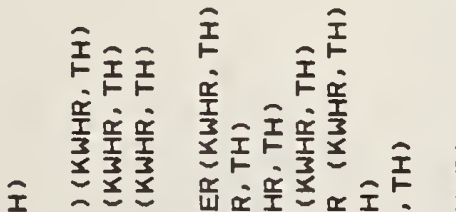
I 舟

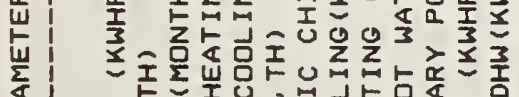

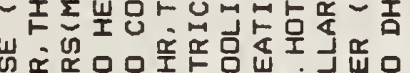

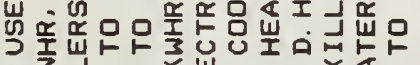

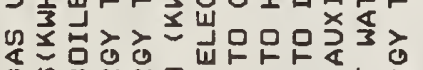

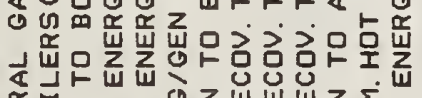

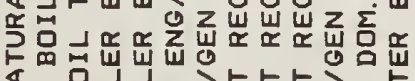

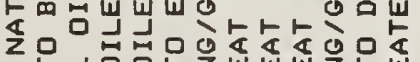

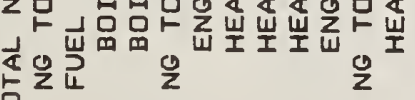

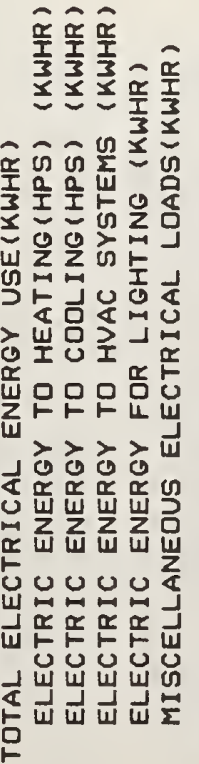

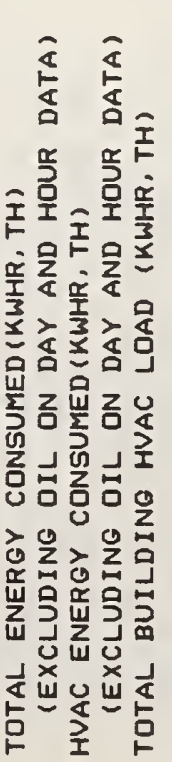

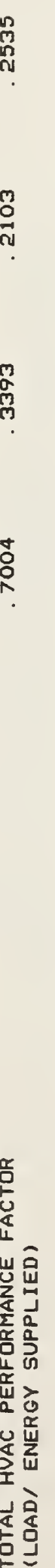




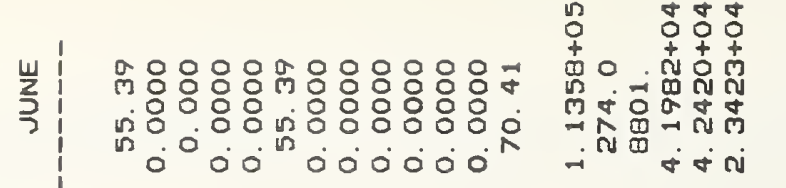

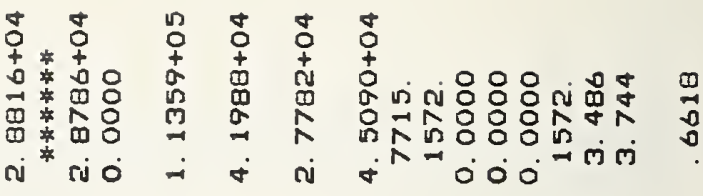

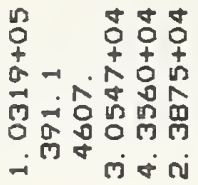

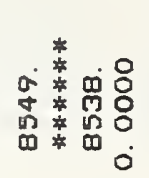

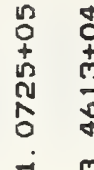

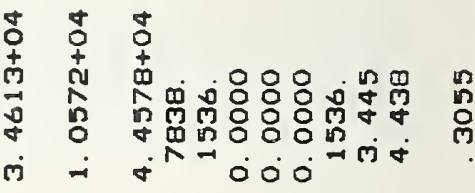

. 五走

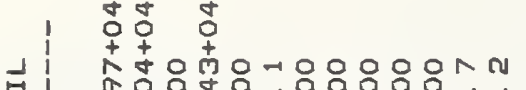

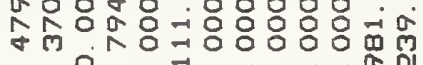

崖管

nก

․․

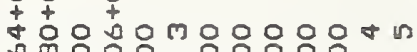

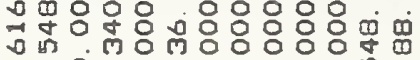

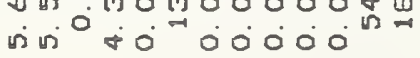

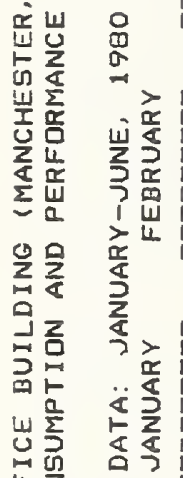

\section{i}

andomanoo,

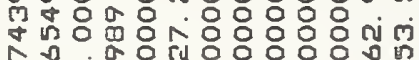

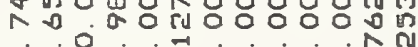
$n n_{0}$ mi $^{-1} 0.0000$

요용

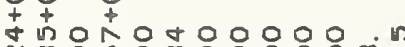

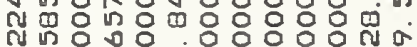
Nho

㟧总

这定

声

rर. 0000000

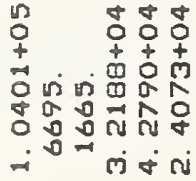

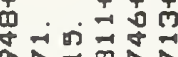

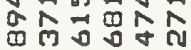

$a^{\circ-1}$ ก

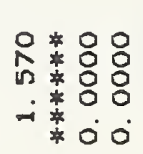

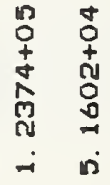

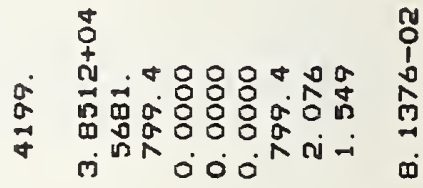

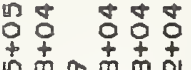

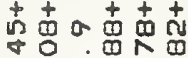

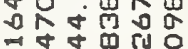

न- मिं

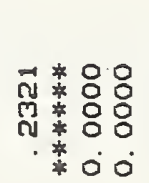

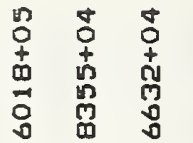

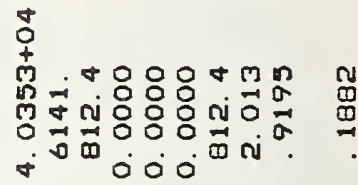

经施却

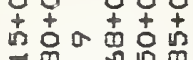

思罚罳

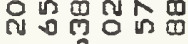

$-i 0+\infty$ i

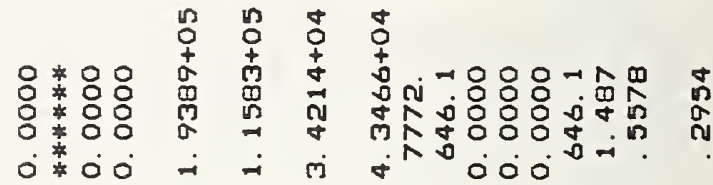

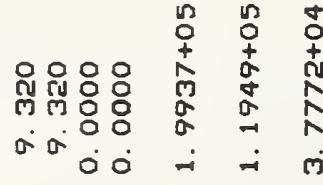

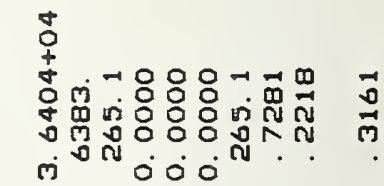

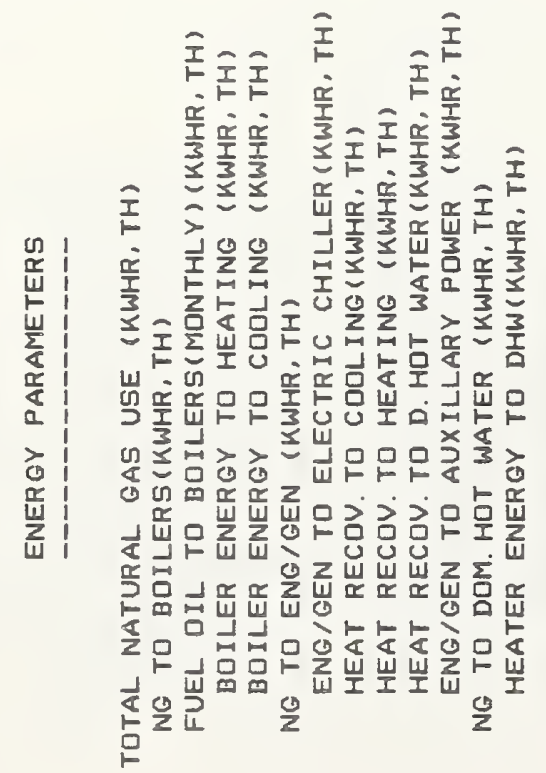
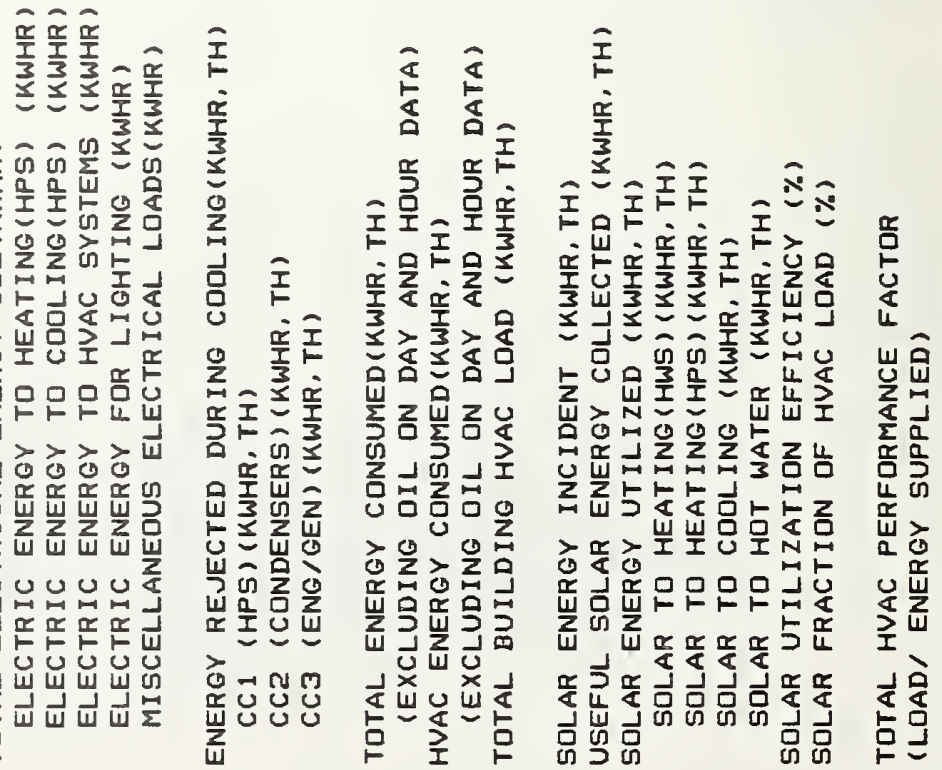


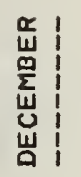

焉:

穹嵌

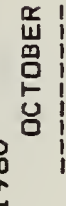



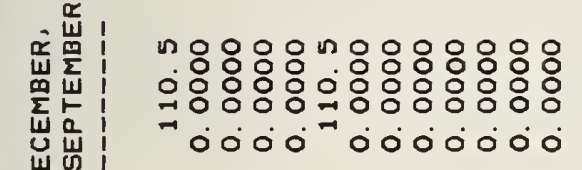

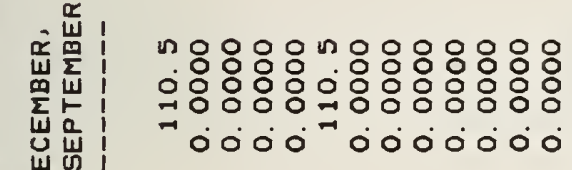

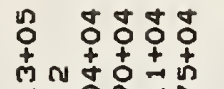

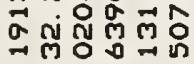

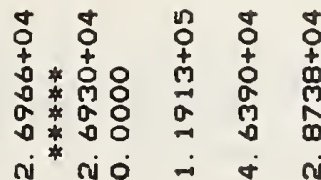

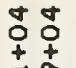
色崖向 岩以

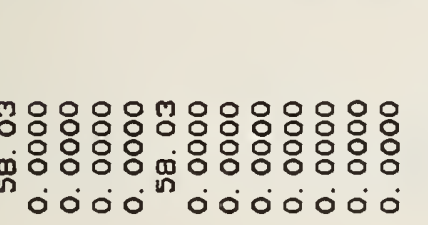

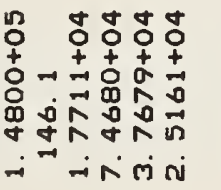

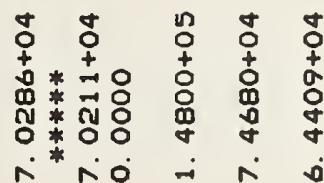

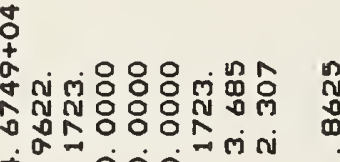

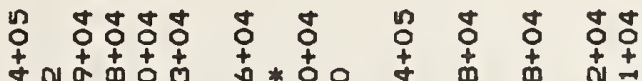

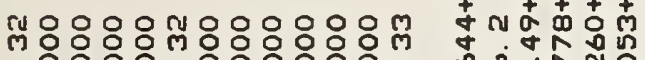
ว| ว| m*

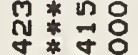
in

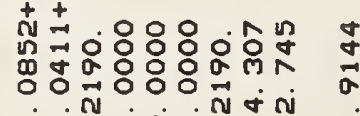
0
0
0
0
0
0
0 


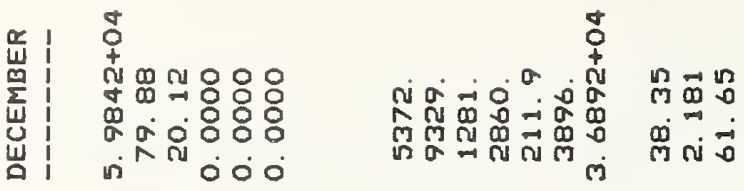

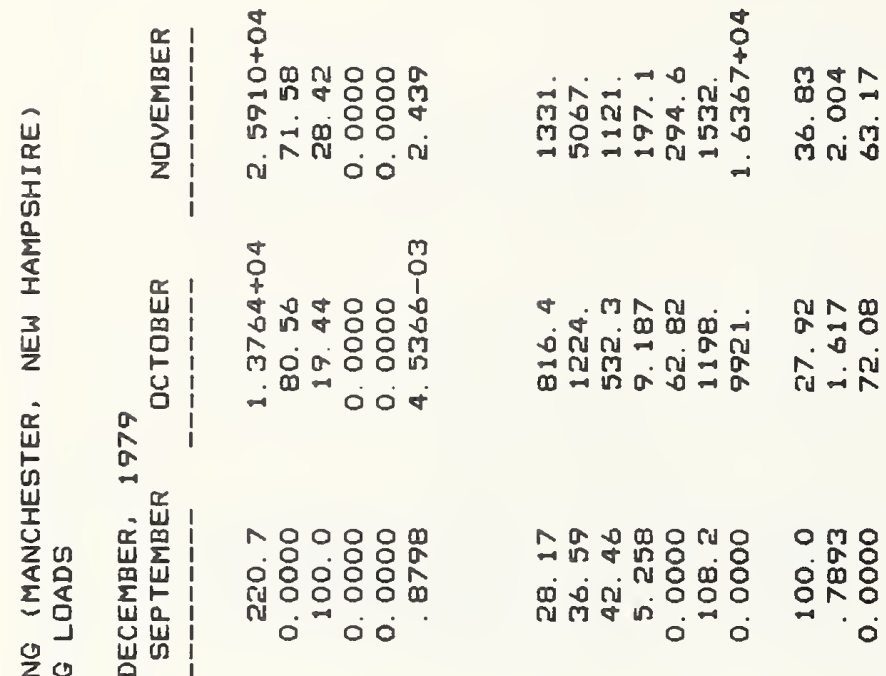

㟒

要

宙岌

$\frac{1}{2}$

วัต

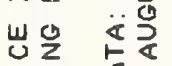

些骂

哇

喜

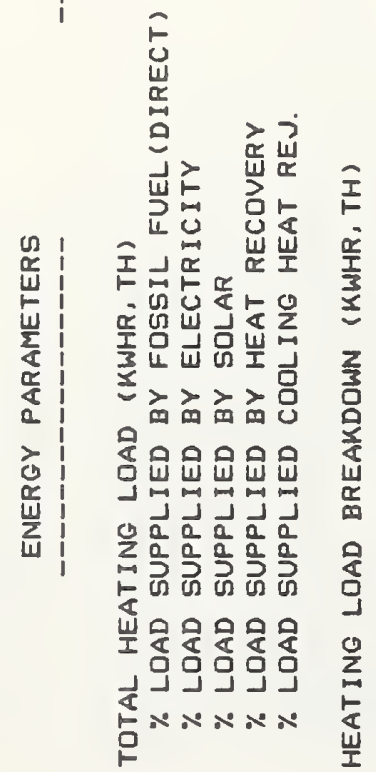

웅 웡 옹

站点

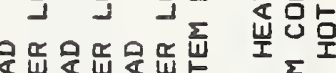

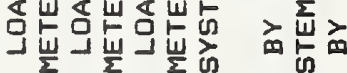

山舟以的的

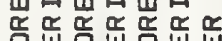

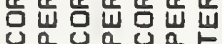

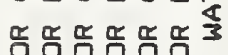

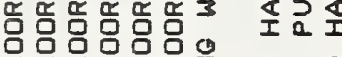

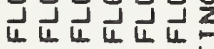

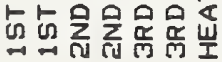

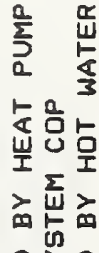

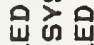

运造是

题岳是

$x \quad x$ 


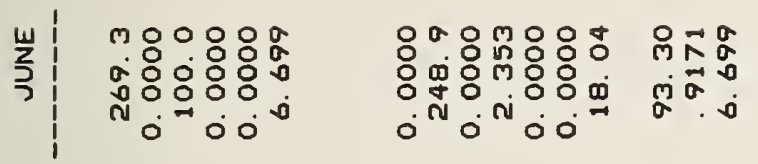

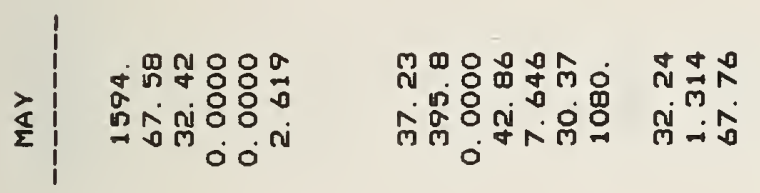

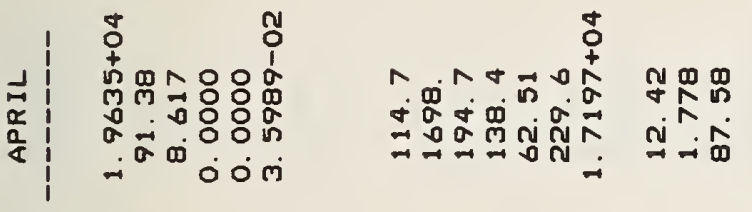

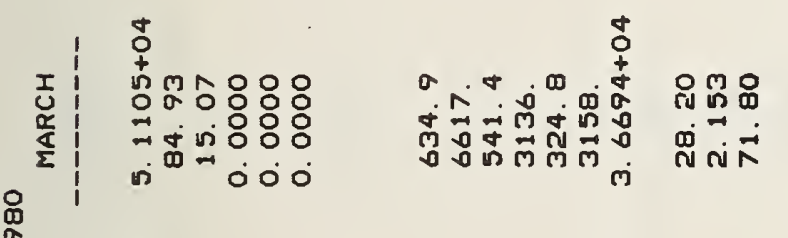

吕

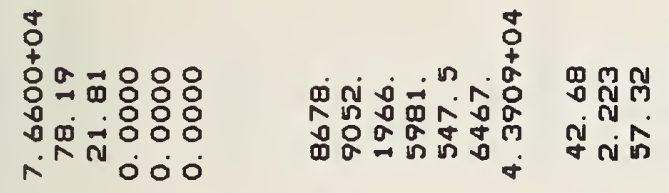

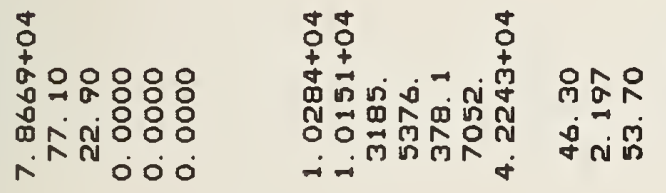

章

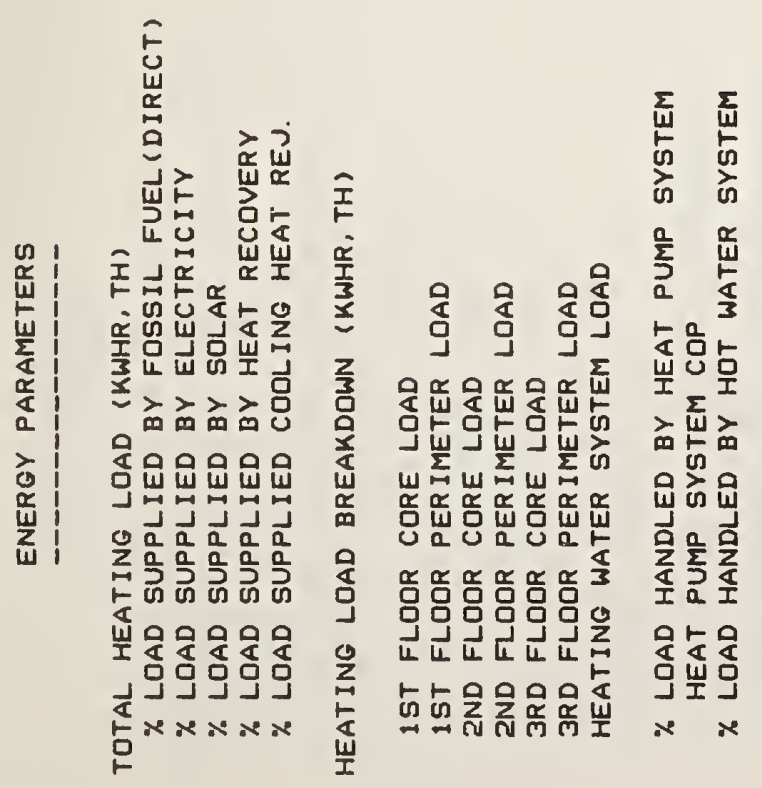


䓌!

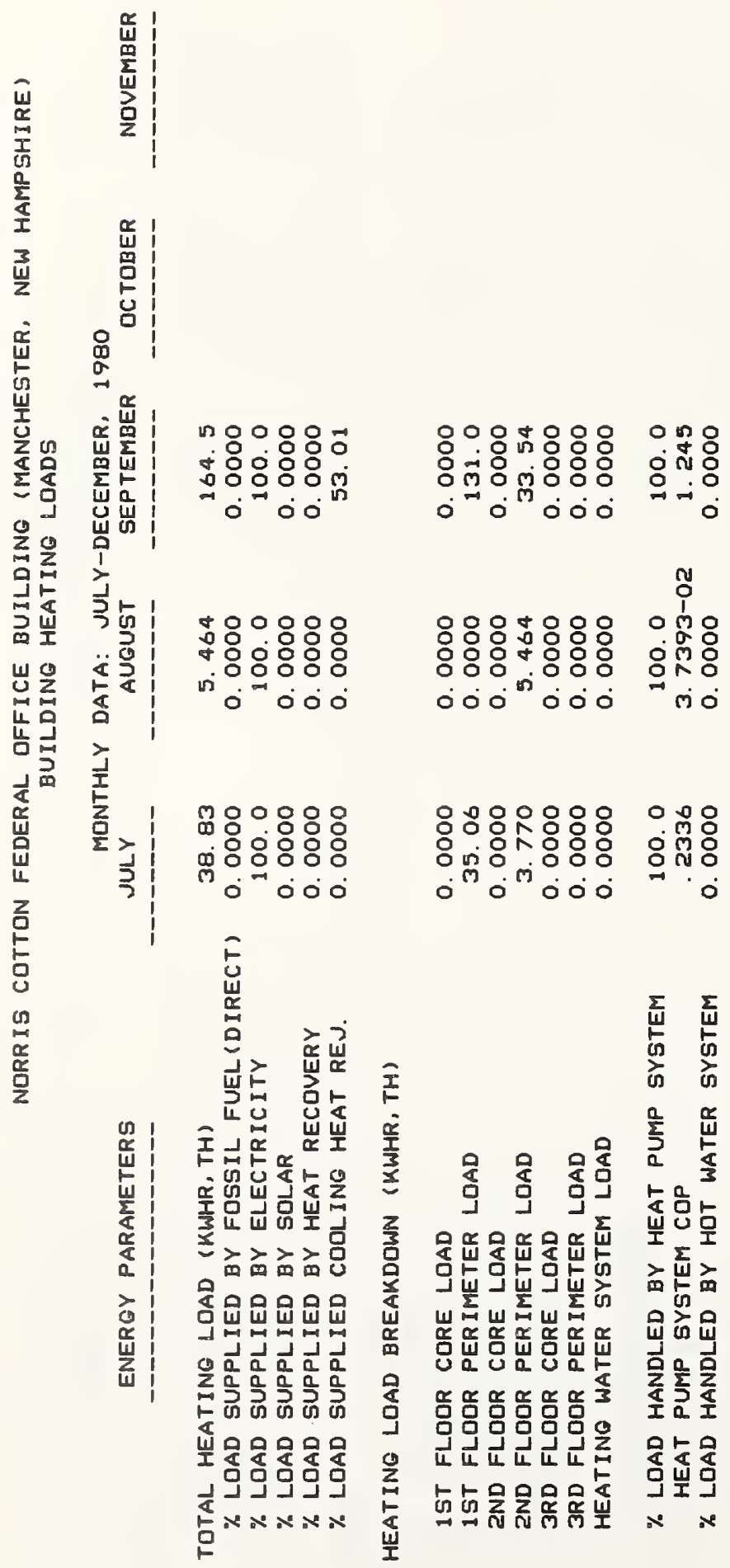




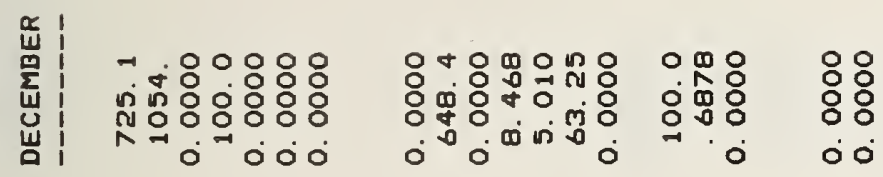

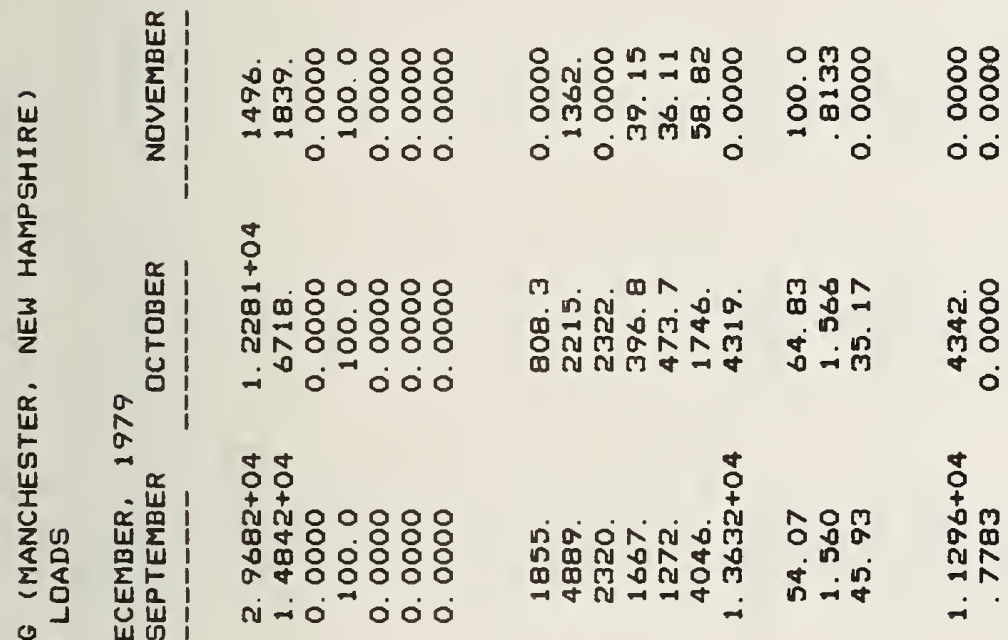

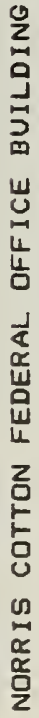

1

可品引官

顸艺

正安

吉牙

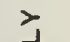

喜

占

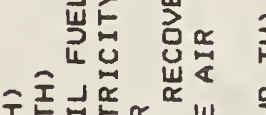

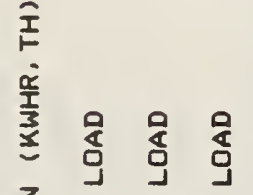

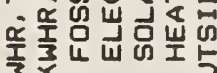

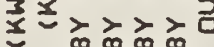

用

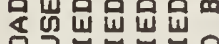

ง

$>0$ a

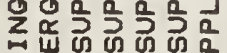

吕比方市

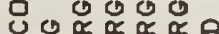

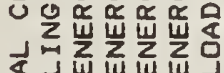

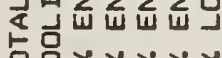

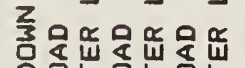

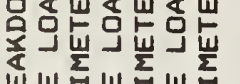

山山心

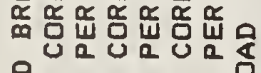

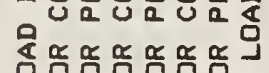

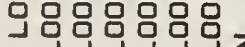

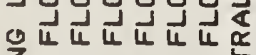

结上우을

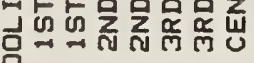

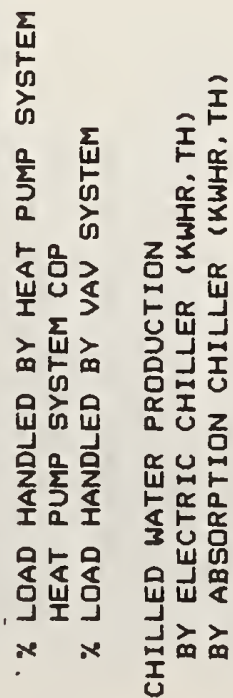




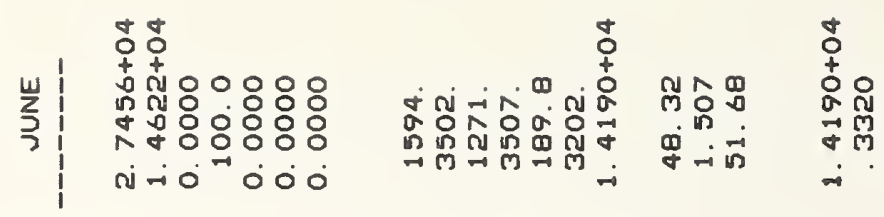

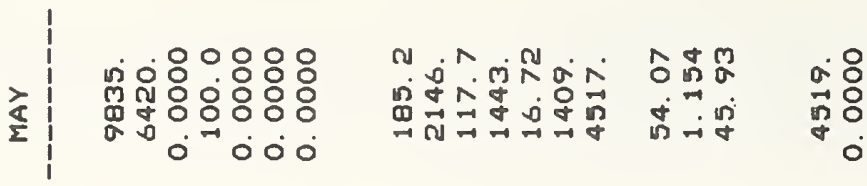

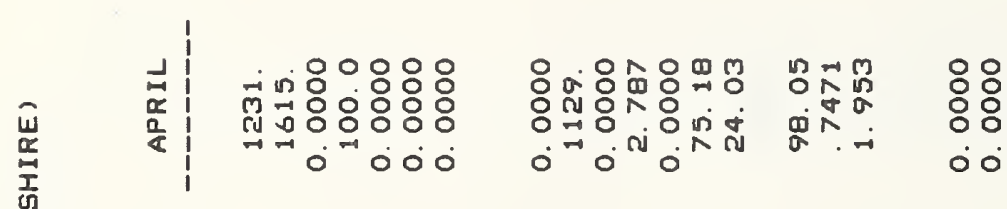

$\frac{\sum^{\frac{1}{I}}}{\mathrm{~S}}$

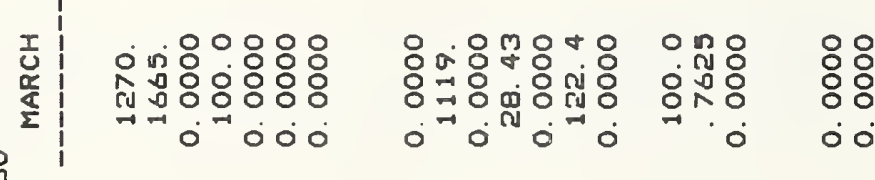

采品

尔

崖

$\sum 0$

品

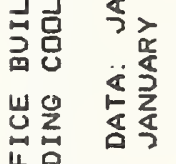

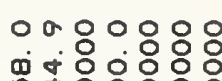

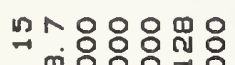

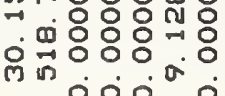

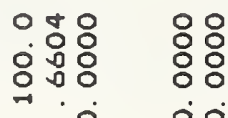

in

0.0 $0^{\circ}$

$\circ \circ$

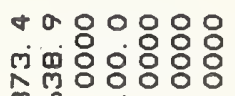

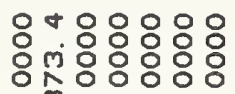

-m.0000

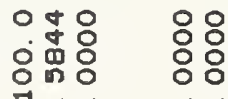

交

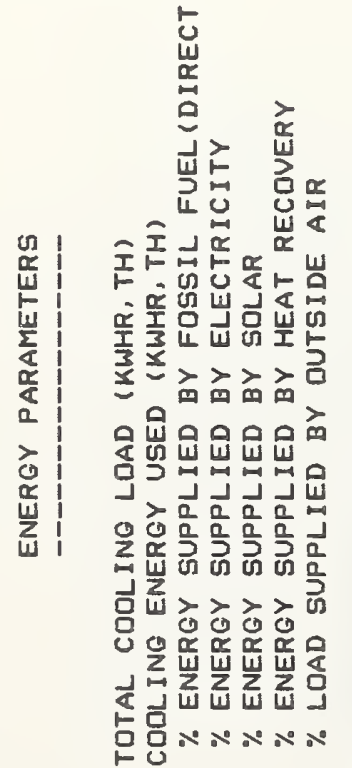

I

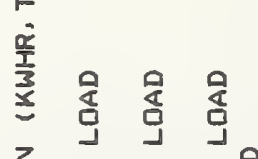

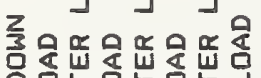

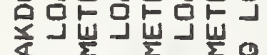

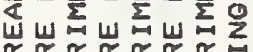

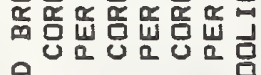

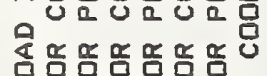

政

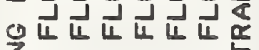

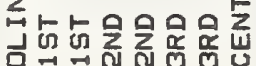

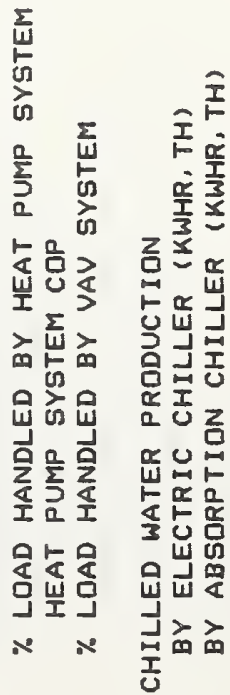




\section{揌:}

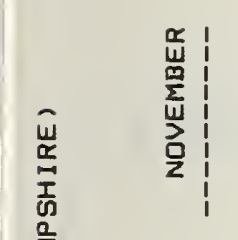

王

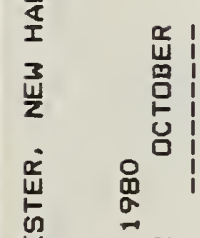

要

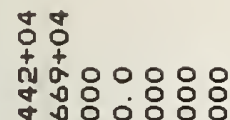

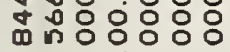
กं

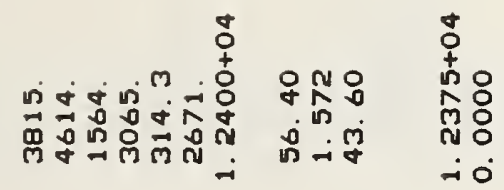

边岩

$+4$

ป。,

+

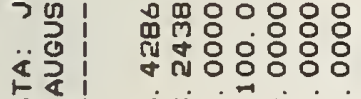

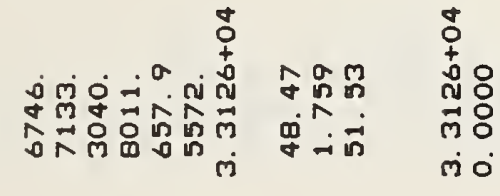

至星

० लं० ०००

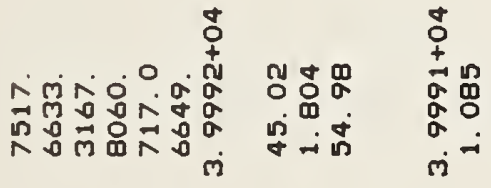

z

ग

m

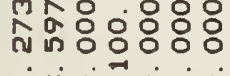

กंตั

㫐

否总焉

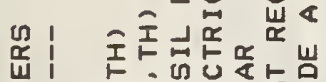

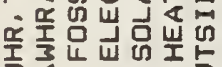

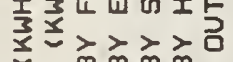
岂员口亩

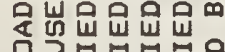
ปว

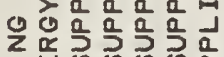
㟧的的约

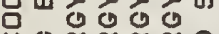

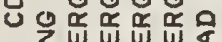

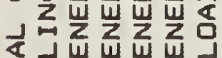
占哭Nハハ
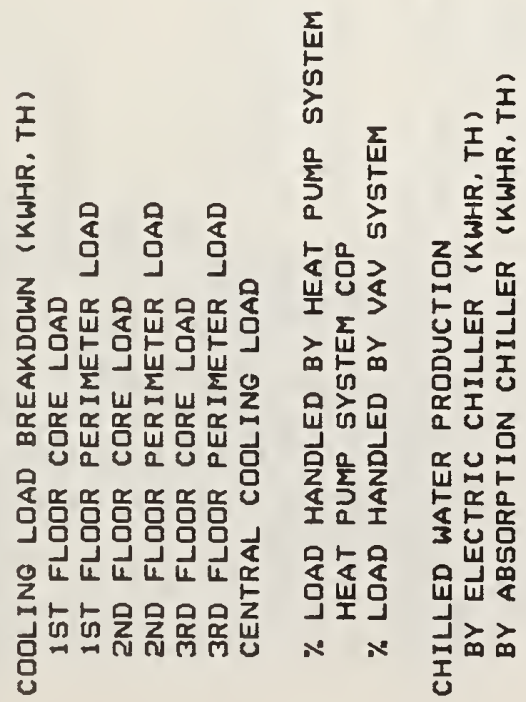


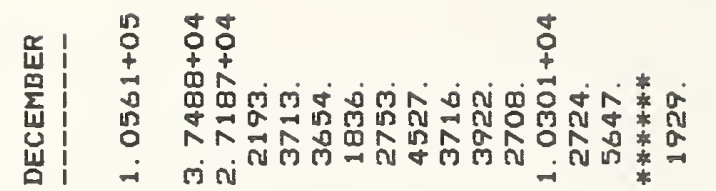

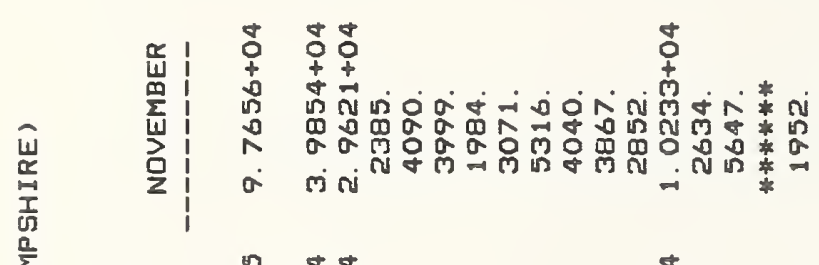

要

I I

농

这

문

灵

向 $\frac{1}{4}$

顸

뚠

岩色

克

峁

는

z

占

02

贻

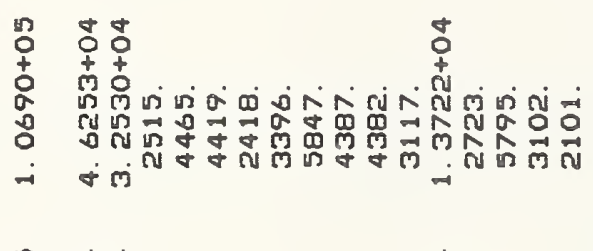
$a$ 舀!

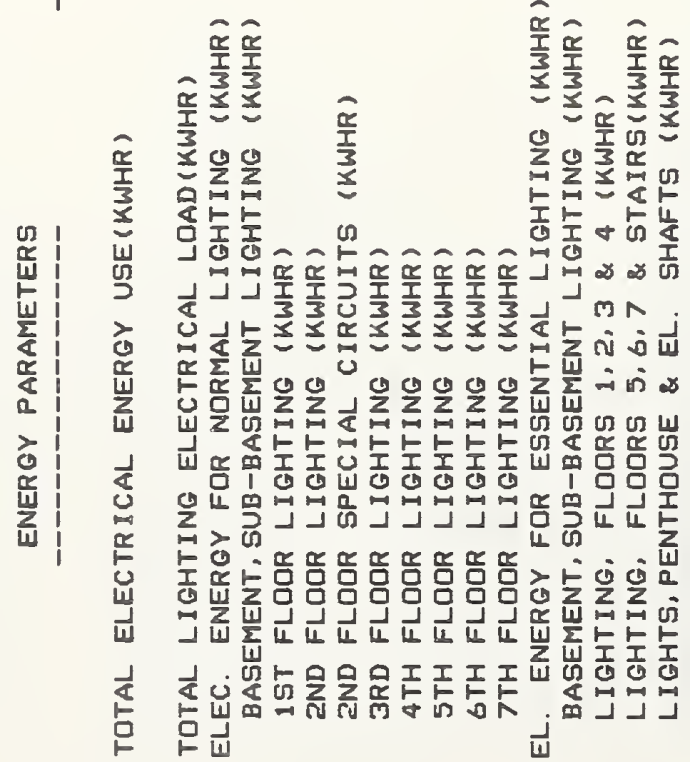

후옹

家

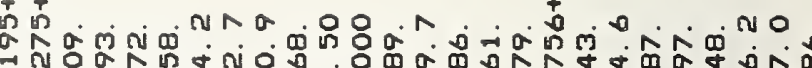

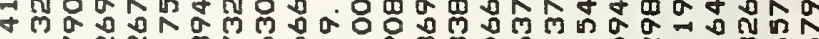
ल

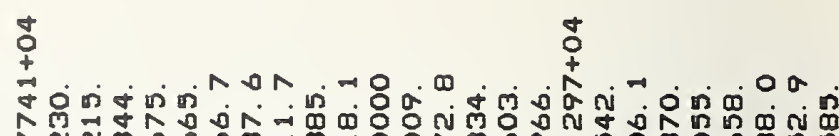

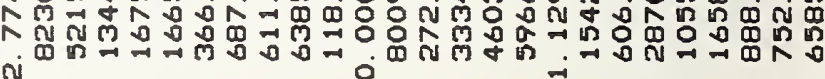

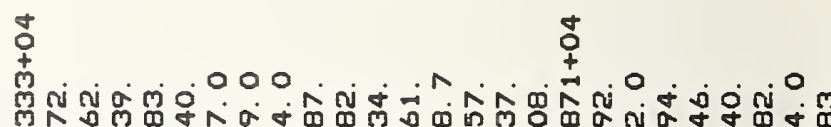
M‥

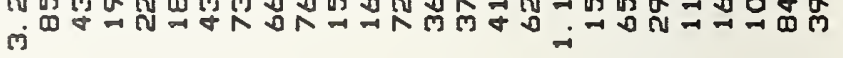

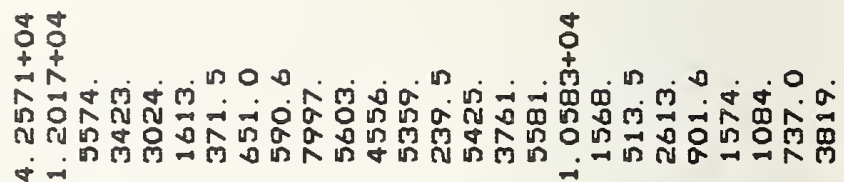




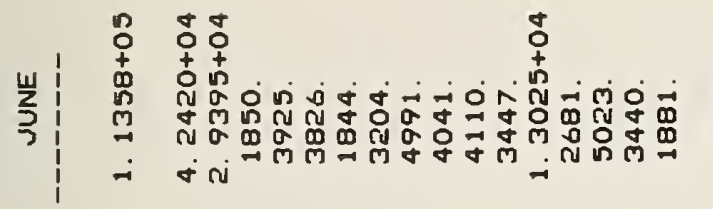

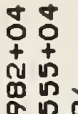

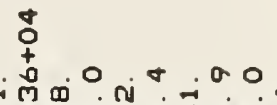

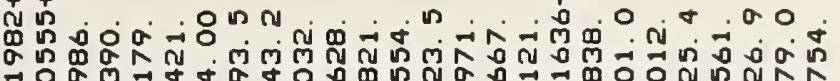

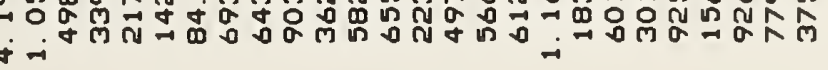

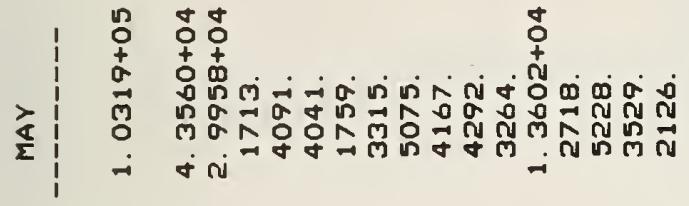

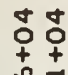

$\stackrel{8}{+}$

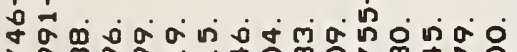

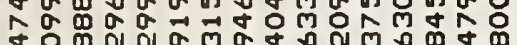

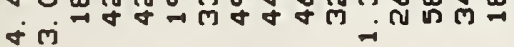

\section{o}

$\stackrel{2}{+2}$

욤

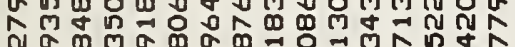

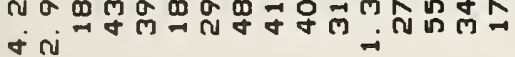

品

㞬

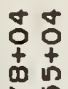

몬

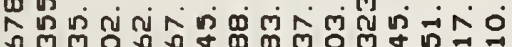
ก

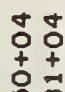

$\stackrel{a}{+}$

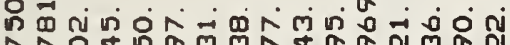

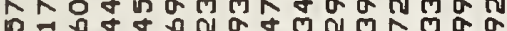
舟

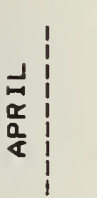

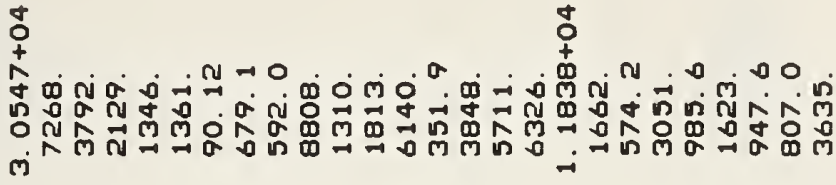
落

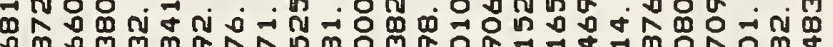
तं

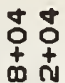

$\stackrel{+}{+}$

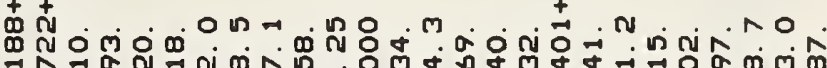
สำ लंন

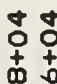

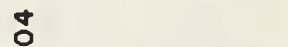

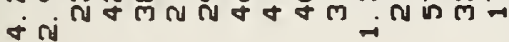

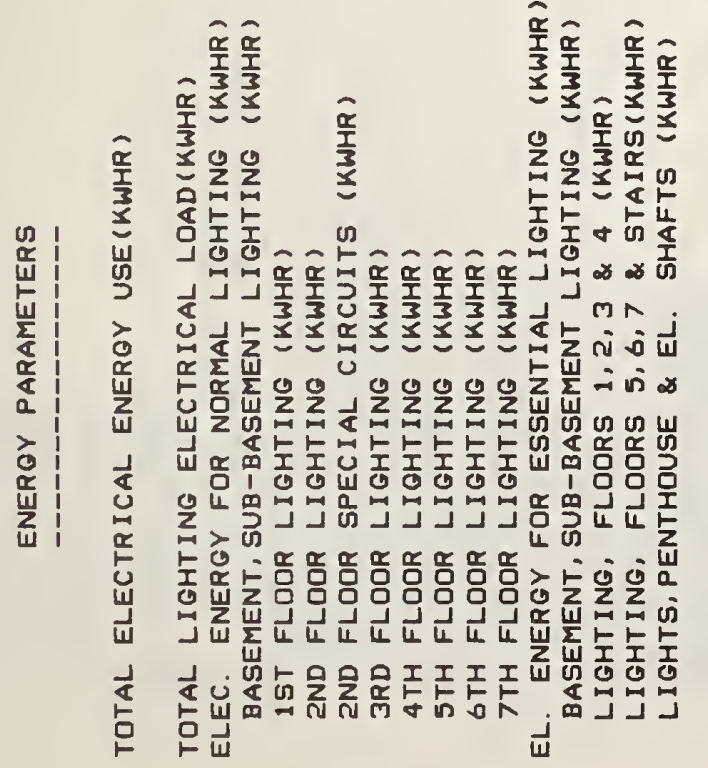

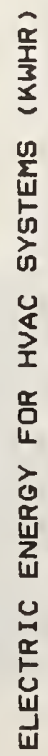

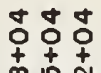

渵

边贻

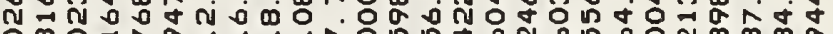

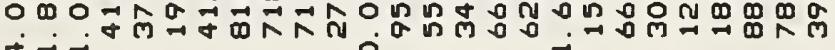

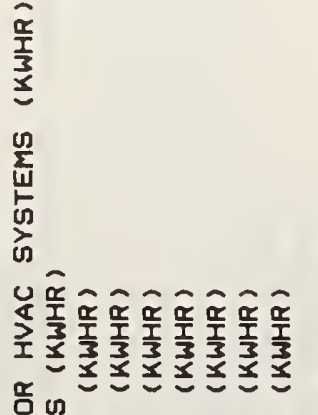

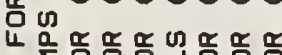

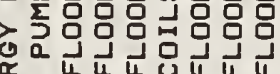

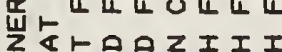

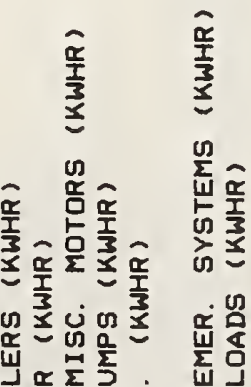

$\frac{\hat{\alpha}}{\frac{\underline{T}}{3}}$

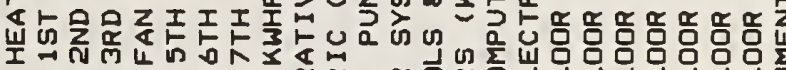

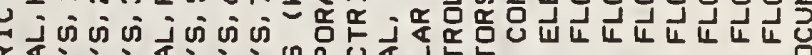

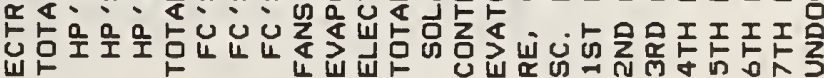
แI 
点!

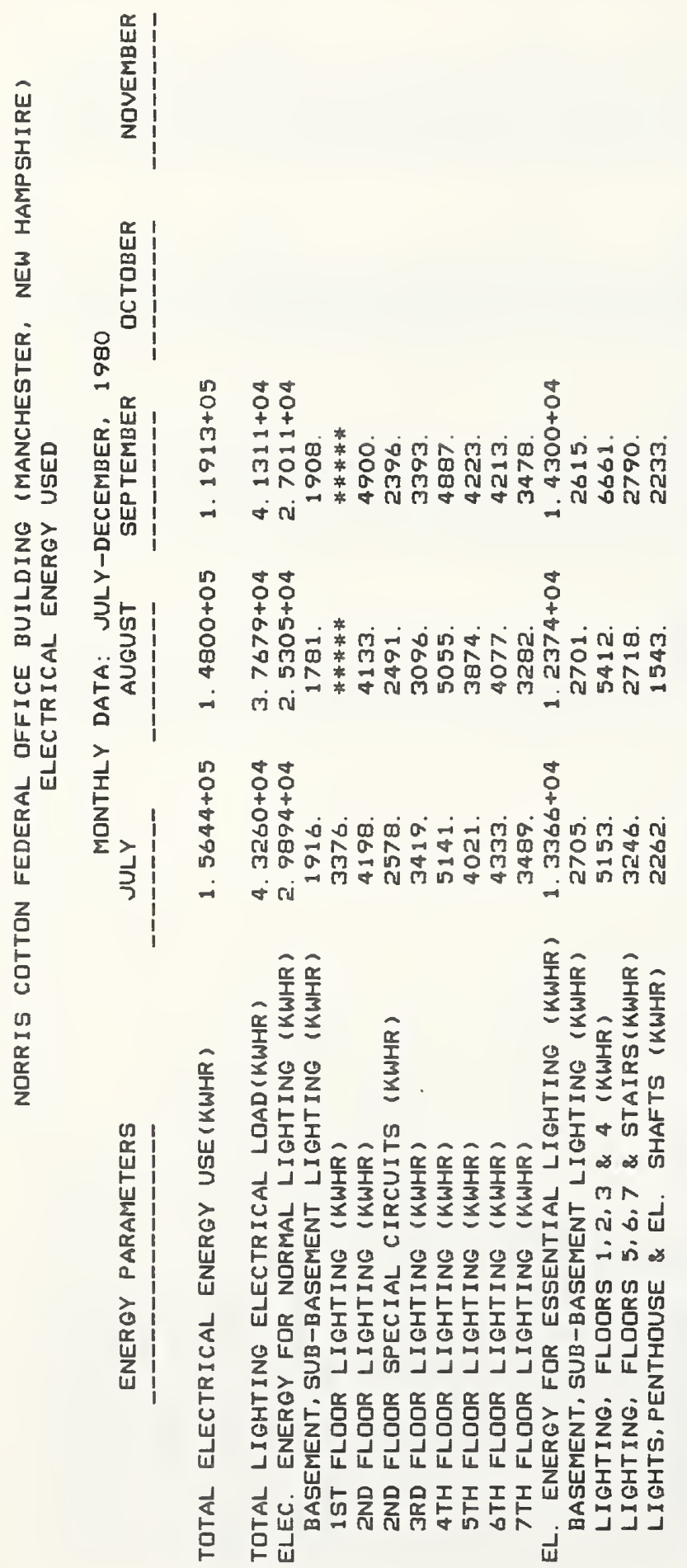

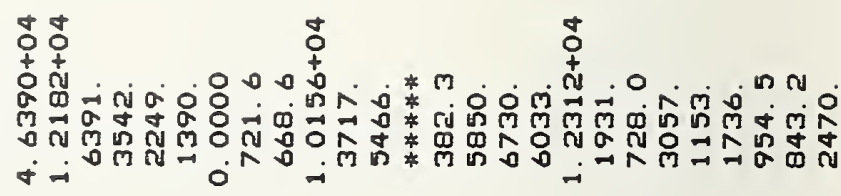

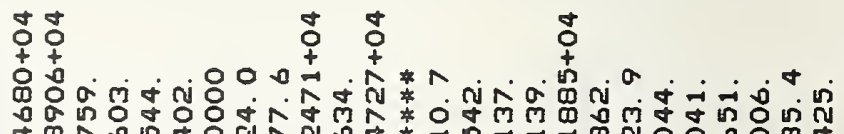

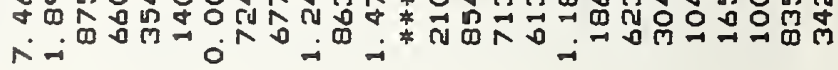

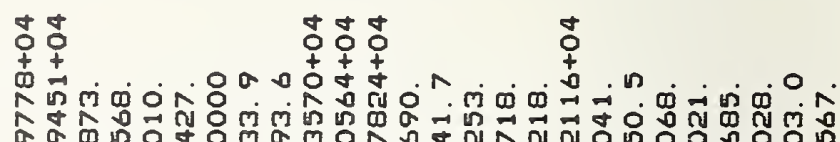

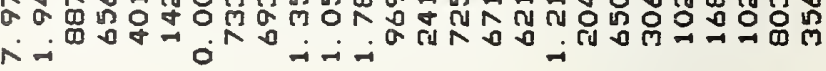

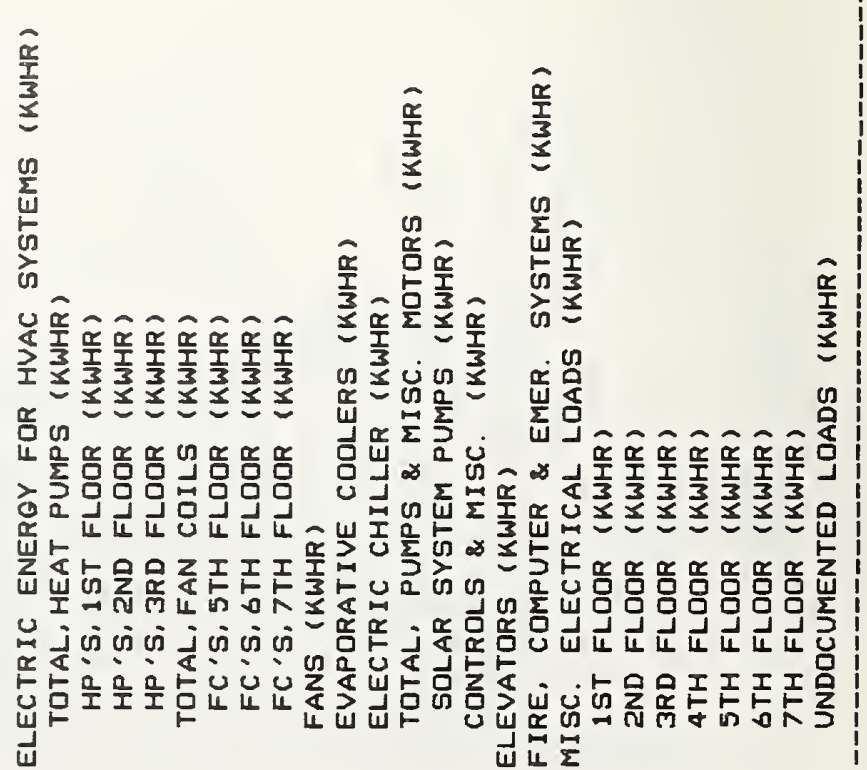




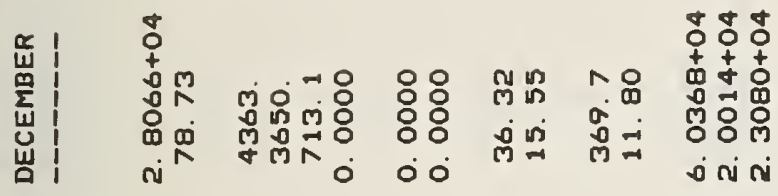

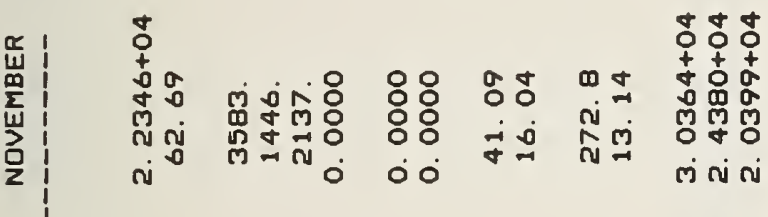

L

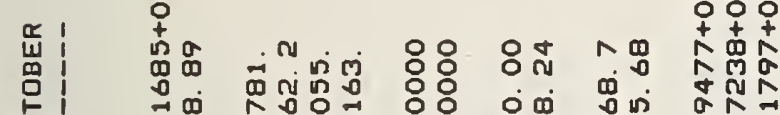

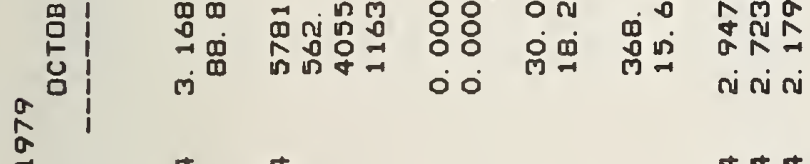

L

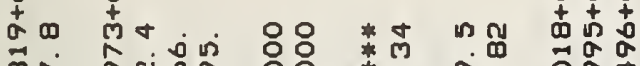

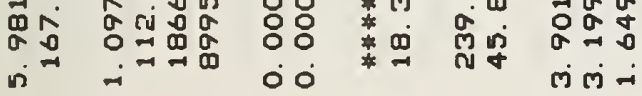

政

문난

㟧

i

ว

ว兽!

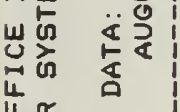

岁毞,

吉

$\frac{n}{\frac{\pi}{\alpha}}$

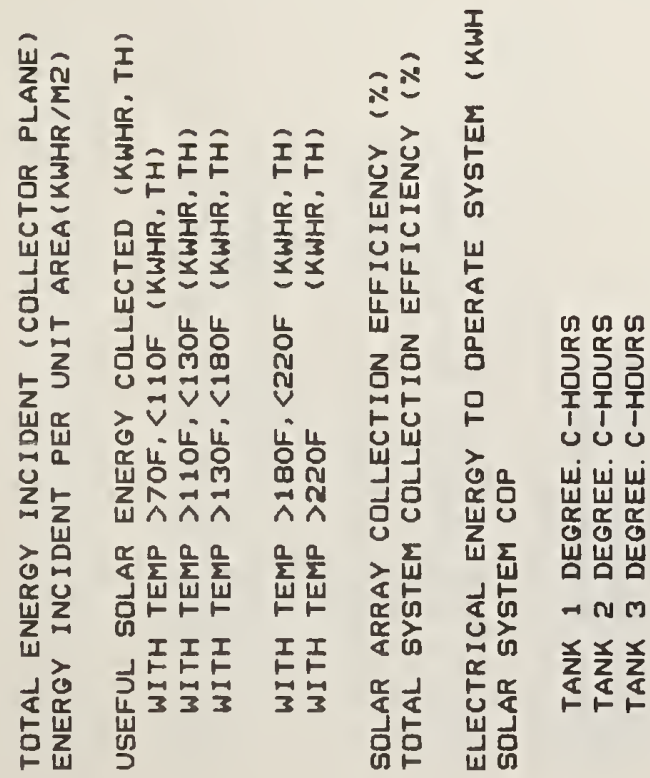




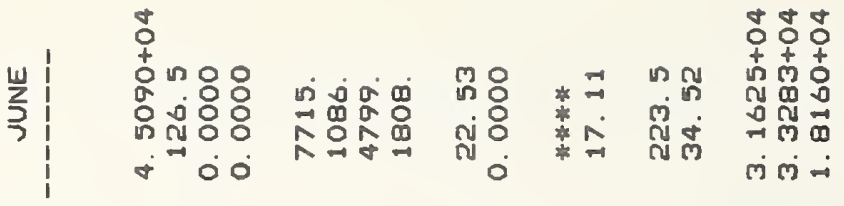

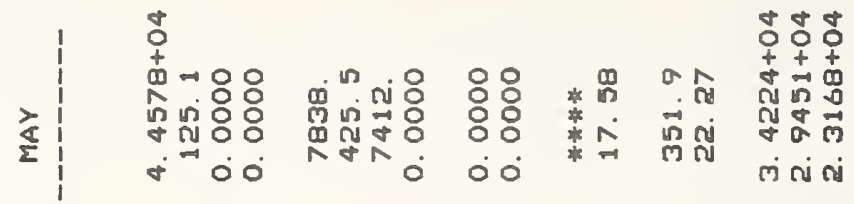

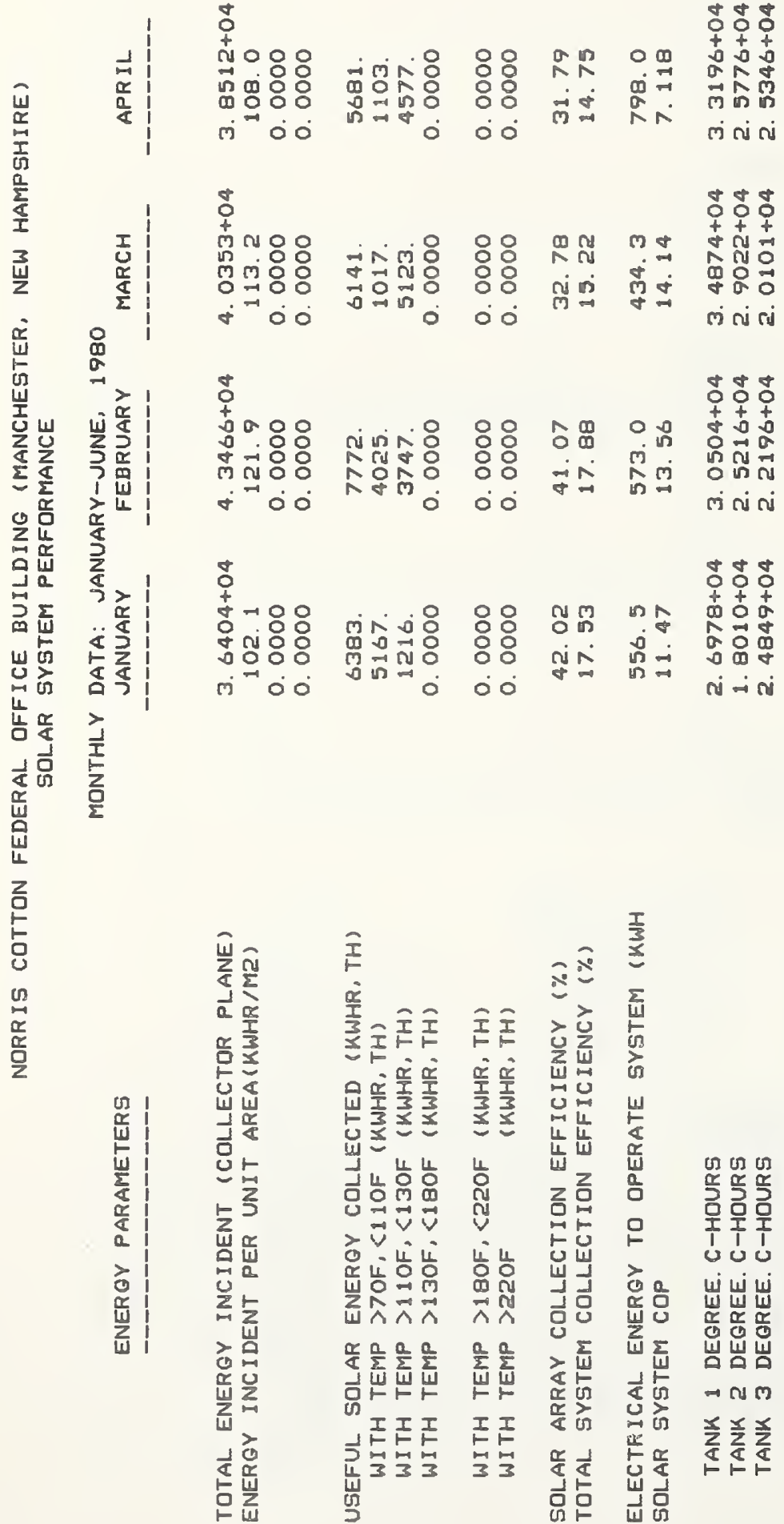

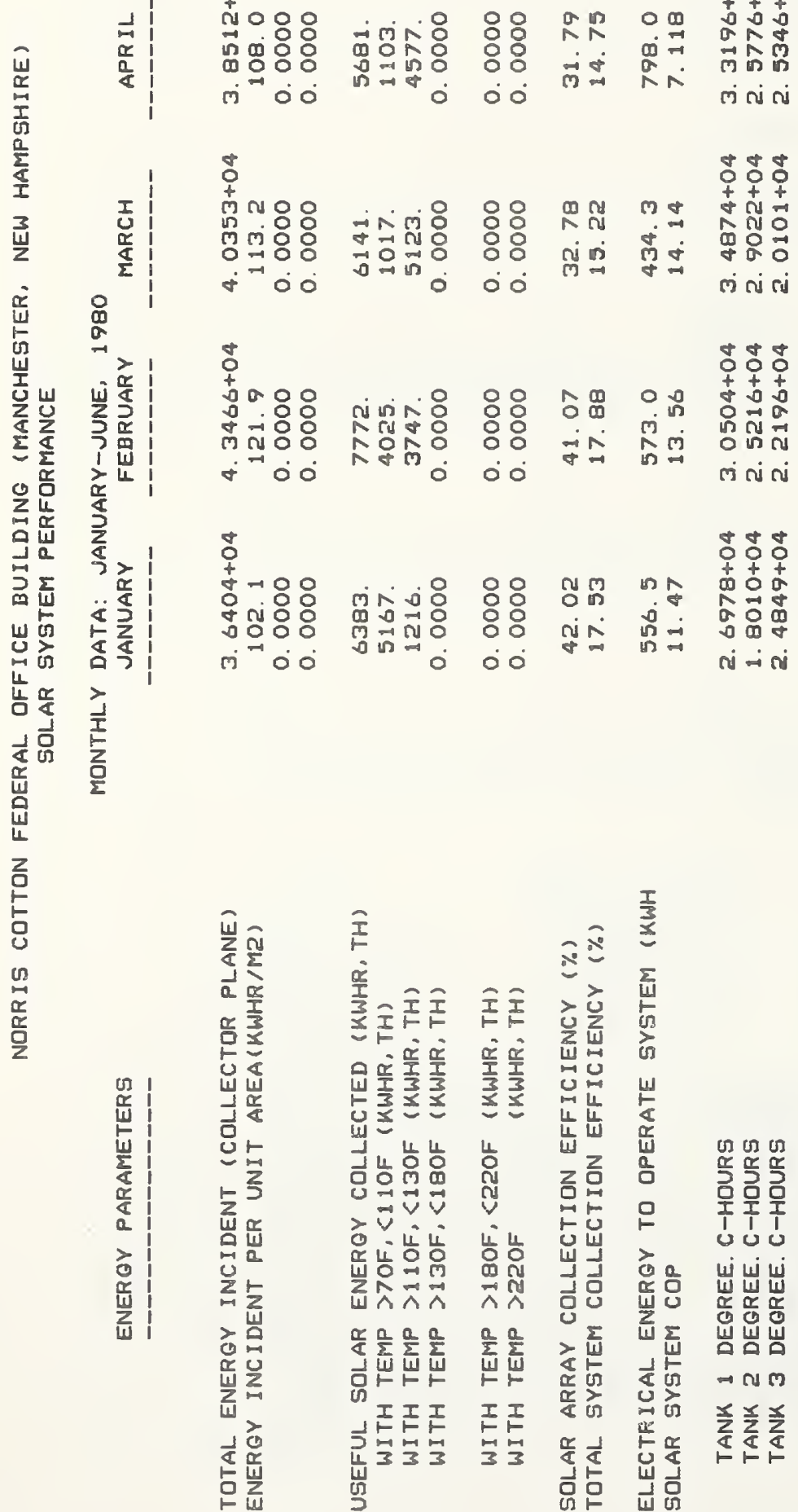

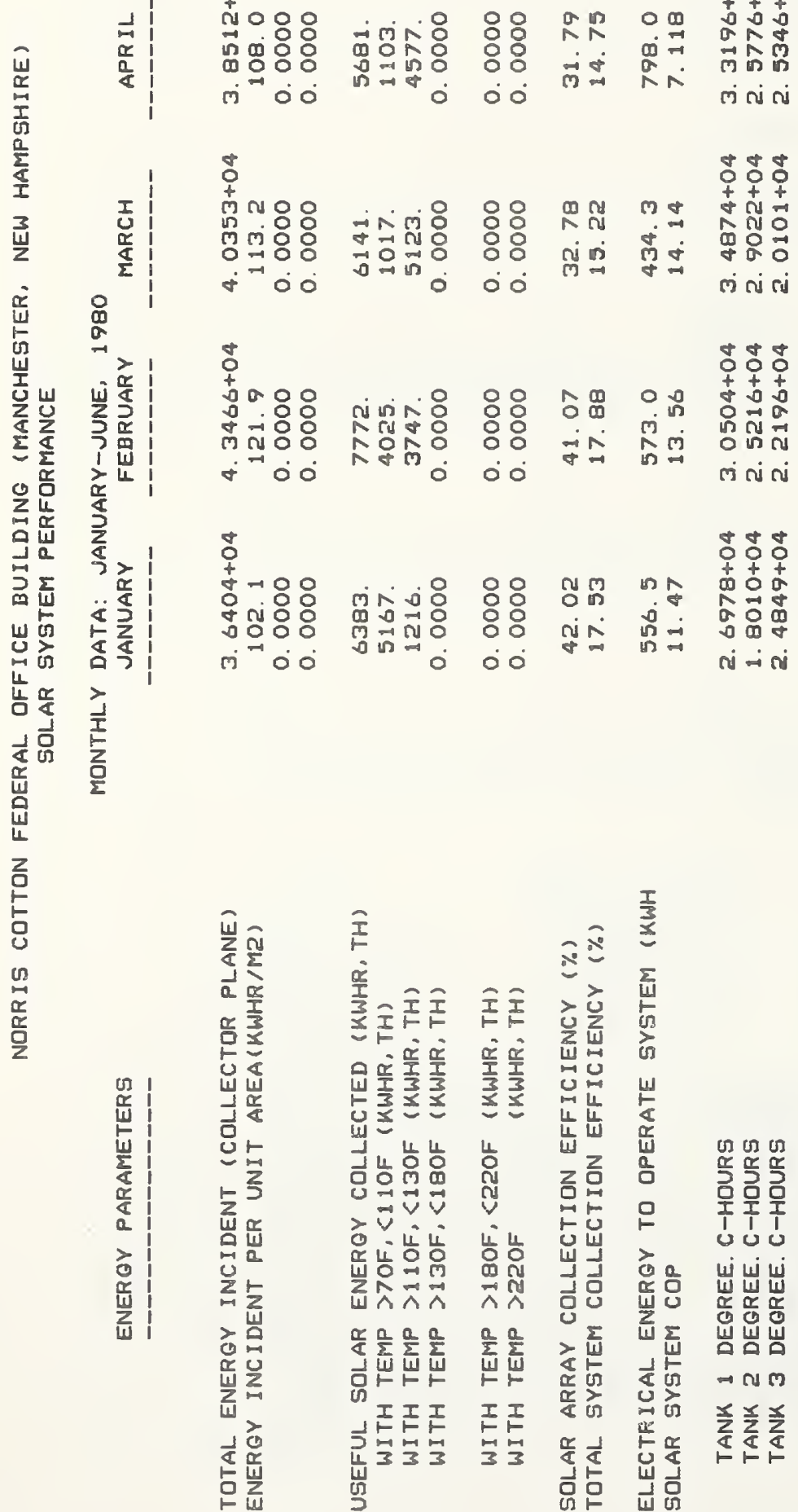




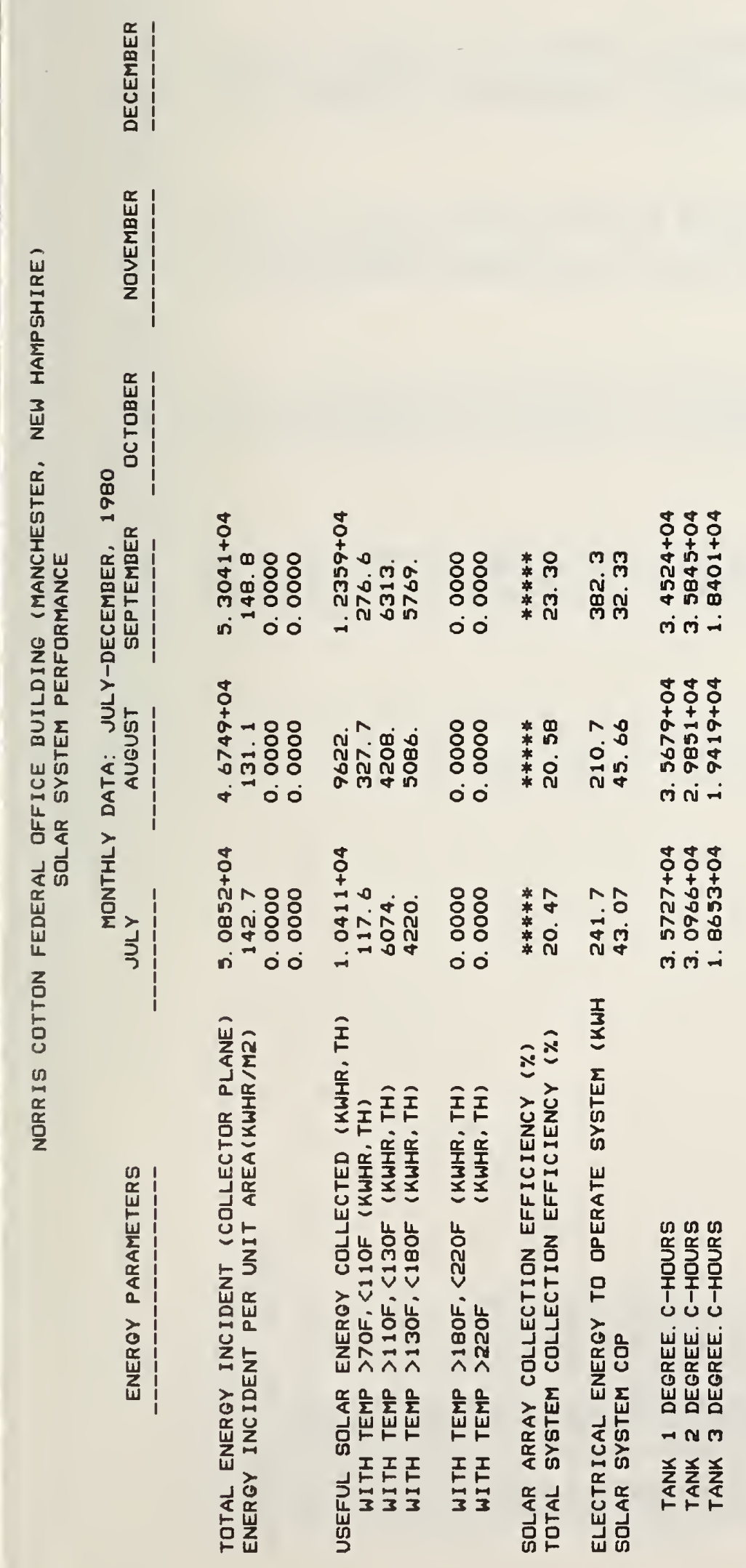




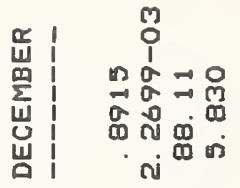

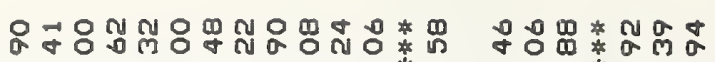

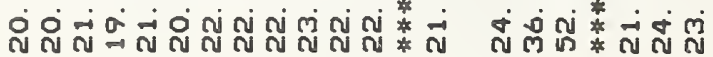

000000015

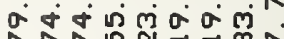

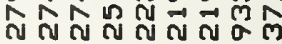

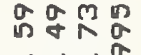

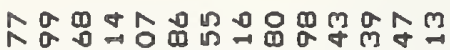

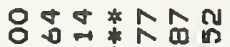
ต่⿻

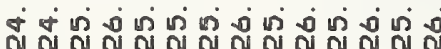
ช่

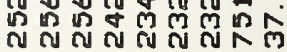

$0 \cdot \frac{1}{8}$

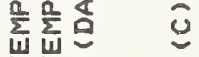

m品之

号罗云

西品是 范荅产。 山山山 山山 年 矿起是 넝 岁嵌岗

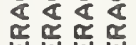

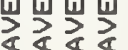

㟧

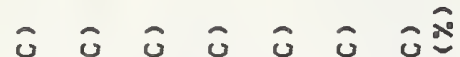
$\sum_{i=1}^{\infty}$ 


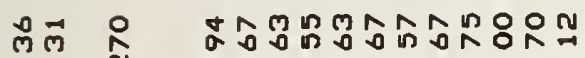
g.0

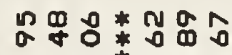

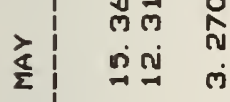

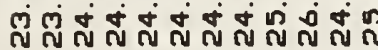

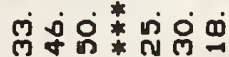

- $000000 \mathrm{mon}$

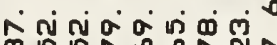

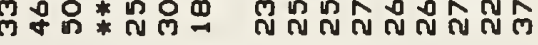

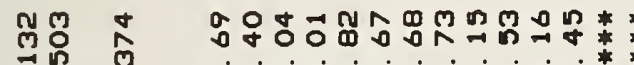
กี่

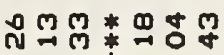

$0000000 \mathrm{~N}$ वंi

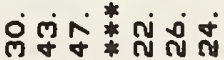

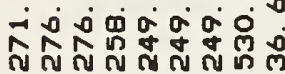

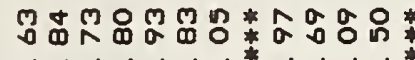

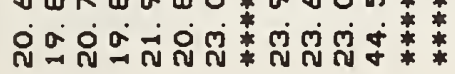

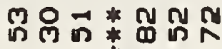

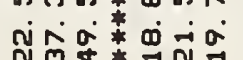

0000000

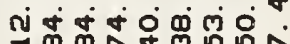

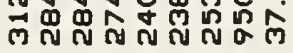

$\stackrel{8}{\circ}$

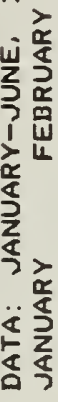

$\overrightarrow{0} \stackrel{+}{2}$

ip in

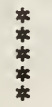

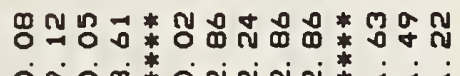

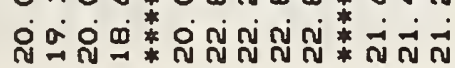

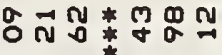

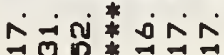

0000000010

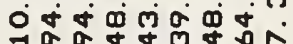

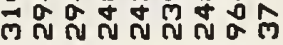

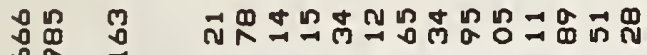
ㅇํำ-

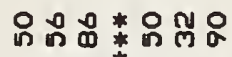

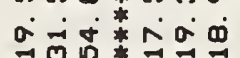
00000000.7

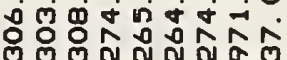

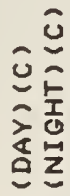

ù

os

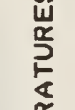

番 ิิ

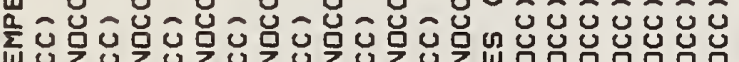

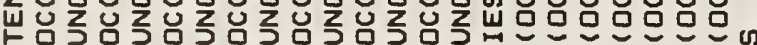

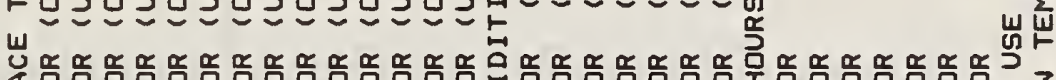

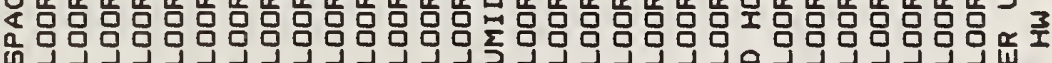

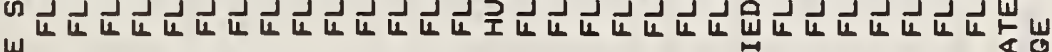

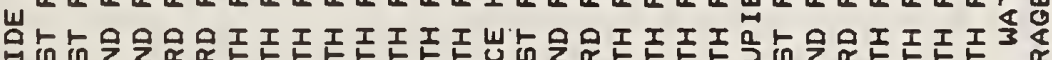

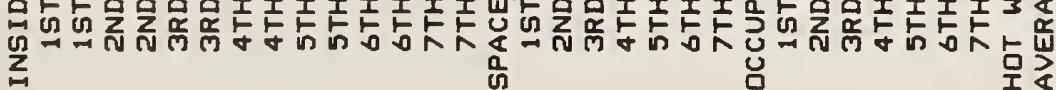




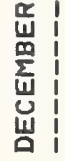

端

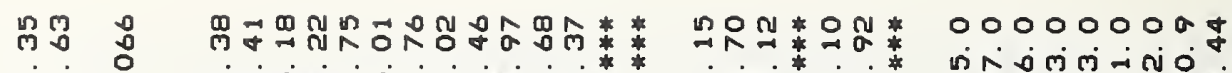
뻐

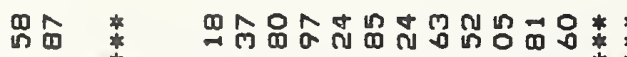

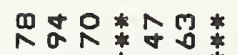

$0000000 \mathrm{~m}$ กู่ * *

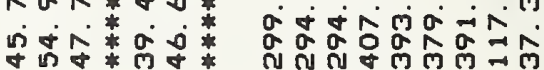

全

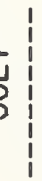

๓⿴囗十

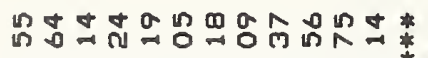

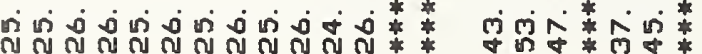

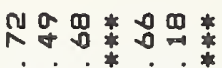

O O O O O O ONm m

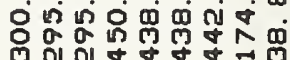

过

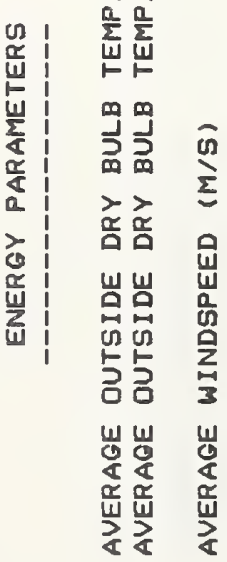

ú

疍

¿

西

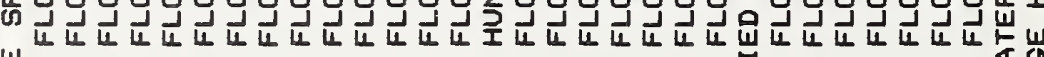

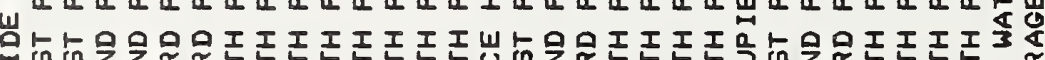

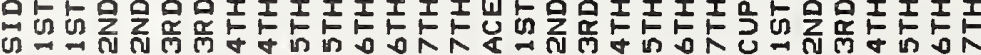
$\sum_{n=1}^{n}$ 
NBS-114A (REV. 2-8C)

U.S. DEPT. OF COMM.

BIBLIOGRAPHIC DATA

SHEET (See in structions)

1. PUBLICATION OR
REPORT NO.
$81-2358$

2. Performing Organ. Report Nof 3. Publication Date

November 1981

4. TITLE AND SUBTITLE

ANALYSIS OF DATA FROM THE ENERGY MONITORING AND CONTROL SYSTEM AT THE NORRIS COTTON FEDERAL OFFICE BUILDING

5. AUTHOR(S)

William B. May, Jr.

6. PERFORMING ORGANIZATION (If joint or other than NBS, see instructions)

7. Contracu Grant No.

NATIONAL BUREAU OF STANDARDS

DEPARTMENT OF COMMERCE

WASHINGTON, D.C. 20234

8. Type of Report \& Period Covered

\section{SFOHSORING ORGANIZATION NAME AND COMPLETE ADDRESS (Street, City, Stote, ZIP)}

The Department of Energy

Washington, D.C. 20585

10. SUPPLEMENTARY NOTES

[.] Document describes a computer program; SF-185, FIPS Software Summary, is attached.

11. ABSTRACT (A 200-word or less factual summary of most significant information. If document includes a significant bibliography or literature survey. mention it here)

The Norris Cotton Federal Office Building (NCFOB) in Manchester, New Hampshire, is a medium-size office building, occupied in September 1976, designed to serve as a demonstration and a feasibility test for energy-conserving building features. A building energy monitoring and control system was operated as a data acquisition system over a 13-month period ending in September 1980. Experience encountered during the checkout and operation of the system is discussed. Results from data reduction procedures used to calculate approximately 160 parameters describing the energy performance of the building are presented on a monthly basis. Hourly data are also presented for daily building operation profiles, building envelope performance, and performance of the mechanical systems.

12. KEY WORDS (Six to twelve entries; alphabetical order; capitalize only proper names; and separate key words by semicolons) Building performance data; computer data acquisition; energy conservation in commercial buildings; building envelope; mechanical systems; energy monitoring and control systems.

13. AVAILABILITY

XXIlimited

For Official Distribution. Do Not Release to NTIS

$\square$ Order From Superintendent of Documents, U.S. Government Printing Office, Washington, D.C. 20402.

14. NO. OF PRINTED PAGES

98

15. Price

XXX Order From National Technical Information Service (NTIS), Springfield, VA. 2216I

$\$ 9.50$ 


